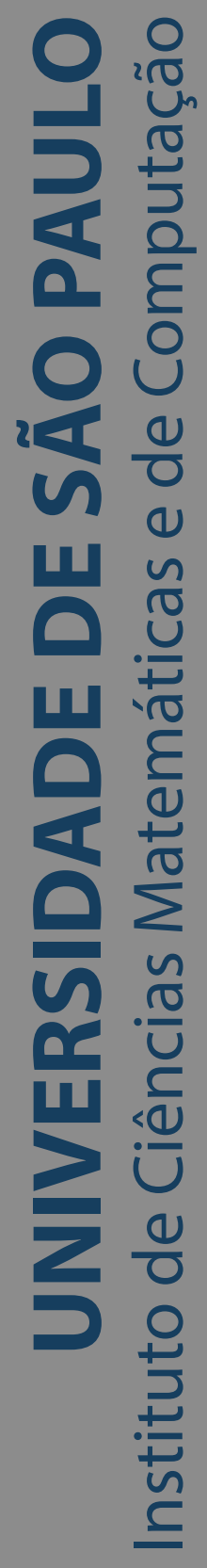

\title{
Visualização exploratória de grafos bipartidos com o paradigma multinível
}

\section{Diego Silva Cintra}

Dissertação de Mestrado do Programa de Pós-Graduação em Ciências de Computação e Matemática Computacional (PPG-CCMC) 

Assinatura:

\title{
Diego Silva Cintra
}

\section{Visualização exploratória de grafos bipartidos com o paradigma multinível}

\begin{abstract}
Dissertação apresentada ao Instituto de Ciências Matemáticas e de Computação - ICMC-USP, como parte dos requisitos para obtenção do título de Mestre em Ciências - Ciências de Computação e Matemática Computacional. EXEMPLAR DE DEFESA
\end{abstract}

Área de Concentração: Ciências de Computação e Matemática Computacional

Orientadora: Profa. Dra. Maria Cristina Ferreira de Oliveira 
Ficha catalográfica elaborada pela Biblioteca Prof. Achille Bassi e Seção Técnica de Informática, ICMC/USP, com os dados inseridos pelo(a) autor(a)

Silva Cintra, Diego Visualização exploratória de grafos bipartidos com - paradigma multinível / Diego Silva Cintra; orientadora Maria Cristina Ferreira de Oliveira. -São Carlos, 2019.

$126 \mathrm{p}$.

Dissertação (Mestrado - Programa de Pós-Graduação em Ciências de Computação e Matemática Computacional) -- Instituto de Ciências Matemáticas e de Computação, Universidade de São Paulo, 2019.

1. Visualização. 2. Grafos Bipartidos. 3. Paradigma Multinível. 4. Sumarização de Grafos. I. Cristina Ferreira de Oliveira, Maria, orient. II. Título. 


\section{Diego Silva Cintra}

\section{Visual exploration in bipartite graphs with the multilevel paradigm}

Master dissertation submitted to the Institute of Mathematics and Computer Sciences - ICMC-USP, in partial fulfillment of the requirements for the degree of the Master Program in Computer Science and Computational Mathematics. EXAMINATION BOARD PRESENTATION COPY

Concentration Area: Computer Science and Computational Mathematics

Advisor: Profa. Dra. Maria Cristina Ferreira de Oliveira

\section{USP - São Carlos}

May 2019 

À memória de minha vó, Maria de Lurdes Gomes da Silva. 

Inicialmente, gostaria de agradecer a Deus e Jesus, por sempre iluminar meus caminhos e me dar ânimo em momentos de cansaço, e à Mãe Maria, que me guia pela mão desde que eu era um garotinho.

Ao meu pai, por ser meu melhor amigo, meu herói e um exemplo para ser um homem melhor sempre. À minha mãe, pela sua imensa dose de amor, paciência e respeito comigo. À minha irmã, por ser parceira de todos os momentos. À minha vó e tio-avô, por compartilharem tantas experiências de vida comigo. E ao restante dos meus familiares, tias, tios e primos, que sempre estiveram junto comigo desde o princípio. Vocês são minha família, e a coisa mais importante que eu tenho. Sou o que sou graças a vocês.

À professora Maria Cristina Ferreira de Oliveira, pelo apoio durante meu mestrado e por toda a paciência pra me atender, indo quase todo o dia na sala da diretoria. Aos meus colaboradores Alan Valejo e Alneu, pelas discussões e ideias que produziram esse trabalho. E também pela paciência do Alan, me explicando linha por linha do seu código e me ajudando quando não conseguia executar sua ferramenta.

Aos meus amigos, colegas e parceiros, que contribuíram no desenvolvimento da minha pesquisa. São muitos nomes, mas não posso deixar de mencionar: Gustavo, Jainor, Mauri, Rogério, Gabriele, Nícolas, Aline, Lucão, Fábio, Thales, Damares, Léo, Eric, Liz, Filomen, Ivar, Germain, Grande Mestre (vulgarmente conhecido como Evandro), Erasmo, Fernando e Thalisson. Obrigado pela parceria e gentileza, direta e indiretamente.

Dedico esse trabalho especialmente em memória da minha velha, Dona Lurdes. Vó, obrigado por me ensinar que a grandeza do ser humano está em sua simplicidade. A vida de amor, honestidade e compaixão que você teve é mais do que exemplo disso. Vou sempre guardar nossos momentos juntos em meu coração. Descanse em paz! Um dia nos veremos novamente. Tenho certeza disso.

Finalmente, gostaria de agradecer o apoio financeiro da Fundação de Amparo à Pesquisa do Estado de São Paulo (FAPESP), com os processos 2016/25107-0 e 2017/05838-3, e o Conselho Nacional de Desenvolvimento Científico e Tecnológico, com os processos 134806/2016-6 e 301847/2017-7. 

"Success is not final, failure is not fatal:

it is the courage to continue that counts."

(Winston Churchill) 



\section{RESUMO}

CINTRA, D. S. Visualização exploratória de grafos bipartidos com o paradigma multinível. 2019. 126 p. Dissertação (Mestrado em Ciências - Ciências de Computação e Matemática Computacional) - Instituto de Ciências Matemáticas e de Computação, Universidade de São Paulo, São Carlos - SP, 2019.

O paradigma multinível tem sido utilizado na resolução de problemas de otimização combinatória em grafos. Ele opera gerando uma hierarquia de grafos contraídos e resolvendo o problema em uma versão reduzida do grafo original, o que reduz o espaço de soluções e permite utilizar um algoritmo cujo tempo de execução seria inviável no grafo original. Recentemente, foi proposto um arcabouço multinível flexível para a solução de problemas em grafos bipartidos, o qual admite vários parâmetros de entrada. Essa dissertação apresenta uma nova metáfora visual que auxilia na interpretação do resultado de executar o paradigma multinível em um grafo bipartido e na avaliação do impacto de diferentes escolhas dos parâmetros nos resultados. O objetivo é ilustrar como a nova metáfora associada ao paradigma multinível apoia tarefas analíticas em grafos bipartidos. Para validar este objetivo um sistema foi desenvolvido como prova de conceito, denominado MObViewer, que além da nova metáfora visual utiliza visualizações adicionais para auxiliar nas tarefas analíticas. Dois tipos de estudos de caso foram conduzidos para validar o MObViewer. O primeiro considera questões analíticas sobre o paradigma multinível elaboradas em conjunto com um especialista, e respondidas considerando grafos sintéticos, construídos em um ambiente controlado. Já o segundo consiste em uma investigação exploratória sobre grafos bipartidos que modelam dados do mundo real. Os resultados mostram que a nova metáfora visual auxilia a identificação do impacto da alteração dos parâmetros de entrada do paradigma multinível e ilustram como a integração entre visualização e o arcabouço multinível pode apoiar a visualização exploratória de grafos bipartidos.

Palavras-chave: Visualização, Grafos bipartidos, Paradigma multinível, Sumarização de grafos. 



\section{ABSTRACT}

CINTRA, D. S. Visual exploration in bipartite graphs with the multilevel paradigm. 2019. 126 p. Dissertação (Mestrado em Ciências - Ciências de Computação e Matemática Computacional) - Instituto de Ciências Matemáticas e de Computação, Universidade de São Paulo, São Carlos - SP, 2019.

The multilevel paradigm has been used in the resolution of combinatorial optimization problems in graphs. It creates a hierarchy of coarsened graphs and solves the problem in a coarsened version of the original graph, which reduces the solution space and allows to use an algorithm whose initial complexity would be cost-prohibitive in the original graph. Recently, a flexible multilevel paradigm framework was proposed for problem-solving in bipartite graphs, which admits several input parameters. This dissertation presents a novel visual metaphor which aids to interpret the result of executing the multilevel paradigm in a bipartite graph and the impact assessment of different input choices in the results. The objective is to show how a novel metaphor associated with the multilevel paradigm supports analytic tasks in bipartite graphs. To evaluate this objective, a system was developed as a proof-of-concept, dubbed MObViewer, which besides using the novel visual metaphor uses additional visualizations to aid in analytic tasks. Two types of case studies were conducted to evaluate MObViewer. The first considers analytic questions about the multilevel paradigm elaborated with an expert, answered considering synthetic graphs, created in a controlled environment. The second consists of an exploratory investigation of real-world data modeled as bipartite graphs. The results show that the new visual metaphor aids in identifying the impact of altering input parameters of the multilevel paradigm and illustrate how the integration between visualization and framework can support in the visual exploration of bipartite graphs.

Keywords: Visualization, Bipartite graphs, Multilevel paradigm, Graph summarization. 



\section{LISTA DE ILUSTRAÇÕES}

Figura 1 - Execução do paradigma multinível sobre um grafo inicial $G_{0} \ldots \ldots$. . . . . . 46

Figura 2 - Etapa de contração sobre um grafo bipartido. Os vértices $a$ e $b$, acizentados, definem os vértices candidatos à contração. . . . . . . . . . . . . . . . . 52

Figura 3 - Exemplos de diferentes tipos de medidas de similaridade. . . . . . . . . 53

Figura 4 - Visão geral do sistema AskGraphView. Na parte superior, visualiza-se a árvore de hierarquia imposta sobre o grafo. No canto superior esquerdo, tem-se a matriz de adjacência do grafo. À esquerda, pode-se expandir um "super-vértice", identificando sua árvore de vértices. Ao centro, tem-se a visualização do grafo em um nível da hierarquia. . . . . . . . . . . . . . .

Figura 5 - Exemplo de redução de dimensionalidade de atributos de uma base de dados utilizando o sistema PivotGraph. Aqui, dois atributos são selecionados: gosto e cor. Os possíveis valores desses atributos são dispostos em linhas e colunas. Agrupamentos de vértices e arestas são representados em tonalidades mais

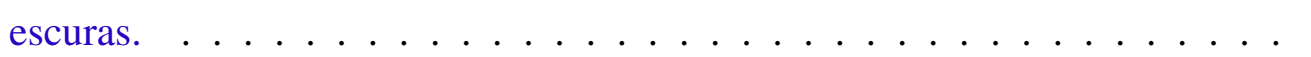

Figura 6 - Processo de contração de grafos em Wong et al. (2009). À esquerda, tem-se o grafo original, e à direita o grafo contraído. Utilizando de zoom-in e zoom-out, pode-se alternar entre o grafo da esquerda e o grafo da direita. . . . . . . . .

Figura 7 - Processo de zoom semântico. Da esquerda para a direita, ao se aplicar zoom-in em uma região, novos vértices são visualizados, previamente ocultos devido ao seu tamanho e relevância. . . . . . . . . . . . . . . . . .

Figura 8 - Visualização do sistema PivotPaths. A autora Mary Czerwinski é escolhida como âncora (à esquerda, no conjunto central) e, com base no filtro estabelecido pelo usuário, são selecionados seus trabalhos mais citados, destacando coautores na parte superior e áreas de interesse na parte inferior. De acordo com o algoritmo de posicionamento implementado, conclui-se que George Robertson é o coautor mais frequente de Mary, sendo disposto no parte mais superior da visualização e com maior tamanho de fonte, e User Study, a área de interesse mais abordada pelos trabalhos, tendo maior tamanho de fonte e disposta na parte mais inferior. . . . . . . . . . . . . . 
Figura 9 - Visualização resultante de Xu et al. (2016). Agrupamentos são representados com matrizes de adjacência ou como treemaps. Por meio da seleção, o usuário pode alternar entre as duas representações, remover ou adicionar elementos e re-enviar agrupamentos editados como parâmetros de entrada para execução do algoritmo de biclustering. . . . . . . . . . . . . . . . . 66

Figura 10 - Visualização resultante de Pezzotti et al. (2018), após a criação da hierarquia de simplificações obtidas com o HSNE. Os agrupamentos $u$ e $v$ são projetados em duas linhas verticais, similar a um algoritmo de desenho tradicional de grafos bipartidos. Explorando os pontos de referência do espaço unidimensional, o espaço bidimensional é transformado de acordo com o nível de hierarquia desejada. . . . . . . . . . . . . . . .

Figura 11 - Metáfora visual introduzida pela ferramenta BiDots. Dois grafos bipartidos são dispostos (documento/tópico e tópico/palavra-chave) em linhas verticais, com uma coluna sendo compartilhada, para permitir a exploração de múltiplos domínios. Arestas são representadas em linhas verticais dentro de caixas que interconectam agrupamentos, e indicam, com o auxílio dos valores no topo da visualização, o peso da conexão entre biclusters. Vértices ou agrupamentos são codificados como círculos com padrões de linhas. Esses padrões diferenciam os biclusters produzidos, e a intensidade de cor indica a quantidade de elementos - quanto mais intenso, mais vértices estão agrupados. 68

Figura 12 - Metáfora visual da ferramenta BiCFlows. Os vértices do grafo bipartido são codificados como retângulos cinza em uma coluna. Os agrupamentos são representados como retângulos coloridos nas colunas adjacentes. . . . . . .

Figura 13 - Metáfora visual de listas de adjacência. As cores indicam os agrupamentos encontrados com o princípio MDL. Na representação por lista de adjacência, os agrupamentos são ordenados por densidade, em ordem decrescente, da esquerda para a direita. O preenchimento dos blocos indica a densidade dos agrupamentos $-q_{3}$, por exemplo, conecta-se com todos os vértices de $p_{3}$. Logo, sua densidade é 1 , e todo o retângulo é preenchido. . . . . . . . . . .

Figura 14 - Visão geral da arquitetura do MObViewer. Um grafo bipartido é contraído no sistema $M O b$, gerando uma hierarquia de grafos contraídos. As conversões de formatos de grafos são aplicadas logo em seguida, resultando em uma representação de uma metáfora visual do grafo. Técnicas de visualização são utilizadas quando o usuário interage com a metáfora visual. As interações do usuário nessas representações permitem a redefinição dos parâmetros do paradigma multinível, para uma nova execução, ou a obtenção de conhecimento. 75 
Figura 15 - Representação da metáfora visual da estrutura multinível aplicado a grafos bipartidos. Cada linha de círculos representa vértices de uma camada em um determinado nível. O grafo mais contraído é representado no centro (nível 4), e os níveis intermediários representados nas linhas seguintes (nível 3, 2 e 1). O grafo original é representado em cinza. Os vértices da camada $V_{1}$ são dispostos na parte inferior, enquanto os de $V_{2}$ ficam na porção superior da visualização. . . . . . . . . . . . . . . . . . . . . .

Figura 16 - Representação da metáfora visual do paradigma multinível aplicado a grafos bipartidos, com interação do usuário. O vértice selecionado é destacado com um círculo vermelho. Seus sucessores e predecessores são representados por um contorno verde, e conectados por linhas pontilhadas verdes. Neste exemplo, são mostrados os vizinhos de um vértice sucessor do vértice selecionado, destacados por contornos azuis e conectados por linhas contínuas da mesma cor . . . . . . . . . . . . . . . . . . . . . .

Figura 17 - Problema de representação com a metáfora visual apresentada. Vértices que formam super-vértices em níveis mais contraídos encontram-se distantes entre si, o que gera um cruzamento de arestas de hierarquia. . . . . . . . . .

Figura 18 - Informações sobre grafos produzidos com o paradigma multinível. Os números representam, em ordem crescente, o grafo original até o grafo mais contraído.

Figura 19 - Histograma de frequência dos atributos associados a um super-vértice selecionado. Os atributos são identificados na parte inferior, separados por vírgula. No exemplo, "age,country,sex”, idade, país e sexo, definem os 3 atributos de cada vértice. As linhas pontilhadas verticais separam os grupos de atributos definidos na parte inferior do histograma. O eixo $y$ varia entre $0 \%$ até a máxima porcentagem no super-vértice selecionado. . . . . . .

Figura 20 - Ao selecionar um super-vértice, os vizinhos dele (destacados em vermelho) criam a nuvem de palavras de acordo com a frequência de um atributo definido pelo usuário. . . . . . . . . . . . . . . . . . .

Figura 21 - Exemplo de atributo colorindo o glifo que representa o vértice. Aqui, "assunto" foi o atributo escolhido do conjunto de dados, que identifica o tema de um determinado documento. Conforme super-vértices são criados, eles são representados por gráficos de setores, proporcional a quantos vértices têm um determinado valor. . . . . . . . . . . . . . . . .

Figura 22 - Legenda de pesos das arestas. Da esquerda para a direita, conforme o peso vai aumentando, a intensidade do azul aumenta. . . . . . . . . . . . . . 
Figura 23 - Resultados de execução de C.CN e C.Jac sobre $G S_{1}$. As cores representam as comunidades de cada vértice ou super-vértice. Exceto a métrica de similaridade, todos os grafos têm como parâmetros de contração $r f_{1}=r f_{2}=50 \%$, $l_{1}=l_{2}=3$ e algoritmo de pareamento GMb. . . . . . . . . . .

Figura 24 - Resultados de execução de C.AA e C.PA sobre $G S_{1}$. As cores representam as comunidades de cada vértice ou super-vértice. Exceto a métrica de similaridade, todos os grafos têm como parâmetros de contração $r f_{1}=r f_{2}=50 \%$, $l_{1}=l_{2}=3$ e algoritmo de pareamento $G M b \ldots \ldots \ldots \ldots$

Figura 25 - Resultados de execução de C.CN e C.Jac sobre $G S_{2}$. As cores representam as comunidades de cada vértice ou super-vértice. Exceto a métrica de similaridade, todos os grafos têm como parâmetros de contração $r f_{1}=r f_{2}=50 \%$, $l_{1}=l_{2}=3$ e algoritmo de pareamento GMb. . . . . . . . . . .

Figura 26 - Resultados de execução de C.AA e C.PA sobre $G S_{2}$. As cores representam as comunidades de cada vértice ou super-vértice. Exceto a métrica de similaridade, todos os grafos têm como parâmetros de contração $r f_{1}=r f_{2}=50 \%$, $l_{1}=l_{2}=3$ e algoritmo de pareamento GMb. . . . . . . . . . .

Figura 27 - Resultados de execução de C.CN e C.Jac sobre $G S_{4}$. As cores representam as comunidades de cada vértice ou super-vértice. Exceto a métrica de similaridade, todos os grafos têm como parâmetros de contração $r f_{1}=r f_{2}=50 \%$, $l_{1}=l_{2}=3$ e algoritmo de pareamento GMb. . . . . . . . . . .

Figura 28 - Resultados de execução de C.AA e C.PA sobre $G S_{4}$. As cores representam as comunidades de cada vértice ou super-vértice. Exceto a métrica de similaridade, todos os grafos têm como parâmetros de contração $r f_{1}=r f_{2}=50 \%$, $l_{1}=l_{2}=3$ e algoritmo de pareamento GMb. . . . . . . . . .

Figura 29 - Interação do usuário em $G S_{1}$. É possível identificar, com a estrutura hierárquica de visualização do paradigma multinível, em qual dos níveis vértices de comunidades distintas se uniram em um super-vértice. . . . . . . . . .

Figura 30 - Visualização do nível mais contraído resultante da execução de C.RF40, C.RF30, C.RF20 e C.RF10 sobre $G S_{1}$. As cores representam as comunidades de cada vértice ou super-vértice. . . . . . . . . . . . . .

Figura 31 - Resultados da execução de C.RF40, C.RF30, C.RF20 e C.RF10 sobre $G S_{2}$. As cores representam as comunidades de cada vértice ou super-vértice. . . . 
Figura 32 - Visualização do sistema VisLists. Tem-se três colunas que representam autores, conferência e ano de publicação. A célula em amarelo indica o elemento selecionado. Os autores indicados em cor laranja são coautores. Nas outras colunas, os elementos alaranjados identificam a principal conferência e período de publicação do autor selecionado. Os números sobrescritos indicam a quantidade de artigos publicados pelo autor, e a barra horizontal preta indica a porcentagem de ocorrências daquele elemento presente no conjunto de dados. . . . . . . . . . . . . . . . . . . . .

Figura 33 - Visualizações parciais do grafo mais contraído e a hierarquia resultantes da aplicação da configuração C.MLP.100-100.10 sobre o IEEEVis. . . . . . . 101

Figura 34 - Legenda de cores dos vértices no conjunto de dados IEEEVis. A cor preta identifica vértices com valor ausente do atributo (Unknown). . . . . . . . . 102

Figura 35 - Visão parcial da hierarquia resultante da aplicação da configuração C.MLP.2020.1 sobre o IEEEVis. (A) e (B) identificam as nuvens de palavras dos vizinhos de super-vértices selecionados, mostrando os autores com maior quantidade de publicações no "InfoVis". Os autores e coautores são comparados com a ferramenta VisLists, sendo os similares destacados em vermelho. 102

Figura 36 - Visão parcial da hierarquia resultante da aplicação da configuração C.GMB.33.50-50 sobre IEEEVis. Em (A), vê-se a hierarquia resultante. Em (B), nuvens de palavras de super-vértices selecionados ilustram os autores mais relevantes em agrupamentos contendo a maioria de artigos pertencentes à conferência "SciVis". . . . . . . . . . . . . . . . . . . 103

Figura 37 - Interação na ferramenta VisLists para a conferência "SciVis", mostrando os principais autores dessa conferência, destacados em retângulos vermelhos. . 103

Figura 38 - Visão parcial da hierarquia resultante da aplicação da configuração C.GMB.55.30-30 sobre o IEEEVis. Em (A), identificam-se a união de coleções de artigos publicados em diferentes conferências. (B) mostra as nuvens de palavras resultantes dos vizinhos dos super-vértices na hierarquia selecionados, e destacados em azul. Observa-se que a nuvem de palavras do nível mais contraído contém nomes dos autores dos níveis anteriores, como "Anna Vilanova" e "Eduard Gröller". . . . . . . . . . . . . . . . . . . . . . . . . . . . 104

Figura 39 - Visão parcial da hierarquia resultante da aplicação da configuração C.GMB.33.50-50 sobre o IEEEVis. . . . . . . . . . . . . . . . . . . . . . . . 104

Figura 40 - Legenda de cores para os vértices no conjunto de dados documento-termos. A cor preta identifica vértices que não possuem valor para o atributo (Unknown).105 
Figura 41 - Visão parcial do da hierarquia de contrações resultantes da aplicação da configuração C.MLP.100-100.10 sobre o conjunto de documento-termos. É possível perceber na camada de artigos (parte inferior) que super-vértices contém documentos de disciplinas distintas. Também identificam-se nuvens de palavras dos vizinhos dos super-vértices selecionados, ilustrando os termos mais frequentes. . . . . . . . . . . . . . . 105

Figura 42 - Resultados da execução de C.MLP.20-20.1 sobre o conjunto de dados documentotermos. . . . . . . . . . . . . . . . . . . . . 107

Figura 43 - Visão parcial da hierarquia de contrações resultantes da aplicação da configuração C.GMB.3-3.50-50 sobre o conjunto de documento-termos. (A) mostra, no nível mais contraído, super-vértices contendo artigos da mesma disciplina, de acordo com a escala de cores. (B) mostra os vértices contidos em um determinado elemento, sendo "subject" o atributo "disciplina" e "title" o título do artigo. Em (C), identifica-se na hierarquia vértices com disciplinas distintas unindo-se em um super-vértice. (D) mostra as nuvens de palavras dos vizinhos de super-vértices selecionados nessa hierarquia. . . . . . . . 108

Figura 44 - Visão parcial da hierarquia de contrações resultantes da aplicação da configuração C.GMB.3-3.50-50 sobre o conjunto de documento-termos. (A) mostra a nuvem de palavras dos vizinhos de um super-vértice contendo artigos das disciplinas "CBR" e "RI". (B) mostra a nuvem de palavras de termos das disciplinas "RI" e "SON". . . . . . . . . . . . . . . . . . . . . . . . . . 109

Figura 45 - Visão parcial da hierarquia de contrações resultantes da aplicação da configuração C.GMB.5-5.30-30 sobre o conjunto de documento-termos. A visualização permite identificar o desbalanceamento de super-vértices. (A) mostra a hierarquia de vértices que, em um determinado nível, uniu vértices com conteúdos de disciplinas distintas em um único super-vértice, destacado em vermelho. (B) mostra, com uma nuvem de palavras, os principais termos de um super-vértice com artigos da disciplina "ILP". . . . . . . . . . . . . 110

Figura 46 - Legenda de cores dos vértices no conjunto de dados Movie Lens. "F" identifica usuários do sexo feminino, e "M", masculino. A cor preta identifica vértices que não possuem valor para o atributo (Unknown). . . . . . . . . 110

Figura 47 - Visão parcial do grafo mais contraído resultante da aplicação da configuração C.MLP.100-100.10. (A) mostra os histogramas de frequências de alguns vértices, que contém, em sua maioria, usuários entre 25-35 anos com profissões distintas. . . . . . . . . . . . . . . . . . . . 111 
Figura 48 - Visão parcial da hierarquia resultante da aplicação da configuração C.MLP.2020.1. (A) mostra os histogramas de frequências e nuvens de palavra explorando coleções de usuário, que contém, em sua maioria, entre 25-35 anos com profissões distintas. As nuvens de palavras destacam que gêneros como "drama", "comédia" e "ação" são os mais populares, de acordo com a vizinhança dos super-vértices selecionados. . . . . . . . . . . . . . . 111

Figura 49 - Visão do grafo mais contraído resultante da aplicação da configuração C.GMB.33.50-50. É possível identificar a presença de vários super-vértices e perfis de usuários específicos. (A) mostra os histogramas de frequência e nuvem de palavras explorando uma coleção de usuários, que contém, em sua maioria, entre 18-44 anos com preferências por filmes de "Animação". (B) mostra os histogramas de frequência e nuvem de palavras de uma coleção de usuários com 25 anos ou mais, preferindo filmes de "Aventura", "Ação", "Comédia", "Drama", "Western" e "Thriller". . . . . . . . . . . . . . . . . . . . . 112

Figura 50 - Visão do grafo mais contraído resultante da aplicação da configuração C.GMB.55.30-30. É possível identificar a presença de poucos super-vértices, em comparação a configuração C.GMB.3-3.50-50. (A) identifica nuvens de palavras explorando coleções de usuários, mostrando que eles preferem filmes de "Ação", "Comédia" e "Drama". . . . . . . . . . . . . . . . . . . . . . . . . 112 



\section{LISTA DE ALGORITMOS}

Algoritmo 1 - Paradigma multinível (adaptado de Valejo et al. (2018)). . . . . . . . . 47

Algoritmo 2 - GMb (adaptado de Valejo et al. (2018)). . . . . . . . . . . . . . 48

Algoritmo 3 - Paradigma multinível para MLP (adaptado de Valejo et al. (2019a)). . 50

Algoritmo 4 - MLP (adaptado de Valejo et al. (2019a)). . . . . . . . . . . . . . 51

Algoritmo 5 - Ordenação de vértices em níveis de hierarquia. . . . . . . . . . . . 78 



\section{LISTA DE CÓDIGOS-FONTE}

Código-fonte 1 - Parâmetros do histograma de frequências. . . . . . . . . . . . . . 80 

Tabela 1 - Parâmetros utilizados na geração dos grafos sintéticos. $G$ representa o nome do grafo sintético, $v$ a quantidade de vértices, $c$ a quantidade de comunidades, $[d, s]$ os parâmetros para definição de densidade, $n$ o ruído, $x$ a quantidade de vértices com comunidades sobrepostas em $V_{1}, y$ a quantidade de vértices com comunidades sobrepostas em $V_{2}, z$ o número de comunidades sobrepostas e $b$ se o grafo possui comunidades balanceadas nas camadas. . . . . . . . . 87

Tabela 2 - Informações sobre conjuntos de dados sintéticos utilizados para estudos de caso. . . . . . . . . . . . . . . . . . . .

Tabela 3 - Lista de testes utilizados nos estudos de caso. Aqui, são definidos os parâmetros utilizados no arcabouço de Valejo et al. (2018) para a etapa de contração.

Tabela 4 - Informações sobre conjuntos de dados do mundo real utilizados para estudos de caso. . . . . . . . . . . . . . . . . . .

Tabela 5 - Lista de configurações utilizadas nos estudos de caso de aplicações do mundo real. . . . . . . . . . . . . . . . . . . . . . . 99 



\section{LISTA DE ABREVIATURAS E SIGLAS}

CBR Área do conhecimento denominada Case-Based Reasoning

ILP Área do conhecimento denominada Inductive Logic Programming

IR Área do conhecimento denominada Information Retrieval

$\mathrm{MOb} \quad$ Acrônimo da ferramenta Multilevel Optimization framework for Bipartite networks

SON Área do conhecimento denominada Sonification 



\section{LISTA DE SÍMBOLOS}

$\mathbb{R}$ — Conjunto dos números reais

$\mathbb{N}$ - Conjunto dos números naturais 

INTRODUÇÃO . . . . . . . . . . . . . . . . 35

$2.1 \quad$ Terminologia e notação . . . . . . . . . . . . . . . . 41

2.2 Visualização da Informação . . . . . . . . . . . . 43

$2.3 \quad$ Paradigma multinível . . . . . . . . . . . . 45

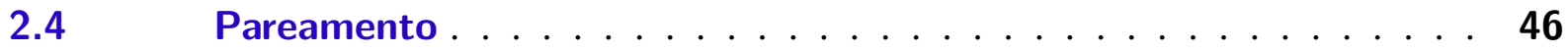

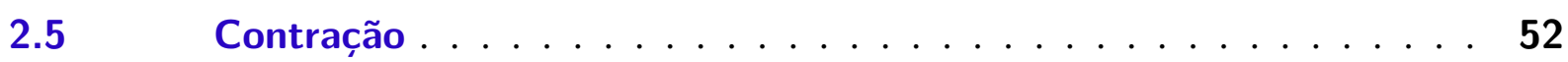

$2.6 \quad$ Medida de similaridade . . . . . . . . . . . . . 52

2.6.1 Vizinhos em comum . . . . . . . . . . . . . . 53

$2.6 .2 \quad$ Jaccard . . . . . . . . . . . . . . . . . . 54

2.6.3 Adamic Adar . . . . . . . . . . . . . . . . 54

2.6.4 Conexão preferencial . . . . . . . . . . . . . . . . 54

$2.7 \quad$ Considerações finais . . . . . . . . . . . . . . 55

3 VISUALIZAC̣ÃO EXPLORATÓRIA EM GRAFOS . . . . . . . . . 57

3.1 Simplificação de grafos genéricos . . . . . . . . . . . 58

3.2 Simplificação de grafos bipartidos . . . . . . . . . . . . 64

3.3 Considerações sobre os trabalhos . . . . . . . . . . . . . 67

4 VISUALIZAÇÃO EXPLORATÓRIA COM O PARADIGMA MULTINÍVEL ......................... . . . . . . . . . .

$4.1 \quad$ Arquitetura do sistema . . . . . . . . . . . . 74

$4.2 \quad$ Metáfora visual . . . . . . . . . . . . . 75

$4.3 \quad$ Análise exploratória de grafos bipartidos . . . . . . . . . . 78

4.3.1 Informações do grafo . . . . . . . . . . . . . . . . . 79

4.3.2 Histograma de frequências . . . . . . . . . . . . . 79

4.3.3 Nuvem de palavras . . . . . . . . . . . . . . . 81

4.3.4 Gráfico de setores . . . . . . . . . . . . . . . . . . 81

$4.4 \quad$ Pesos das arestas .................. 82

$4.5 \quad$ Considerações finais . . . . . . . . . . . . . 83 
5 ESTUDOS DE CASO E RESULTADOS . . . . . . . . . . 85

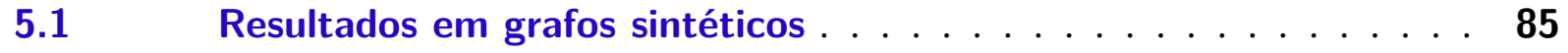

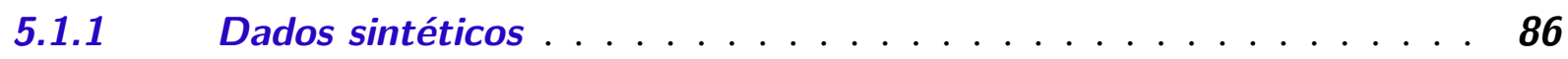

5.1.2 Questões analíticas e parâmetros de configuração . . . . . . . . 887

5.1.3 Estruturas de comunidade (Q1) . . . . . . . . . . . 89

5.1.4 União de vértices com comunidades distintas (Q2) . . . . . . 93

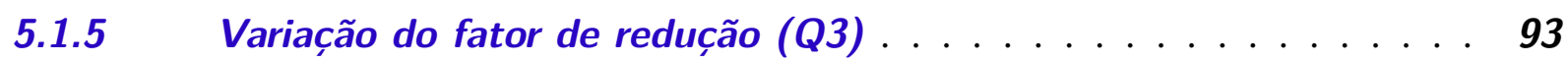

$5.2 \quad$ Resultados em aplicações do mundo real . . . . . . . . . . . 97

5.2.1 Dados de aplicações do mundo real . . . . . . . . . . . . . 97

5.2.2 Parâmetros de configuração . . . . . . . . . . . . . . . 99

$5.2 .3 \quad$ IEEEVis . . . . . . . . . . . . . . . . . 100

5.2.4 Documento-termos . . . . . . . . . . . . . . . . . . . . 104

5.2.5 Movie Lens . . . . . . . . . . . . . . . . . . . . . . 108

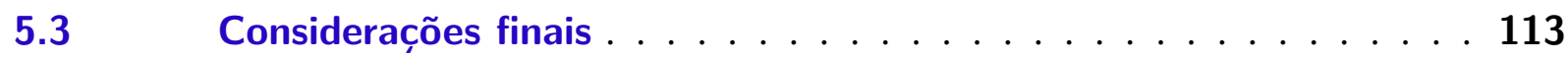

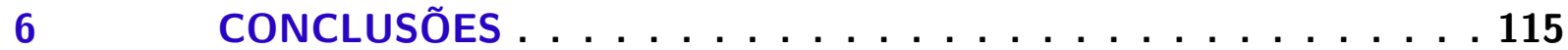

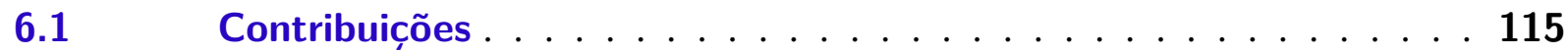

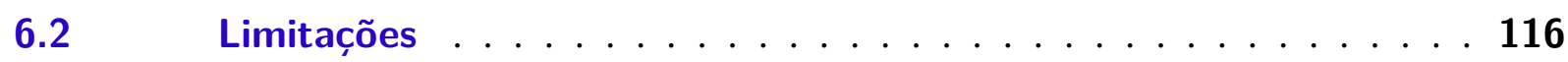

6.3 Direcionamentos Futuros . . . . . . . . . . . . . . . . . . . 117

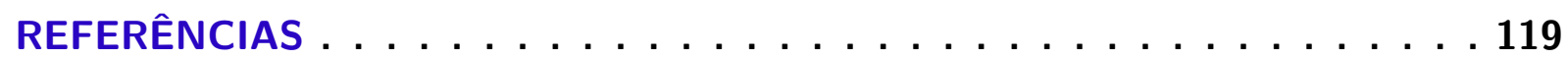




\section{1}

\section{INTRODUÇÃO}

A Visualização da Informação é uma área do conhecimento que utiliza modelos gráficos para criar representações abstratas de dados que não necessariamente possuem uma representação espacial (OLIVEIRA; LEVKOWITZ, 2003). Ela busca ampliar a cognição humana para compreensão e assimilação de informações (CARD; MACKINLAY; SHNEIDERMAN, 2009). Em Visualização da Informação, dado e informação são termos com significados distintos: o primeiro identifica valores sem nenhum tratamento e interpretação inferida. Já o segundo identifica dados que, com o auxílio de alguma técnica de Visualização, agora possuem algum significado ou interpretação específica.

Dados são, muitas vezes, armazenados sem qualquer tipo de tratamento, na expectativa de no futuro extrair deles algo relevante, gerando muitas vezes redundância. Em Visualização de Informação, instâncias de dados podem ser descritas por um conjunto de atributos, como gênero, idade e altura de um indivíduo. Esses atributos, em uma abstração matemática, podem ser mapeados em coordenadas espaciais, definindo um espaço $m$-dimensional, cada um deles representando uma dimensão. Isso caracteriza essas bases de dados como multidimensionais (PAULOVICH et al., 2008).

No contexto atual, em que grandes volumes de dados são coletados e acumulados, a Visualização da Informação é uma área de pesquisa que vem amadurecendo e cuja relevância vem se estabelecendo, já que a compreensão e obtenção de informação apoiada por interfaces visuais é mais eficiente e ágil do que a leitura de um texto ou tabela. A representação gráfica também sobrepõe a barreira de linguagem, podendo ser utilizada como instrumento de comunicação universal. A Visualização de Informação tem incorporado técnicas de Mineração de Dados, dando origem a novas disciplinas como Mineração Visual de Dados (KEIM, 2002; OLIVEIRA; LEVKOWITZ, 2003) e Visual Analytics (KEIM et al., 2008). Visual Analytics é descrita como a ciência do raciocínio analítico auxiliado por interfaces visuais interativas (THOMAS; COOK, 2006). Seu foco é, dada alguma representação visual de um conjunto de dados, viabilizar 
a condução de análises exploratórias e raciocínio analítico de maneira a obter conhecimento (informação), permitindo ao usuário descobrir novos cenários e confirmar hipóteses. A Mineração Visual de Dados é mais do que o uso de recursos visuais aplicados a algoritmos de mineração de dados. A forte coesão entre ambas as disciplinas é fundamental para o processo analítico, utilizando da visualização como parte efetiva de algoritmos de mineração de dados (OLIVEIRA; LEVKOWITZ, 2003; WONG, 1999).

Existem técnicas de visualização de dados multidimensionais consolidadas, como coordenadas paralelas (INSELBERG, 1985), matrizes de dispersão (UTTS, 2014) e RadViz (HOFFMAN et al., 1997). Existem também técnicas cuja estratégia é mapear o espaço $m$-dimensional, com $m$, geralmente um valor alto, para um espaço $d$-dimensional, usualmente sendo $d$ uma dimensão menor, por exemplo $d=\{1,2,3, \ldots\}$; tais técnicas são denominadas projeções multidimensionais. Exemplos de técnicas consolidadas incluem o Principal Component Analysis, ou PCA (WOLD; ESBENSEN; GELADI, 1987), t-distributed Stochastic Neighborhood Embedding, ou t-SNE (MAATEN; HINTON, 2008) e Least Square Projection, ou LSP (PAULOVICH et al., 2008).

Outras técnicas de visualização manipulam dados relacionais, isto é, aqueles em que existem estruturas de relações entre instâncias de dados, como Treemap (JOHNSON; SHNEIDERMAN, 1991), Sunburst (STASKO; ZHANG, 2000) e árvores hierárquicas. Saindo do escopo de visualização e focando em formas de armazenamento desses dados relacionais, tem-se os grafos como uma estrutura que armazena informações de relação entre instâncias de elementos. Eles podem ser utilizados em aplicações como hierarquia de arquivos, redes biológicas e sociais (HERMAN; MELANCON; MARSHALL, 2000; DIAS et al., 2015).

Usualmente, grafos são compostos por vértices e arestas, onde vértices caracterizam os elementos de um determinado espaço e arestas codificam as relações entre esses elementos. Grafos bipartidos são a categoria especial de grafos que possuem algumas propriedades interessantes. Relações entre documentos e palavras, redes de coautoria e redes de proteína são exemplos de aplicações do mundo real que podem ser modeladas como grafos bipartidos (ROSSI; LOPES; REZENDE, 2016; NEWMAN, 2001; JEONG et al., 2000). Além disso, grafos podem ser utilizados para representar dados multidimensionais, onde um vértice representa uma instância com múltiplos atributos associados.

Além de estruturas abstratas de armazenamento, grafos podem ser utilizados para a representação visual de dados relacionais. As duas principais representações adotadas na literatura são nó-aresta (EADES, 1984), em que vértices são em geral apresentados como círculos e arestas são caracterizadas como linhas que conectam esses vértices, e a matricial (ELMQVIST et al., 2008), que representa uma matriz utilizada como forma de armazenamento dessa estrutura em um computador, conforme será discutido no Capítulo 2.

A criação de representações visuais de grafos está relacionada à área de Desenho de Grafos, sendo que muitas soluções (EADES, 1984; GAJER; KOBOUROV, 2001; HAREL; 
KOREN, 2002) já foram propostas para esse problema. Entretanto, a Visualização de Informação considera um cenário mais amplo, pois tem por objetivo fornecer representações interativas em que as relações entre as instâncias são relevantes para a interpretação e análise dos atributos associados aos vértices de um grafo, que podem representar dados multidimensionais.

As representações nó-aresta são consideradas mais intuitivas para a identificação de caminhos relevantes e estruturas topológicas de um grafo (GHONIEM; FEKETE; CASTAGLIOLA, 2004). Entretanto, a visualização de grafos que contém milhares de vértices e arestas utilizando a representação nó-aresta pode ser lenta, e produz representações muito densas com sobreposição de elementos, o que prejudica a obtenção de informação por meio de atividades exploratórias (LANDESBERGER et al., 2011).

Uma forma de tratar esses problemas é por meio da simplificação da visualização do grafo. Isso inclui utilizar alguma propriedade fundamental do grafo ou realizar uma amostragem, de maneira a reduzir a quantidade de vértices e arestas a serem visualizados (LESKOVEC; FALOUTSOS, 2006; ARCHAMBAULT; MUNZNER; AUBER, 2007). Também pode-se simplificar o grafo com a construção de "super-vértices" ou "super-arestas", que são uma agregação de diversos vértices ou diversas arestas, respectivamente. Estratégias de agregação permitem criar representações gráficas em múltiplos níveis de abstração, o que favorece a interação do usuário e sua navegação em regiões, ou partes, do grafo, em cenários inviáveis ou indesejáveis à manipulação de uma representação do grafo completo.

O paradigma multinível é um arcabouço genérico para tratar problemas de otimização em grafos (WALSHAW, 2004). Seu funcionamento básico consiste em gradualmente reduzir um grafo inicial, por um processo denominado contração, produzindo uma hierarquia de sucessivos grafos simplificados. Após essa etapa, resolve-se o problema de otimização no grafo de nível mais contraído. A solução obtida é projetada de maneira reversa na hierarquia de grafos simplificada, até retornar ao grafo original. Mais detalhes sobre o funcionamento do paradigma estão presentes no Capítulo 2. O arcabouço permite resolver uma variedade de problemas de otimização em grafos, como particionamento (PADMAVATHI; GEORGE, 2014; WALSHAW; CROSS; EVERETT, 1997) e fatorização de matrizes esparsas (GUPTA; KARYPIS; KUMAR, 1997). Ele também foi utilizado como estratégia para desenho de grafos (HAREL; KOREN, 2002).

\subsection{Motivação}

Valejo et al. (2018) introduziram um novo arcabouço multinível aplicável a grafos bipartidos, modificando algumas etapas do processo para adequá-lo a essa categoria de grafos. Esse arcabouço traz algumas melhorias que garantem maior flexibilidade, entretanto, isso introduz o desafio de definir quais escolhas devem ser feitas nas diferentes etapas do processo. Por exemplo, diferentes algoritmos de contração podem ser aplicados, e pode-se escolher os 
múltiplos níveis intermediários existentes na hierarquia produzida. Fazer escolhas adequadas a priori, lidando com grafos com propriedades topológicas diferentes, torna-se uma tarefa desafiadora.

Uma motivação inicial para este trabalho é de encontrar uma solução em Visualização de Informação que norteie o entendimento dos resultados produzidos por execuções do paradigma multinível, ou seja, a hierarquia de grafos simplificada resultante da aplicação de um algoritmo de contração escolhido. Além disso, o funcionamento do paradigma, especialmente a etapa de contração, tem o potencial de ser utilizado como uma estratégia para apoiar tarefas de análise, visto que a hierarquia produzida oferece múltiplos níveis de abstração. Portanto, uma outra motivação é investigar até que ponto visualizações obtidas com a execução do paradigma multinível podem apoiar a visualização exploratória de dados multidimensionais representados como grafos bipartidos.

A razão de abordar a visualização exploratória no contexto de grafos bipartidos parte da vasta disponibilidade de conjuntos de dados modelados nessa categoria potencialmente relevantes, como detalhado no Capítulo 5. Ademais, técnicas existentes de agregação e visualização exploratória consideram grafos em geral, não sendo específicas para grafos bipartidos, como abordado no Capítulo 3. O paradigma multinível de Valejo et al. (2018) é flexível e pode ser integrado com técnicas exploratórias de visualização, com potencial para apoiar atividades exploratórias sobre grafos bipartidos.

\subsection{Objetivos e contribuições}

Em vista da contextualização da Visualização da Informação, representação de grafos bipartidos e flexibilidade do paradigma multinível, e destacando as necessidades dessas áreas, tem-se como principais objetivos deste trabalho de mestrado:

(i) Gerar uma nova metáfora de visualização para apoiar a interpretação e o entendimento do paradigma multinível e do papel dos diferentes parâmetros na obtenção de uma representação multinível;

(ii) Verificar como a integração entre a visualização proposta e o paradigma multinível pode apoiar atividades exploratórias em grafos bipartidos.

Para cumprir os objetivos, um conjunto de passos foi delineado. Primeiramente, estudouse melhor o comportamento do paradigma multinível, utilizando a implementação disponibilizada por Valejo et al. (2018) para entender a execução da técnica e o papel dos diferentes parâmetros. Em seguida, um sistema foi desenvolvido como prova de conceito, com a finalidade de retratar uma representação visual interativa da hierarquia do paradigma multinível. Nesse sistema, uma nova metáfora de visualização de grafos bipartidos foi introduzida, permitindo a interação com a 
representação hierárquica e apoiando atividades exploratórias em conjuntos de dados reais. Em resumo, as principais contribuições desse trabalho de mestrado são:

- Uma nova metáfora visual para representar hierarquias de grafos bipartidos obtidas com o paradigma multinível;

- Uma interface de visualização integrada ao arcabouço proposto por Valejo et al. (2018), servindo de prova de conceito para observar o comportamento do paradigma multinível quando submetido a diferentes parâmetros de configuração, apoiando o entendimento desse paradigma;

- Estudos de caso ilustrando como a integração entre a interface visual e o paradigma multinível apoiam em atividades exploratórias aplicadas em conjuntos de dados reais multidimensionais modelados como grafos bipartidos.

\subsection{Organização}

Esse texto está organizado da seguinte forma:

- Neste Capítulo 1, Introdução, o contexto no qual o problema está inserido é apresentado, juntamente com a motivação inicial, objetivos gerais e resultados esperados;

- No Capítulo 2, Conceitos Fundamentais, uma breve revisão dos conceitos necessários para a compreensão deste trabalho é apresentada, incluindo notação e conceitos de grafos, grafos bipartidos e o funcionamento do paradigma multinível;

- No Capítulo 3, Visualização em Grafos, são apresentados alguns dos principais trabalhos correlatos de visualização exploratória em grafos e técnicas de agregação, e também uma análise comparativa;

- No Capítulo 4, Visualização Exploratória com o Paradigma Multinível, é delineada a sequência de passos utilizada para a integração entre o paradigma multinível e a visualização nó-aresta de um grafo bipartido. O sistema desenvolvido como prova de conceito é apresentado.

- No Capítulo 5, Estudos de Caso e Resultados, estudos de caso são apresentados. Primeiramente, os estudos são feitos com dados sintéticos, demonstrando o apoio que a visualização fornece para o entendimento do paradigma multinível. Posteriormente, dados reais são estudados, identificando como a integração entre a nova metáfora visual e o paradigma multinível apoia atividades exploratórias. 
- Por fim, no Capítulo 6, Conclusões, faz-se um breve retrospecto do que foi apresentado nesse documento, quais as contribuições ao conhecimento científico, principais limitações e direcionamentos futuros. 


\section{CONCEITOS FUNDAMENTAIS}

Neste Capítulo, são introduzidos conceitos essenciais para o entendimento deste trabalho. A Seção 2.1 introduz alguns conceitos de grafos e a notação adotada neste texto, bem como as formas consolidadas de armazenamento dessa estrutura. A área de Visualização da Informação também é introduzida na Seção 2.2, bem como uma taxonomia das técnicas. As principais técnicas de representação de grafos são destacadas. Uma introdução ao arcabouço multinível aplicado a grafos bipartidos, proposto por Valejo et al. (2018), é apresentada na Seção 2.3, detalhando as principais etapas do seu funcionamento.

Para a compreensão e execução do paradigma multinível, é fundamental entender os algoritmos de pareamento utilizados e as medidas de similaridade adotadas, abordados na Seção 2.4. As vantagens de cada um dos métodos de pareamento e funções de similaridade são destacadas. Na Seção 2.5, detalha-se o processo de contração que gera a hierarquia de níveis contraídos. Por fim, na Seção 2.6 são explicadas as principais medidas de similaridade adotadas na execução do paradigma multinível.

\subsection{Terminologia e notação}

As definições e terminologia adotadas neste texto têm como referência os trabalhos de Bondy e Murty (1976), Batini, Furlani e Nardelli (1985) e Skiena (1998). Um grafo é uma coleção de vértices e arestas representado por $G=(V, E)$, em que $V(G)$ e $E(G)$ indicam, respectivamente, o conjunto dos vértices e o conjunto das arestas do grafo G. Dados dois vértices $u, v \in V(G)$, uma aresta que os conecta é denotada por $(u, v) \in E(G)$. $|V|$ e $|E|$ indicam, respectivamente, os números de vértices e de arestas em $G$.

Quando as arestas têm direção, tem-se um grafo dirigido, e caso elas possuam valores temse um grafo ponderado, ou grafo com pesos. Vértices também podem possuir valores associados e definem um grafo ponderado. Um subgrafo de $\mathrm{G}$ é um grafo $H$ tal que $V(H) \subseteq V(G)$ e 
$E(H) \subseteq E(G)$. Em um grafo bipartido o conjunto de vértices $V$ pode ser particionado em dois subconjuntos disjuntos $V_{1}$ e $V_{2}$, de tal maneira que para qualquer aresta $(u, v) \in E(G)$ tem-se $u \in V_{1}$ e $v \in V_{2}$. A representação de um grafo bipartido pode ser descrita como $G=\left(V_{1}, V_{2}, E\right)$, e $V_{1}$ e $V_{2}$ são denominadas camadas do grafo.

O número de arestas incidentes a um vértice determina o seu grau, representado por $d_{G}(v) . \delta(G)$ e $\Delta(G)$ definem, respectivamente, o grau mínimo e o grau máximo dos vértices de G. Os vértices $u$ e $v$ são vizinhos, ou adjacentes, quando $(v, u) \subset E$. Grafos completos são tais que $d_{G}(v)=|V|-1, \forall v \in V$, ou seja, cada vértice está conectado a todos os demais. Em um grafo bipartido a vizinhança $h$-hop de um vértice $v$ é dada pelos vértices conectados a $v$ por um caminho de tamanho $h$, formalmente definida como $\Gamma_{h}(v)=\{u \mid$ existe um caminho de tamanho $h$ entre $v$ e $u$. Em um grafo bipartido, a vizinhança $\Gamma_{2}(u)$ define vértices adjacentes a $u$ que pertencem à mesma camada $V_{1}$ ou $V_{2}$.

Grafos são ditos conexos quando todos os seus vértices estão conectados por um caminho. Esse caminho em $G$ é definido como sendo uma sequência não nula finita $C=\left\{v_{0}, v_{1}, \ldots, v_{k}\right\}$ de vértices, em que $\left\{\left(v_{i-1}, v_{i}\right) \subset E(G), v_{i-1} \neq v_{i} \quad \mid \forall v \in C, 0 \leq i \leq k\right\}$. Um grafo possui um ciclo quando existe um subgrafo $S=(V, E)$ tal que $V(S)=\left\{v_{1}, v_{2}, \ldots, v_{k}\right\}$ e $E(S)=\left\{\left\{v_{i}, v_{i+1}\right\}: 1 \leq\right.$ $i<k \quad$ । $\left.\left\{v_{1}=v_{k}\right\}\right\}$, ou seja, um caminho em que $v_{1}=v_{k}$. Grafos com ciclo são ditos cíclicos. O tamanho de um caminho é denotado por $|C|$.

Um conjunto independente em um grafo $G$ é todo aquele cujos vértices não são adjacentes, ou seja, $\{S \subset G,(u, v) \notin E(S) \quad \forall u, v \in V(S)\}$. Já uma clique denota justamente o contrário, um conjunto em que todos os vértices são adjacentes, ou seja, $\{S \subset G,(u, v) \in E(S) \quad \forall \forall u, v \in V(S)\}$.

Um particionamento de $G$ pode ser definido como a subdivisão do conjunto $V$ em $k$ subconjuntos disjuntos, i.e., $S=\left\{V_{1}, V_{2}, \ldots, V_{k}\right\}, V_{i} \cap V_{j}=\emptyset$. Um grafo bipartido é um exemplo de partição em que $k=2$. Já em uma sobreposição, dada por $S=\left\{V_{1}, V_{2}, \ldots, V_{k}\right\}, V_{i} \cap V_{j} \neq \emptyset$, as partições do conjunto de vértices não são disjuntas.

As notações e terminologias apresentadas anteriormente são comumente utilizadas em contextos matemáticos, pertinentes à teoria dos grafos (BONDY; MURTY et al., 1976). Entretanto, uma ramificação aplicada dessa área é a teoria de Redes Complexas, cujo foco é o estudo das propriedades topológicas e dos padrões de conexão encontrados em aplicações do mundo real (NEWMAN, 2003). Apesar de adotar parte das notações acima, sua terminologia é, às vezes, distinta. Frequentemente, os seguintes termos serão utilizados: nós, que referem-se a vértices, conexões, que indicam arestas, e redes para indicar grafos.

Redes que modelam aplicações do mundo real podem codificar mais do que conexões que indicam relacionamentos. Atributos topológicos podem estar associados aos nós, coletivamente, indicando uma estrutura de comunidades. Essas comunidades podem identificar propriedades topológicas e funcionais em uma rede, e podem ser definidas utilizando os conceitos apresentados de particionamento e sobreposição, em que cada subconjunto distinto identifica uma comunidade. 
Nesse contexto, um particionamento $P$ indica nós que pertencem, exclusivamente, a uma única comunidade. Já uma sobreposição $S$ indica que nós podem pertencer a múltiplas comunidades simultaneamente.

Existem algumas métricas utilizadas em redes complexas para análise de redes, que identificam algumas das suas características topológicas. Uma delas é a densidade, que indica a quantidade de conexões existentes em uma rede, dada pela Equação 2.1. Valores próximos a 1 indicam um grafo muito denso.

$$
D=\frac{2|E|}{|V|(|V|-1)}
$$

Outra métrica é a homogeneidade, que indica o quão distintos são os atributos de nós em uma rede. Em uma rede de autores e artigos, por exemplo, se todos os autores possuem no atributo "área de atuação" o valor "Computação", isso indica uma rede totalmente homogênea para esse atributo. Dessa maneira, quando um atributo possui múltiplos valores distintos ao longo de toda rede, isso caracteriza alta heterogeneidade (WASSERMAN; FAUST, 1994).

Para melhor entendimento dos trabalhos relacionados discutidos no Capítulo 3, é importante compreender as principais formas de armazenamento de um grafo. Essa estrutura, concebida como um modelo abstrato, precisa ser armazenada em um computador de alguma maneira. Os métodos mais consolidados utilizados são as matrizes de adjacência e as listas de adjacência. O primeiro consiste em, dada uma matriz $M(|V|,|V|)$, cada célula ser definida como:

$$
M(u, v)= \begin{cases}1, & (u, v) \in E(G) \\ 0, & (u, v) \notin E(G)\end{cases}
$$

Já uma lista de adjacências contém um arranjo de $|V|$ listas. Cada posição desse arranjo corresponde a um vértice no grafo, e os vértices adjacentes são adicionados à sua lista. Em termos de eficiência nas operações de acesso - como encontrar um vértice ou inserção e remoção -, a matriz de adjacência é a estrutura mais indicada, por permitir o acesso direto a vértices, com tempo constante $O(1)$. Utilizando uma lista de adjacência, no pior caso, localizar ou remover um vértice gasta tempo $O(|V|)$. Já no que diz respeito à eficiência do uso de memória, listas de adjacência são mais indicadas por terem custo computacional menor, $O(|E|+|V|)$, ao contrário das matrizes, que consomem tempo $O\left(|V|^{2}\right)$.

\subsection{Visualização da Informação}

A Visualização pode ser definida como a representação de informação de maneira visual, utilizando interatividade e o auxílio de um computador, permitindo a ampliação da cognição e do conhecimento (SCHNEIDERMAN, 1999). Em um contexto mais específico, a área de Visualização da Informação ocupa-se em utilizar a interatividade unida ao auxílio 
computacional para prover representações abstratas de dados, que permitem a interpretação e obtenção de informação. Uma única imagem pode conter uma ampla gama de informações, e seu processamento é muito mais rápido do que um conjunto de palavras. Isso acontece porque sua interpretação é feita em paralelo, ao passo que a leitura restringe a atividade de cognição a seções sequenciais de texto. Outra característica de imagem é que ela sobrepõe-se a barreira universal da linguagem, sendo geralmente compreensível por um grupo de pessoas com idiomas diferentes (WARD; GRINSTEIN; KEIM, 2015).

Existem diversas taxonomias apresentadas na literatura que buscam categorizar as técnicas de visualização existentes, sendo que a maioria separa as técnicas de acordo com os tipos de dados e as tarefas realizadas (KELLER et al., 1994; SHNEIDERMAN, 1996; KEIM, 2002). O escopo deste projeto abrange principalmente os tipos de dados multidimensionais, grafos e suas representações.

A disciplina de Desenho de Grafos apresenta diversas soluções e estratégias referentes a representação visual dessas estruturas (HACHUL; JÜNGER, 2007). Entretanto, como mencionado no Capítulo 1, este projeto requer aliar representação e atividades exploratórias em dados em um mesmo cenário. Por isso, destacam-se as principais técnicas consolidadas de representação em grafos adotadas na área de Visualização da informação.

Para a representação visual de grafos, existem duas estratégias consolidadas: ou a nóaresta ou a matricial. Para a nó-aresta, tem-se abordagens que buscam modelar o grafo com um conjunto de círculos, representando vértices, que são conectados por linhas que denotam as arestas. Pode-se utilizar uma solução que modela o grafo como um sistema de partículas conectadas por molas, como no trabalho de Eades (1984), otimizado posteriormente (FRUCHTERMAN; REINGOLD, 1991; KAMADA; KAWAI, 1989). Pode-se também incorporar o próprio paradigma multinível, detalhado na Seção 2.3, para acelerar os algoritmos de desenho em grafos, como nos trabalhos de Harel e Koren (2000), Gajer e Kobourov (2001), Hachul e Jünger (2004).

A outra estratégia de visualização de grafos inclui a representação matricial, que utiliza a matriz de adjacência. Dessa maneira, é possível ordenar as linhas e as colunas da matriz, para evidenciar padrões de relacionamento entre vértices e arestas (MUELLER; MARTIN; LUMSDAINE, 2007). Diversas abordagens na literatura (HENRY; FEKETE; MCGUFFIN, 2007; GUALDRON; CORDEIRO; RODRIGUES, 2015; ABELLO; HAM, 2004; ELMQVIST et al., 2008) ilustram a utilização da representação matricial, destacando a eficiência para obtenção de informação dos dados relacionais. O foco delas é garantir uma ordenação que evidencie as propriedades topológicas dos grafos. As abordagens também mostram evidências de que esse tipo de representação garante um maior apoio para a visualização de grandes grafos, sendo mais escalável quando comparada à representação nó-aresta com um sistema de forças.

Comparações entre ambas as formas de representação já foram realizadas, por exemplo por Ghoniem, Fekete e Castagliola (2004) Para isso, os autores organizaram 7 testes em que 
determinadas tarefas deveriam ser realizadas em um mínimo de tempo possível. Também foi definido que os testes seriam realizados com grafos de 20, 50 e 100 vértices, com diferentes níveis de densidade de arestas. Os resultados obtidos indicaram que, em quase todos os experimentos, a representação matricial propiciou as respostas mais rápidas, salvo em uma tarefa, em que a representação nó-aresta garantiu resultados mais rápidos.

Apesar da tentativa de realizar medições quantitativas, visualizações com grafos possuem propósitos complexos, que não podem ser facilmente descritos por meio de tarefas. A generalização de atividades "corriqueiras" não é muito eficaz, pois depende da aplicação. A comparação entre representações de grafos sempre é uma questão complexa, por envolver fatores inerentes à interação humano-computador difíceis de serem mensurados ou quantificados. $\mathrm{O}$ trabalho de Ghoniem, Fekete e Castagliola (2004) não contempla tarefas típicas de visualização em grafos, ou seja, tarefas ilustrativas da visualização exploratória. Um exemplo desse tipo de tarefa seria a capacidade de identificar um determinado conjunto de vértices com características similares. Portanto, neste trabalho utiliza-se uma representação nó-aresta de grafos bipartidos, sem necessariamente usar um sistema de forças.

\subsection{Paradigma multinível}

O paradigma multinível é aplicável, de modo geral, a problemas de otimização combinatória em computação (WALSHAW, 2004). A abordagem pode ser interpretada como um condensador de problemas, em situações em que é inviável obter uma solução sem um processo de compactação. Assim, o paradigma multinível busca agrupar as variáveis, construindo um espaço mais restrito em que soluções podem ser aplicadas utilizando técnicas consolidadas que não são escaláveis. No contexto de grafos, ele pode ser aplicado de maneira a agregar vértices, aplicando-se alguma técnica alvo para resolver um problema sobre o novo grafo agregado $G_{n} \mathrm{e}$ posteriormente projetando a solução obtida em sucessivas expansões, até o grafo original $G$.

A abordagem contempla três fases, sumarizadas na Figura 1. Partindo de um grafo original $G_{0}$, na fase de contração cria-se uma sequência de aproximações do grafo original $\left\{G_{1}, G_{2}, \ldots, G_{N}\right\}$, ou $N$ níveis, por meio da junção de pares ou de grupos de vértices, com consequente remoção de arestas, formando super-vértices, de modo que $\left|V_{0}\right|>\ldots\left|V_{N}\right|$. Na fase de solução inicial, aplica-se algum algoritmo, que no grafo original teria um tempo de execução inviável, sobre o grafo mais contraído $G_{N}$, obtendo-se uma solução inicial $G_{S}$. Na fase de projeção a solução obtida $G_{S}$ é projetada sobre os grafos intermediários $G_{N-1}, G_{N-2}, \ldots$ até o grafo original $G_{0}$.

O processo é definido no Algoritmo 1. Tem-se como parâmetros de entrada os elementos definidos nas linhas 2-6. O grafo bipartido é dado por $G_{0}$. O número de níveis, definido com o vetor $L$, indica os níveis intermediários produzidos para cada um dos conjuntos $V_{1}$ e $V_{2}$. O fator de redução $r f$ indica a porcentagem de vértices a serem reduzidos em cada um dos níveis, 
Figura 1 - Execução do paradigma multinível sobre um grafo inicial $G_{0}$.

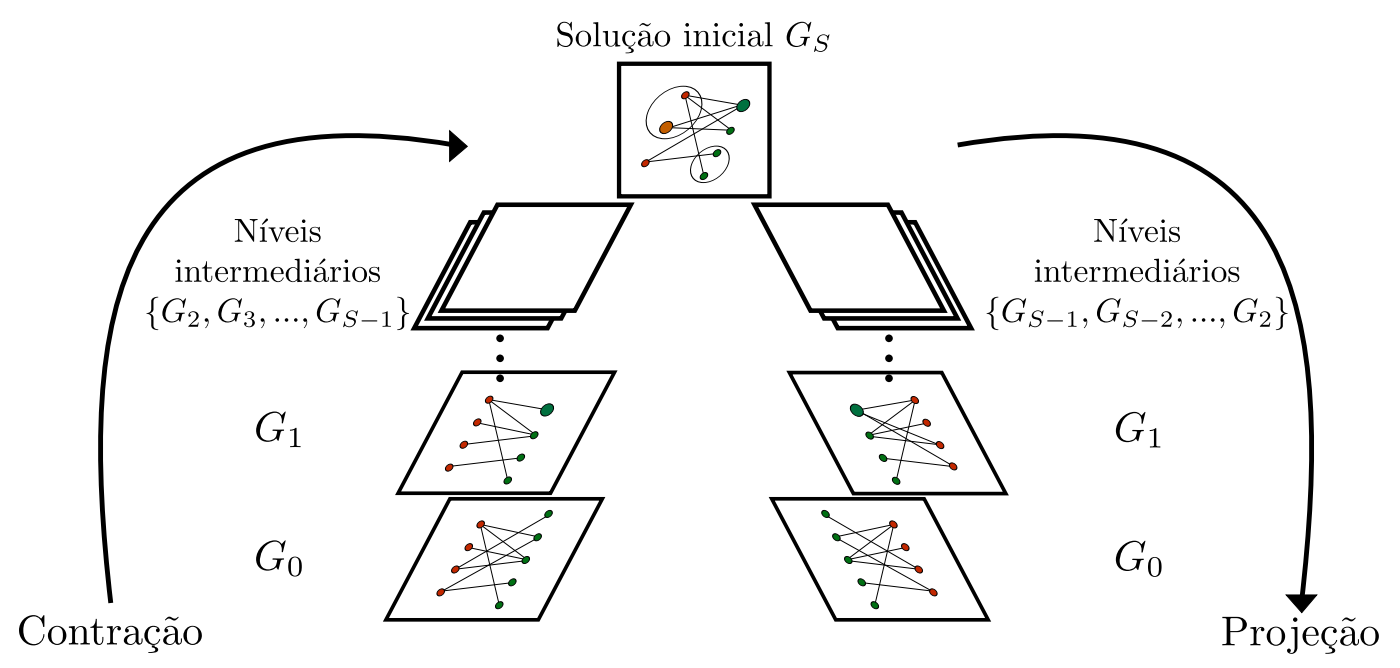

Fonte: Elaborada pelo autor.

representado por valores decimais entre 0.0 a 0.5 . Pode-se definir valores de tal maneira que $r f_{1} \neq r f_{2}$. layers é um vetor de dois elementos e define quais camadas serão contraídas, por exemplo, pode-se contrair ambas ou apenas uma delas. Se somente um valor, ou $[1,0]$ ou $[0,2]$, é passado, somente a camada correspondente não nula será contraída, caso $[1,2]$ seja definido, então ambas as camadas sofrerão o processo de contração. Por fim, a função de pareamento é o parâmetro que define qual algoritmo será aplicado para formar pares ou conjuntos de vértices. Mais detalhes dos tipos de algoritmos de pareamento existentes são apresentados na Seção 2.4.

Nas linhas 8-16, dependendo das camadas a serem contraídas e do número de níveis intermediários definidos, ocorrem as fases de pareamento e contração, gerando a hierarquia $\left\{G_{1}, G_{2}, \ldots, G_{l}\right\} . M$ define um conjunto de vértices candidatos a agrupamento, formando supervértices, denotados por $s V_{i}, i \in\left[0,\left|V_{1}\right|+\left|V_{2}\right|\right)$. Na linha 17, tendo-se o grafo mais contraído $G_{l}$, aplica-se o algoritmo alvo, obtendo uma solução inicial $G_{S}$. Por fim, nas linhas $18-22$, tendo $G_{S}$, projeta-se essa solução na hierarquia $\left\{G_{l}, G_{l-1}, \ldots, G_{1}\right\}$, executando, se possível, um refinamento da solução (linha 18).

O escopo deste trabalho não engloba as etapas descritas entre as linhas 17-22, que são a obtenção de uma solução inicial, projeção e refinamento. Valejo et al. (2018) detalha a utilização de técnicas de refinamento e projeção. A seguir, os processos de pareamento e contração serão detalhados, cujas funcionalidades são fundamentais para a compreensão deste trabalho.

\subsection{Pareamento}

A função de contração, definida na linha 12 do Algoritmo 1, é precedida de uma etapa de pareamento, ou matching (linha 11), que estabelece quais pares ou conjuntos de vértices são 


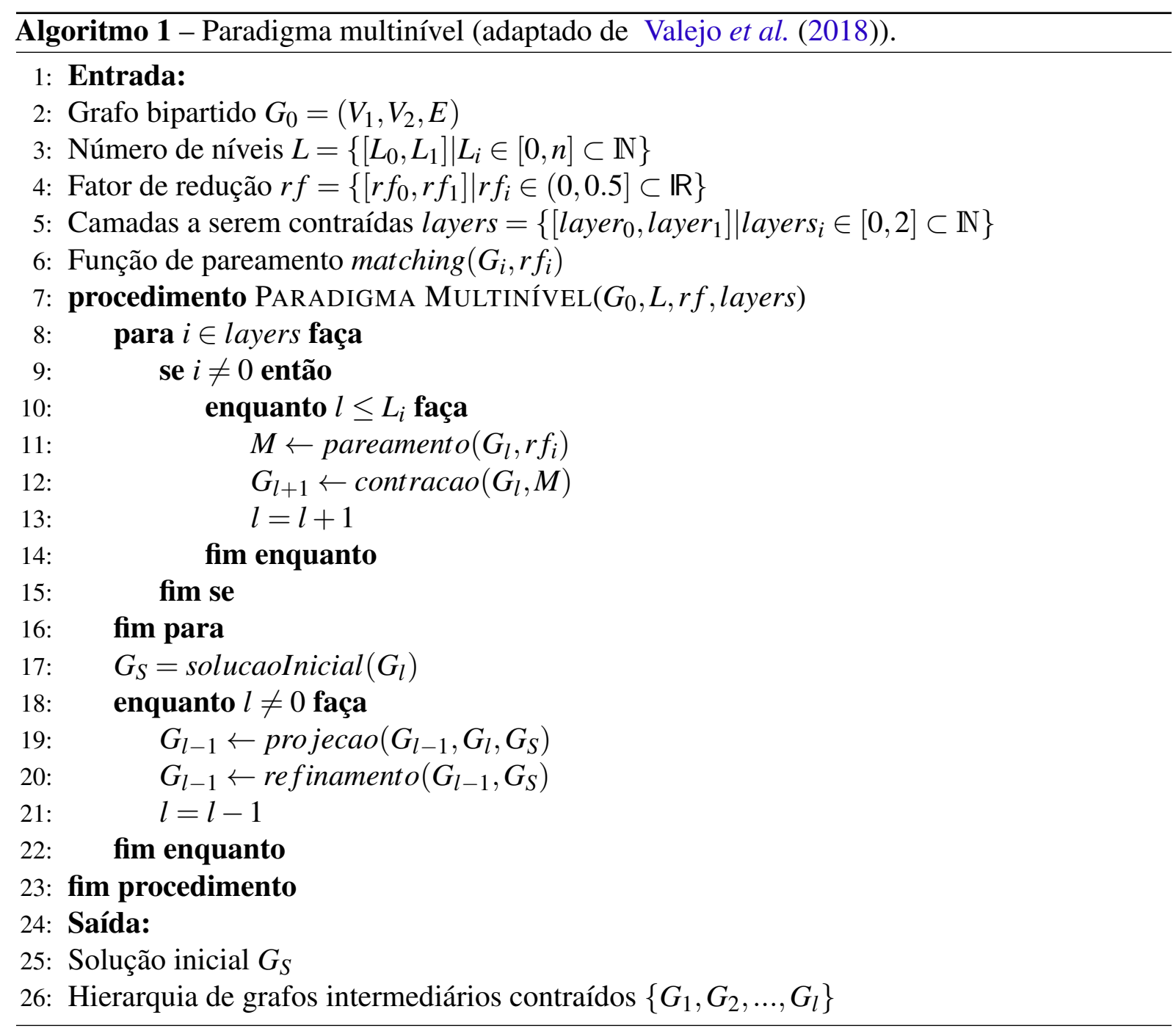

candidatos a serem contraídos e transformados em super-vértices. A seguir, descrevem-se alguns dos principais algoritmos de pareamento utilizados neste trabalho.

Greedy Matching for Bipartite Networks (GMb)

Esse algoritmo de pareamento para uso em grafos bipartidos foi introduzido em Valejo et al. (2018). Uma visão detalhada dessa estratégia encontra-se no Algoritmo 2. Sua sequência de passos resume-se a:

1. Inicialize uma fila de prioridades em ordem decrescente $Q$;

2. Selecione, para todo vértice $u$ de um determinado conjunto $V_{i}$, o vizinho $v \in \Gamma_{2}(u)$ com similaridade $S(u, v)$ maximal, e insira o par $(u, v)$ em $Q$;

3. Enquanto ou a fila de prioridades $Q$ possuir elementos ou o fator de redução não for alcançado, remova os pares $(u, v)$ do topo da lista de prioridades $Q$ e, caso nenhum dos dois componha um super-vértice, adicione-os a um conjunto $M$ de super-vértices. 


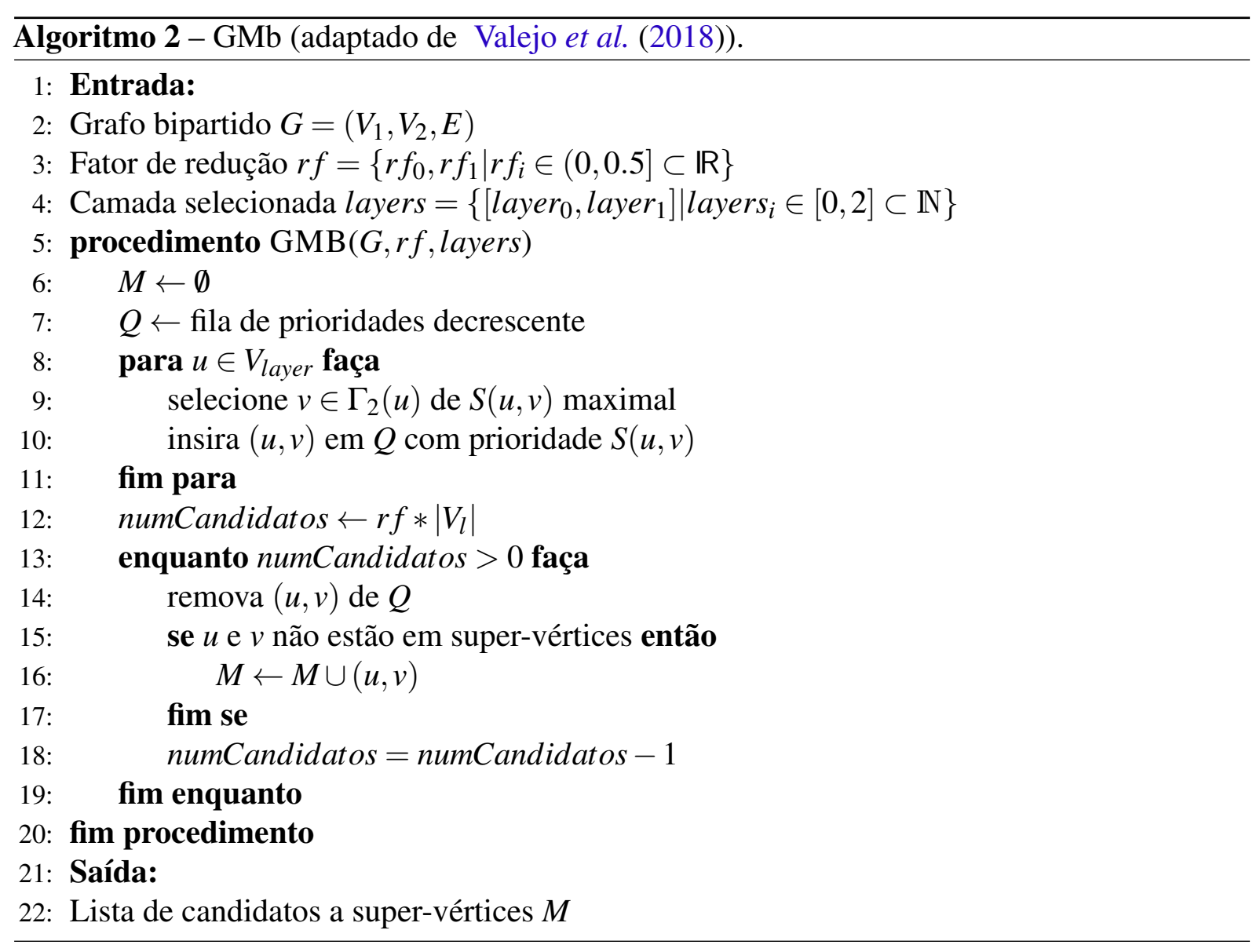

Como entrada, o algoritmo recebe o grafo bipartido $G$, o fator de redução $r f$ e em qual camada os candidatos a super-vértices são selecionados, definida por layers. Nas linhas 6 e 7, são definidos o conjunto $M$ e a fila de prioridades $Q$, que é construída entre as linhas 8-11. A variável numCandidatos é definida na linha 12 e armazena a quantidade de vértices que comporão o nível mais contraído. Por fim, a iteração nas linhas 13-19 remove os pares em $Q$, e caso eles não componham nenhum super-vértice, são adicionados ao conjunto $M$.

Os elementos dominantes do tempo de execução desse algoritmo são o fator de redução $r f$ e a quantidade de vértices da camada a ser contraída, definida por $\left|V_{\text {layer }}\right|$. Para cada vértice $u$, o pareamento requer encontrar seu vizinho $\Gamma_{2}(u)$, o que resulta em um tempo de execução $O\left(\left|V_{\text {layer }}\right| d_{G}(G) h\right)$, em que $d_{G}(G)$ é o grau médio do grafo $G$ e $h$ é o tamanho $h$ do caminho entre $v$ e $u$ (VALEJO et al., 2018).

Matching Label Propagation (MLP)

Observando o comportamento do algoritmo GMb, percebe-se que a união de vértices aos pares acaba "forçando" o pareamento em níveis mais contraídos, o que pode resultar em pareamentos inadequados. Por exemplo, se um fator de redução $r f_{1}=r f_{2}=50 \%$ é aplicado, a cada nível da hierarquia produzida, metade dos vértices terão se transformado em super-vértices, o que pode resultar em soluções de baixa qualidade. 
Buscando sanar esses problemas, Valejo et al. (2019a) introduziram o MLP, um algoritmo que toma como base a ideia de propagação de rótulos, ou label propagation, descrita em Raghavan, Albert e Kumara (2007). Inicialmente, cada vértice recebe um único rótulo; com a execução do algoritmo, o resultado forma super-vértices como grupos de vários vértices, e não somente pares, que devido à distância entre si, adotam uma mesma rotulação.

Para o correto funcionamento desse algoritmo, algumas premissas são adotadas. Para a propagação de rótulos funcionar, os vértices devem ser ponderados. Inicialmente, todos eles assumem o mesmo valor, unitário; conforme os super-vértices são construídos, seus pesos são somados. Buscando manter um balanceamento dos super-vértices construídos, eles têm um limitante de peso. Outra premissa é que o fator de redução e número de níveis, definidos no Algoritmo 1 como $r f$ e $L$, são substituídos por outros dois parâmetros: a quantidade de iterações e o número mínimo de vértices. O segundo parâmetro indica qual o número desejável de vértices ao final da execução do algoritmo. Já a quantidade de iterações indica quantas vezes o algoritmo será executado.

Suponha um grafo $G_{0}$, com $\left|V_{1}\right|=200,\left|V_{2}\right|=200$ e $|E|=10000$. Com a execução do $M L P$, a quantidade mínima de vértices desejada é 50 em ambas as camadas em 10 iterações. $\mathrm{O}$ algoritmo irá tentar, 10 vezes, reduzir o número de vértices o mais próximo possível de 50, produzindo o grafo $G_{1}$. Caso isso não seja possível, então um novo grafo $G_{2}$ é criado, com o mesmo número de vértices e arestas de $G_{1}$, executando 10 iterações novamente. Esse processo continua até o número mínimo de vértices ser alcançado no grafo bipartido $G_{S}$, gerando uma hierarquia de grafos contraídos $G_{1}, G_{2}, \ldots, G_{S}$.

Com essas alterações, faz-se necessário modificar o Algoritmo 1, adequando-o a esses novos parâmetros de entrada. Isso resulta no Algoritmo 3. Tem-se como parâmetros de entrada os elementos definidos nas linhas 2-5. O grafo $G$ é entrada para execução. A quantidade mínima de vértices é dada por $\zeta$, podendo assumir valores entre 1 até a quantidade máxima de vértices para cada camada. O limitante de peso $\mu$ define o peso máximo admito para um super-vértice. A quantidade de iterações $T$ define quantas vezes o algoritmo $M L P$ irá executar até obter a solução desejada. A principal mudança é no laço condicional, que itera enquanto a quantidade mínima de vértices não é atingida (linhas 10-14), compondo a hierarquia contraída de grafos em $H$. A variável $l$ é utilizado como índice para navegar na hierarquia de grafos.

O MLP é detalhado no Algoritmo 4, e pode ser resumido na seguinte sequência de passos:

1. Seja $V_{\text {layer }}$ a camada a ser contraída. Selecione um vértice $u \in V_{\text {layer }}$ e inicialize uma fila de prioridades $Q$ com valores 0.0 , de comprimento igual à quantidade de rótulos existentes.

2. Para todos os vizinhos $\Gamma_{2}(u)$, determine o valor de seus rótulos, de acordo com a métrica de similaridade $S(u, v)$; 


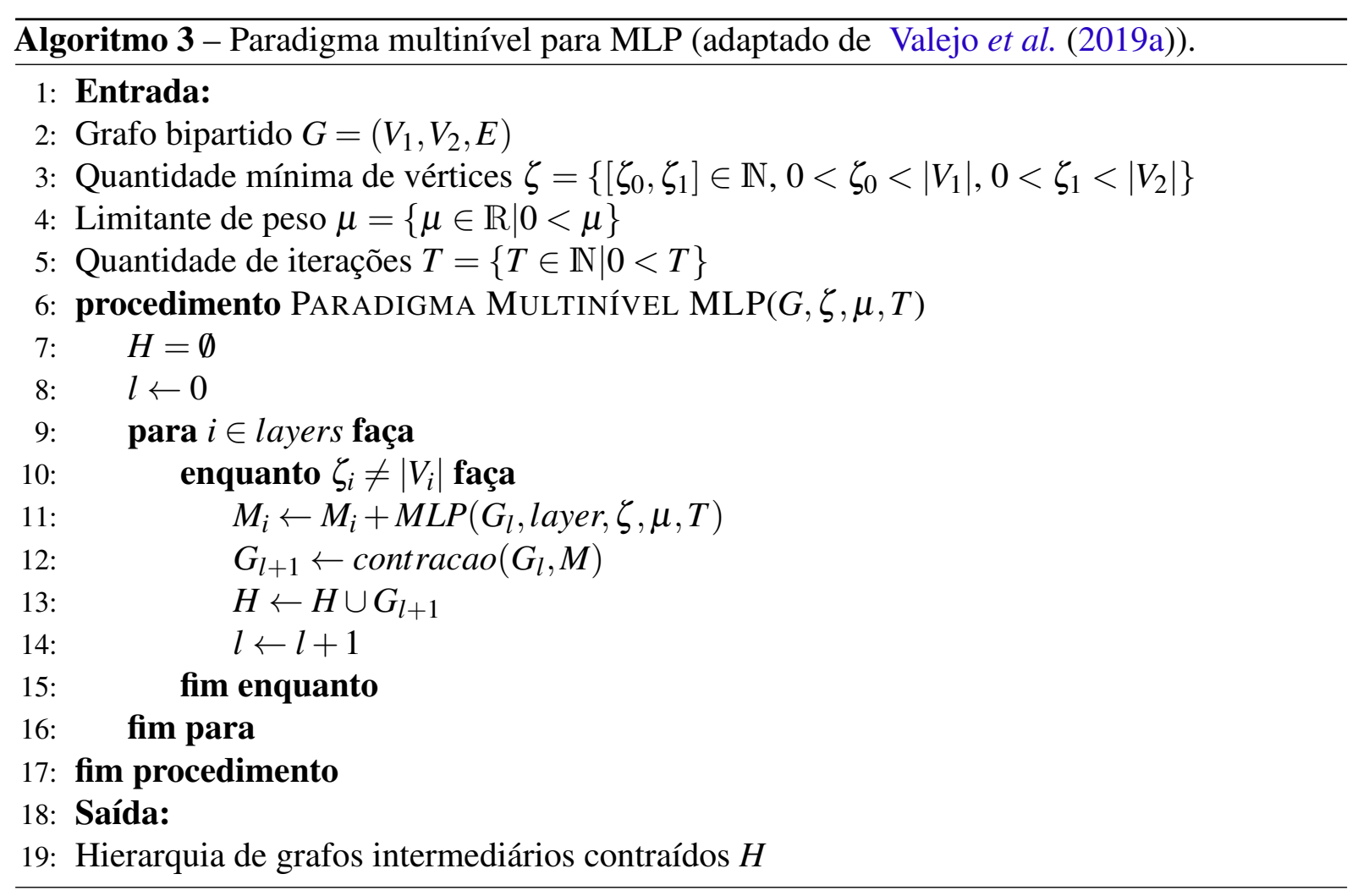

3. Se o rótulo de maior valor for diferente do rótulo de $u$, então $u$ recebe o rótulo de maior valor;

4. Termine o algoritmo se a quantidade mínima de vértices desejada foi alcançada. Do contrário, se a quantidade máxima de iterações ainda não foi atingida, crie um novo grafo e repita o processo.

O grafo bipartido $G$ e o conjunto selecionado layer são entradas, assim como no Algoritmo 2, definindo a qual camada do grafo $G$ a contração será aplicada. A quantidade mínima de vértices $\zeta$ é definida pelo usuário, e indica a quantidade desejável de vértices da camada ao final da execução do algoritmo. Se uma contração é aplicada à camada $V_{1}$, com $\left|V_{1}\right|=547$, o usuário pode, por exemplo, definir $\zeta=230$ como número final de vértices a ser atingido. Na linha 9 , atribui-se à lista de candidatos a super-vértices $M=V_{\text {layer }}^{\text {original }}$, ou seja, todos os vértices do grafo inicial não contraído e da camada layer.

O parâmetro $\mu$ define o peso máximo que super-vértices podem atingir e é utilizado na linha 8 do Algoritmo 4, enquanto $T$ indica a quantidade máxima de iterações. A função find (linhas 15 e 21) é uma abstração de acesso a vértices da estrutura $M$, contendo a lista de candidatos a super-vértices. Uma fila de prioridades $Q$ é inicializada na linha 13, atribuindo um valor para cada rótulo existente. Nas linhas 14-19 do algoritmo todos os vizinhos de $u$ são percorridos, e atualizam-se os valores de seus rótulos em $Q$, desde que respeitem o limitante de peso dos super-vértices (condicional da linha 16). A função find na linha 15 retorna o índice do vértice $v$. Na linha 20, argmax encontra o índice de maior valor em $Q$, atribuindo-o a max. 


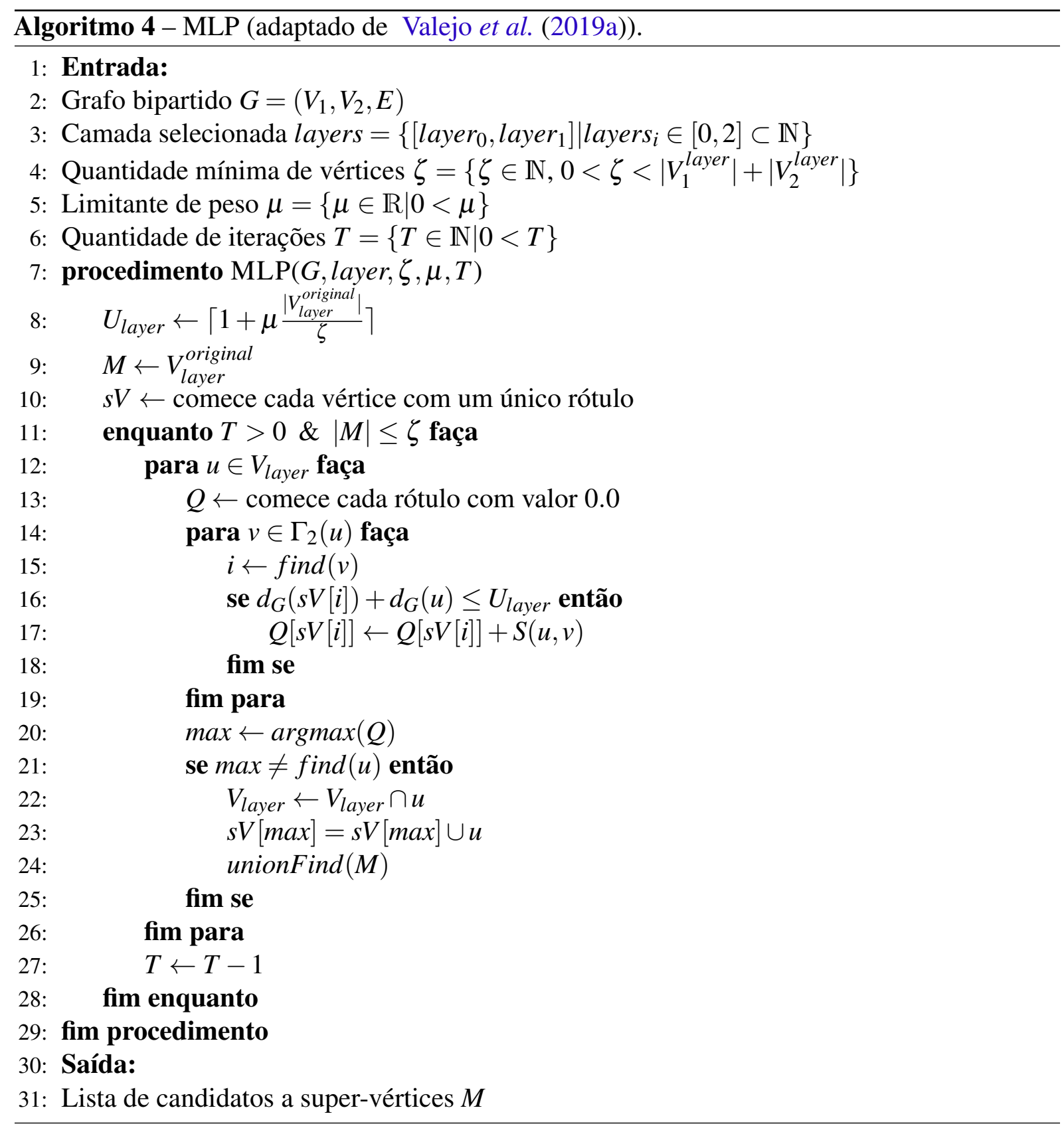

Por fim, na linha 21, compara-se os índices max com o índice resultante de find $(u)$. Caso o vértice $u$ já possua o rótulo com maior valor em $s V[\max ]$, não há nada a fazer. Do contrário, o rótulo de $u$ é atualizado e ele é eliminado do conjunto de vértices $V_{\text {layer }}$. Além disso, a operação unionFind atualiza a estrutura $M$, realocando elementos aos super-vértices apropriados. Em relação à complexidade de tempo, o algoritmo tem como fatores mais importantes a quantidade de iterações e o número mínimo de vértices. No pior caso, o algoritmo executa em tempo $O\left(|V|^{2}\right)$, em um grafo denso e contendo vértices de alto grau (VALEJO et al., 2019a).

Em comparação com o GMb, a abordagem de propagação de rótulos como cerne do algoritmo MLP é mais "natural” e mais fluida, não forçando a junção de vértices aos pares. Outra característica do MLP é a criação de um nível somente quando a quantidade de iterações for atingida. A convergência alcançada quando a quantidade de iterações é definida é mais fluida 
do que estabelecer, a priori, uma quantidade fixa de níveis de grafos intermediários. Uma das considerações a serem feitas é que, para seu correto funcionamento, o MLP deve ser executado sobre um grafo que contém um único componente. Do contrário, mais de um componente conexo pode dificultar na convergência do algoritmo para a obtenção da quantidade de vértices desejada.

\subsection{Contração}

Definida a escolha dos candidatos a comporem super-vértices, de acordo com o algoritmo de pareamento, a contração e simplificação do grafo bipartido é propriamente feita, como ilustrado na Figura 2. Nesse exemplo, utiliza-se o algoritmo GMb, com $r f=16 \%$ e layers $=1$. Os vértices $a$ e $b$ são candidatos a se transformarem em um super-vértice $a b$, portanto, no grafo $G_{l+1}$ resultante, $a b$ é criado, e as arestas que conectavam os vértices $a$ e $b$ são unidas, tendo seus pesos somados.

Figura 2 - Etapa de contração sobre um grafo bipartido. Os vértices $a$ e $b$, acizentados, definem os vértices candidatos à contração.

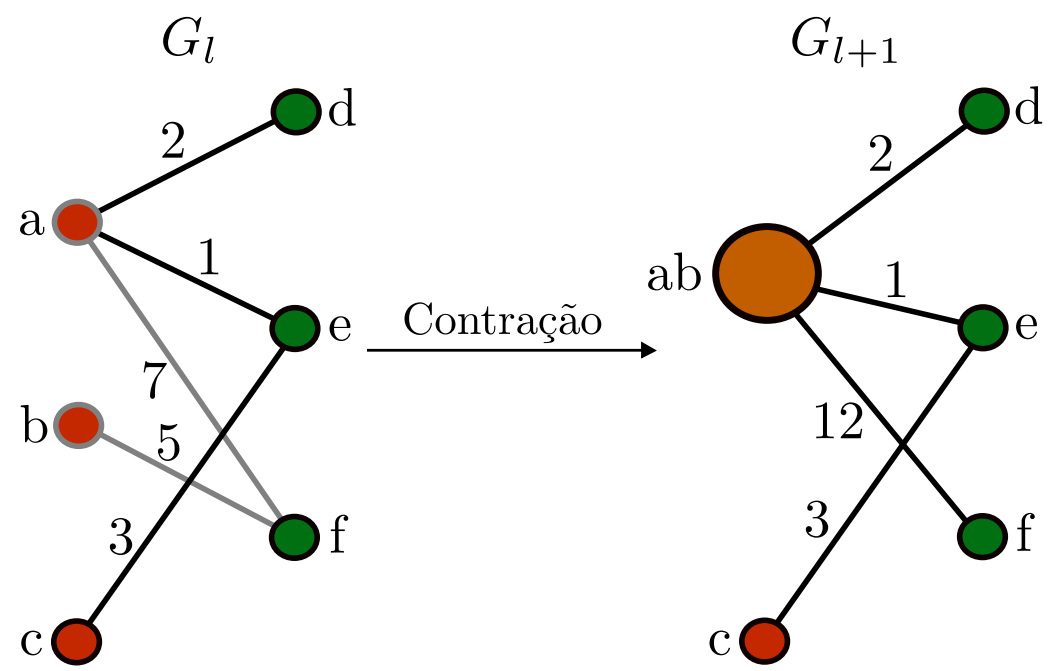

Fonte: Elaborada pelo autor.

\subsection{Medida de similaridade}

Na aplicação de um algoritmo de pareamento sobre um grafo bipartido $G$, o cálculo da similaridade entre vértices, definido em ambos Algoritmos 2 e 4 como $S(u, v)$, é central na definição de quais vértices serão pareados.

A similaridade $S\left(x_{i}, x_{j}\right)$, com $x_{i}, x_{j} \in V$ e $S: V \times V \mapsto \mathbb{R}$, calcula a similaridade entre dois vértices com base em algum atributo ou propriedade. A medida de similaridade selecionada deve se adequar ao domínio da aplicação, por exemplo, em uma coleção de documentos e palavras ou uma de artistas e filmes, diferentes medidas de similaridade produzirão diferentes resultados. A 
seguir, descrevem-se as principais medidas de similaridade utilizadas em aplicações de redes sociais, além de medidas populares adaptadas para grafos bipartidos, com o auxílio da Figura 3.

Figura 3 - Exemplos de diferentes tipos de medidas de similaridade.

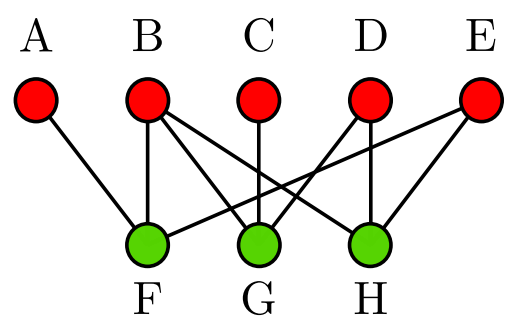

(a) Grafo bipartido exemplo para medidas de similaridade.

$$
\begin{aligned}
& S(B, A)=\left|\Gamma_{1}(B) \cap \Gamma_{1}(A)\right|=1 \\
& S(B, C)=\left|\Gamma_{1}(B) \cap \Gamma_{1}(C)\right|=1 \\
& S(B, D)=\left|\Gamma_{1}(B) \cap \Gamma_{1}(D)\right|=2 \\
& S(B, E)=\left|\Gamma_{1}(B) \cap \Gamma_{1}(E)\right|=2
\end{aligned}
$$

(b) Distância do vértice $B$ aos demais utilizando vizinhos em comum como métrica de similaridade.

$$
\begin{aligned}
S(B, A) & =\frac{1}{\log _{2}(2)}=3.32 \\
S(B, C) & =\frac{1}{\log _{2}(3)}=2.09 \\
S(B, D) & =\frac{1}{\log _{2}(3)}+\frac{1}{\log _{2}(2)}=5.41 \\
S(B, E) & =\frac{1}{\log _{2}(3)}+\frac{1}{\log _{2}(2)}=5.41
\end{aligned}
$$

(d) Distância do vértice $B$ aos demais utilizando Adamic Adar como métrica de similaridade.

$$
\begin{aligned}
& S(B, A)=\frac{\left|\Gamma_{1}(B) \cap \Gamma_{1}(A)\right|}{\left|\Gamma_{1}(B) \cup \Gamma_{1}(A)\right|}=\frac{1}{3} \\
& S(B, C)=\frac{\left|\Gamma_{1}(B) \cap \Gamma_{1}(C)\right|}{\left|\Gamma_{1}(B) \cup \Gamma_{1}(C)\right|}=\frac{1}{3} \\
& S(B, D)=\frac{\left|\Gamma_{1}(B) \cap \Gamma_{1}(D)\right|}{\left|\Gamma_{1}(B) \cup \Gamma_{1}(D)\right|}=\frac{2}{3} \\
& S(B, E)=\frac{\left|\Gamma_{1}(B) \cap \Gamma_{1}(E)\right|}{\left|\Gamma_{1}(B) \cup \Gamma_{1}(E)\right|}=\frac{2}{3}
\end{aligned}
$$

(c) Distância do vértice $B$ aos demais utilizando índice de Jaccard como métrica de similaridade.

$$
\begin{aligned}
& S(B, A)=\left|\Gamma_{1}(B)\right| \cdot\left|\Gamma_{1}(A)\right|=3 \\
& S(B, C)=\left|\Gamma_{1}(B)\right| \cdot\left|\Gamma_{1}(C)\right|=3 \\
& S(B, D)=\left|\Gamma_{1}(B)\right| \cdot\left|\Gamma_{1}(D)\right|=6 \\
& S(B, E)=\left|\Gamma_{1}(B)\right| \cdot\left|\Gamma_{1}(E)\right|=6
\end{aligned}
$$

(e) Distância do vértice $B$ aos demais utilizando conexão preferencial como métrica de similaridade.

Fonte: Elaborada pelo autor.

\subsubsection{Vizinhos em comum}

Formalizado por Watts (2004), a premissa na similaridade de vizinhos em comum é que dois estranhos que compartilham um amigo em comum podem ser introduzidos por ele. Essa métrica, no contexto do paradigma multinível, tende a agrupar em super-vértices os vértices com mais vizinhos em comum. Ela pode ser descrita formalmente como

$$
S(u, v)=\left|\Gamma_{1}(u) \cap \Gamma_{1}(v)\right|, \forall u, v \in V_{1}, V_{2}
$$


Tomando o grafo da Figura 3a como exemplo e selecionando o vértice $B$ como alvo, tem-se os resultados de sua similaridade com os demais vértices da mesma camada na Figura $3 b$. Uma variação dessa métrica considera os pesos das arestas como um fator relevante; portanto, caso dois vértices $u, v$ tenham o mesmo número de vizinhos em comum, o fator determinante de sua similaridade será dado pelos pesos das arestas desses vizinhos. Assumindo, por exemplo, que um peso em uma aresta defina a proximidade de relação entre pessoas, une-se um vértice àqueles com maior proximidade.

\subsubsection{Jaccard}

Baseado no índice de Jaccard (TAN; STEINBACH; KUMAR, 2005), que calcula a similaridade entre conjuntos, essa adaptação garante que a relação entre vértices $u, v$ seja independente da quantidade de vizinhos e vértices existentes em um grafo. A Equação 2.4 define formalmente essa métrica de similaridade. Um exemplo dos resultados dessa métrica aplicada ao vértice $B$ da Figura 3a é visto na Figura 3c.

$$
S(u, v)=\frac{\left|\Gamma_{1}(u) \cap \Gamma_{1}(v)\right|}{\left|\Gamma_{1}(u) \cup \Gamma_{1}(v)\right|}, \forall u, v \in V_{1}, V_{2}
$$

\subsubsection{Adamic Adar}

Com essa métrica, para o cálculo da similaridade entre $u$ e $v$, a cada vizinho em comum, atribui-se um fator de relevância, que no $M O b$ é o grau do vértice. O somatório desses fatores de relevância irá definir $S(u, v)$, sendo a métrica proposta por Adamic e Adar (2003). No contexto do paradigma multinível, a similaridade entre $u$ e $v$ será maior conforme o grau de seus vizinhos for menor. $\mathrm{O}$ resultado dessa métrica, aplicada ao vértice $B$ da Figura 3d, é formalmente definida como

$$
S(u, v)=\sum_{w \in \Gamma_{1}(u) \cap \Gamma_{1}(v)} \frac{1}{\log _{2}\left(d_{G}(w)\right)}, \forall u, v \in V_{1}, V_{2}
$$

\subsubsection{Conexão preferencial}

Também conhecida como preferential attachment ${ }^{1}$, essa medida utiliza das informações topológicas para definir que, para um vértice $u$, quanto maior o grau de um vértice $v$ vizinho a ele, maior é a similaridade entre os dois. No contexto de pessoas relacionadas em uma rede, isso significa juntar pessoas com muitos amigos. A Equação 2.6 define formalmente essa métrica. A Figura 3e ilustra os resultados dessa métrica aplicada ao vértice $B$ da Figura $3 a$.

$$
S(u, v)=\left|\Gamma_{1}(u)\right| \cdot\left|\Gamma_{1}(v)\right|
$$

1 O termo "conexão preferencial" foi livremente adaptado. 


\subsection{Considerações finais}

Neste Capítulo, foram apresentados os principais conceitos relevantes para a compreensão do trabalho de pesquisa realizado. As noções básicas sobre grafos e redes complexas, terminologia e definições são fundamentais para compreender essas estruturas, utilizadas tanto abstratamente quanto visualmente. Ao longo deste documento serão utilizadas as terminologias convencionais, como vértices, arestas e grafos.

A Visualização da Informação é tema central desta dissertação. As principais formas de representação em grafos no âmbito de Visualização também foram destacadas, sendo que as principais técnicas que utilizam grafos serão abordadas no Capítulo 3. O paradigma multinível foi introduzido, tendo em vista que os objetivos apresentados no Capítulo 1 envolvem utilizar a visualização como apoio e compreensão do paradigma multinível e integrá-lo à visualização para apoio em atividades de visualização exploratória de dados.

Do paradigma, apenas as etapas de pareamento e contração foram detalhadas, sendo as principais incorporadas neste trabalho, em que também foram revisados os principais algoritmos de pareamento existentes para grafos bipartidos. $\mathrm{O}$ funcionamento desses algoritmos depende de medidas de similaridade, que também foram detalhadas na Seção 2.6. O arcabouço apresentado por Valejo et al. (2018) implementa todas as similaridades e algoritmos de pareamento citados, possibilitando a execução de testes para verificação dos objetivos deste trabalho. 



\section{3}

\section{VISUALIZAÇÃO EXPLORATÓRIA EM GRAFOS}

No Capítulo 2, foi feita uma breve apresentação de trabalhos sobre Desenho de Grafos, que somente exibem uma representação do grafo, sem proporcionar nenhuma interação. Neste Capítulo, é feita uma revisão de trabalhos correlatos que realizam algum tipo de visualização exploratória sobre um grafo, permitindo a interação do usuário sobre essa estrutura na obtenção de informação, por exemplo, sobre dados associados aos vértices ou arestas. Com o aumento da quantidade de dados disponíveis, a visualização de um grafo sofre tanto de limitação de espaço de tela como também na quantidade de informação que um usuário pode absorver em uma única visualização (NACHMANSON et al., 2015). Buscando contornar esse problema, técnicas de simplificação podem ser aplicadas a um grafo, mantendo sua estrutura topológica e destacando pontos interessantes para viabilizar estratégias exploratórias (LANDESBERGER et al., 2011).

As técnicas apresentadas podem ser classificadas de duas maneiras distintas: aplicadas a grafos genéricos ou aplicadas especificamente a grafos bipartidos. Essas técnicas podem incluir estratégias como amostragem, agrupamento utilizando algum algoritmo específico ou agrupamento baseado nas preferências do usuário. Técnicas de simplificação podem ser aplicadas tanto a vértices quanto a arestas.

Na agregação de vértices, as arestas são unidas em consequência da junção de vértices, transformando-se em um elemento único e sofrendo a atualização de pesos. Já a agregação de arestas consiste na junção desses elementos, entretanto, sem perder suas propriedades individuais, ocupando o mesmo lugar na representação visual. Holten (2006) é um dos trabalhos pioneiros que realiza a agregação de arestas, denominado edge bundling, simplificando a visualização deformando as arestas como curvas suaves, agrupando-as em ramos. Outros trabalhos também adotam essa premissa, realizando algumas otimizações (ZHOU et al., 2008; HURTER; ERSOY; TELEA, 2012; ZWAN; CODREANU; TELEA, 2016). No escopo desse projeto, as abordagens que utilizam agregação de arestas não são tratadas, pois o foco da metáfora visual é entender o 
funcionamento do paradigma multinível e servir de apoio para atividades exploratórias sobre grafos bipartidos.

Na Seção 3.1, são apresentados trabalhos de visualização exploratória que realizam simplificações em grafos genéricos. Já na Seção 3.2, consideram-se estratégias de simplificação aplicadas a grafos bipartidos. A Seção 3.3 conclui este Capítulo com algumas observações sobre os trabalhos apresentados, e como a construção de uma nova metáfora visual para o paradigma multinível se encaixa no contexto de visualização exploratória em grafos bipartidos.

\subsection{Simplificação de grafos genéricos}

Uma das primeiras abordagens que realizam a simplificação de um grafo é proposta por Eades e Huang (2000), apresentando uma estratégia de agregação de vértices feita pelo usuário, cujo posicionamento final na visualização utiliza o algoritmo de molas de Eades (1984). O sistema apresentado adota uma arquitetura genérica capaz de processar grafos e criar uma hierarquia. O usuário interage na seleção de uma parte do grafo para indicar se deseja criar um agrupamento entre vértices selecionados ou expandir um agrupamento existente, ou seja, a construção da hierarquia de grafos contraídos é feita de maneira manual.

Buscando permitir um processo automático da construção de agrupamentos, Abello, Ham e Krishnan (2006) apresentam o sistema ASK-GraphView, que tem como propósito permitir a visualização de grandes grafos que não cabem na memória principal. Uma hierarquia é construída sobre o grafo, agrupando automaticamente vértices, e permitindo a interação e exploração dessa hierarquia pelo usuário. O algoritmo de agrupamento é executado automaticamente pelo sistema, bem como a decisão da quantidade de níveis de hierarquia existentes. Uma variante do algoritmo Markov Cluster Process, ou MCL (DONGEN, 2000) é utilizada para o agrupamento dos vértices. A Figura 4 ilustra a interface desse sistema, com suas principais funcionalidades. Outros trabalhos (HENRY; FEKETE; MCGUFFIN, 2007; ELMQVIST et al., 2008) também realizam um processo automático de agrupamento de vértices, entretanto, as visualizações finais utilizam a representação matricial, que está fora do escopo deste trabalho.

Wattenberg (2006) destaca que grafos podem ser multidimensionais, ou seja, vértices e arestas podem ter múltiplos atributos associados, e que as representações nó-aresta têm seus inconvenientes na visualização dessas informações. Por exemplo, para representar uma base de dados multidimensional com um desenho nó-aresta, pode-se utilizar outras técnicas de visualização para codificar os atributos dos vértices, o que aumenta a complexidade da visualização. Ao invés disso, a abordagem codifica atributos transformando a representação nó-aresta do grafo.

Exemplificando, tem-se um conjunto de dados com os atributos "gosto" e "cor". Sendo esse espaço bidimensional, representam-se os possíveis valores que os atributos podem assumir como linhas e colunas em uma grade, como "Salty", "Sour", "Sweet" para "gosto" e "Blue", 
Figura 4 - Visão geral do sistema AskGraphView. Na parte superior, visualiza-se a árvore de hierarquia imposta sobre o grafo. No canto superior esquerdo, tem-se a matriz de adjacência do grafo. À esquerda, pode-se expandir um "super-vértice", identificando sua árvore de vértices. Ao centro, tem-se a visualização do grafo em um nível da hierarquia.

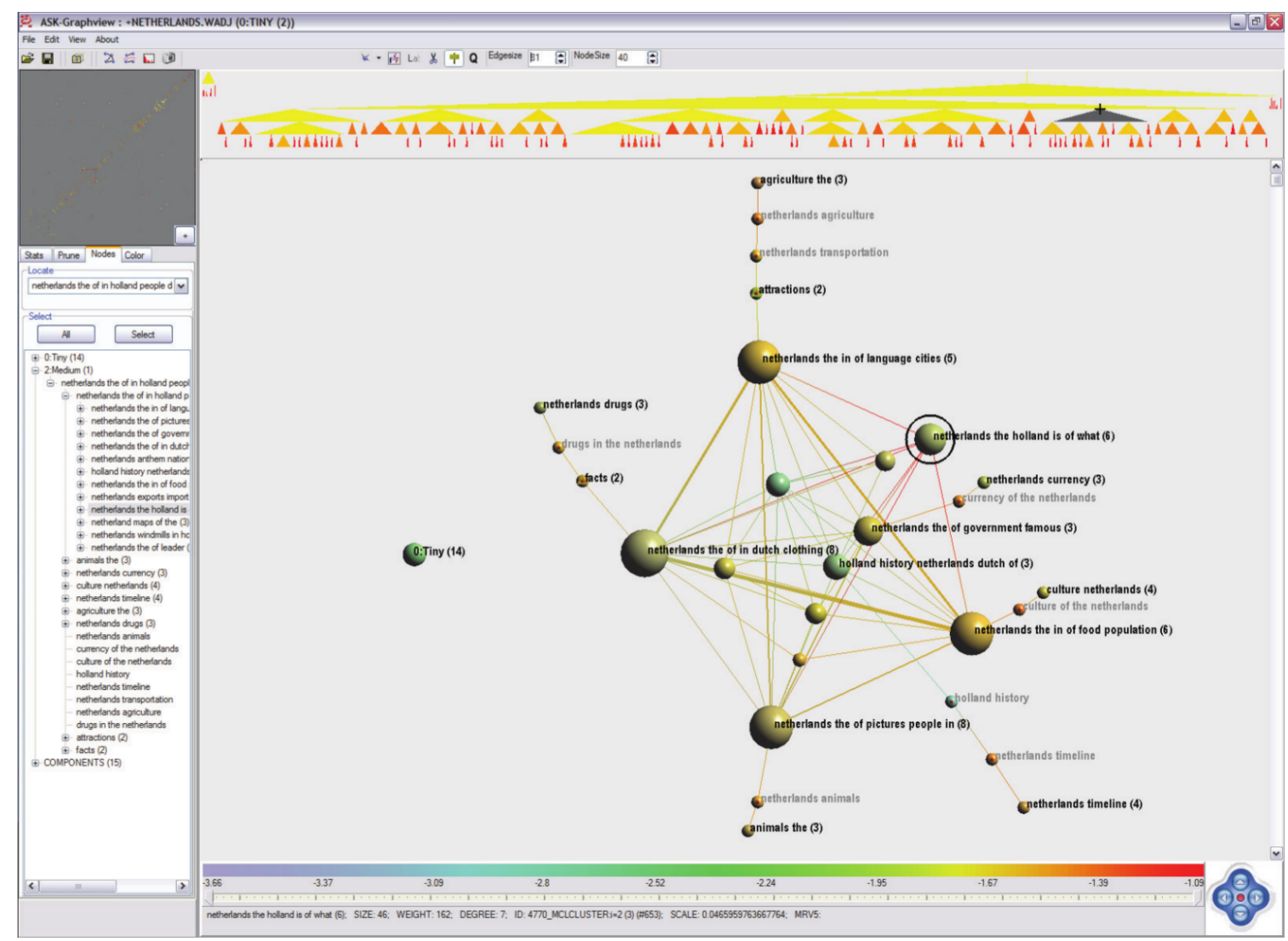

Fonte: Abello, Ham e Krishnan (2006).

"Red" e "Green" para "cor". Cria-se um grafo sobre essa representação, como visto na Figura 5. Vértices são posicionados conforme os valores de seus atributos, criando um agrupamento de vértices e arestas representados com uma tonalidade mais escura. Caso a base de dados contenha mais de dois atributos, pode-se selecionar apenas dois para dispô-los em uma grade.

Portanto, o sistema PivotGraph, desenvolvido como prova de conceito, realiza uma redução de dimensionalidade na base de dados, sacrificando a topologia e disposição dos vértices em detrimento do agrupamento de características comuns. Ele permite que usuários selecionem atributos como medida de agrupamento de vértices, ou seja, quais serão os valores das linhas e colunas do grafo em grade, caracterizando um agrupamento manual.

Outra abordagem que utiliza atributos para simplificação foi desenvolvida por Archambault, Munzner e Auber (2008), no qual a agregação de vértices é feita por meio da imposição de uma hierarquia gerada com base em um dos atributos dos vértices. Sendo assim, múltiplas abstrações de hierarquias podem ser criadas, de acordo com um determinado atributo utilizado como critério. Isso permite que o usuário faça diferentes interpretações do grafo, visualizando hierarquias construídas por atributos distintos. 
Figura 5 - Exemplo de redução de dimensionalidade de atributos de uma base de dados utilizando o sistema PivotGraph. Aqui, dois atributos são selecionados: gosto e cor. Os possíveis valores desses atributos são dispostos em linhas e colunas. Agrupamentos de vértices e arestas são representados em tonalidades mais escuras.

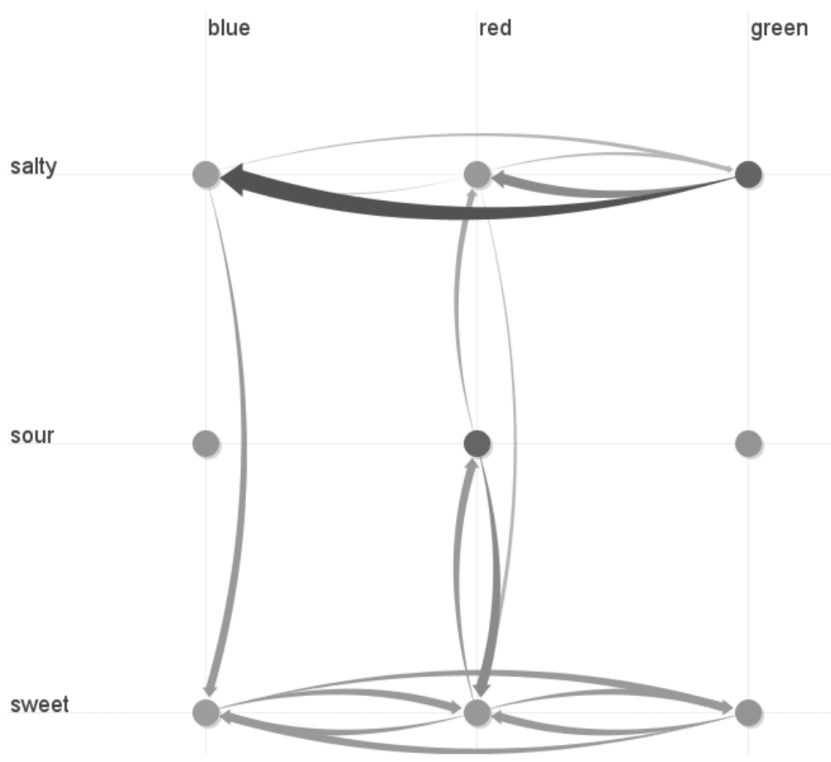

Fonte: Wattenberg (2006).

Existem duas maneiras de criar uma hierarquia. Uma é por casamento de padrão, ou pattern match, no qual a hierarquia resultante terá duas ramificações: em uma, os vértices têm um valor de atributo definido como busca no casamento de padrão, e na outra, todos os outros valores. A segunda maneira é por categoria, em que são criadas $n$ ramificações em um grafo, de acordo com a quantidade de valores que um atributo assume. Exemplificando, tem-se uma base de dados de filmes e atores, com um dos atributos sendo "gênero", que pode assumir cinco valores distintos: "ação", "suspense", "comédia", "romance" e "sci-fi". Com o pattern match, cria-se 2 ramificações, sendo uma somente contendo filmes do gênero "ação", por exemplo, ao passo que a outra conterá todos os outros gêneros. Já na criação por categoria, produz-se 5 ramificações, separando os filmes em "ação", "suspense", "comédia", "romance" e "sci-fi". A criação dessas hierarquias pode ser feita em um determinado nível de detalhe, não sendo necessariamente aplicada em todo o grafo.

Apesar de existirem diversos trabalhos que fazem a visualização de todo o grafo, garantindo ao usuário a captura de algum padrão inerente, alguns autores adotam a premissa de que não é necessário visualizar um grande grafo completamente, pois possivelmente não há nenhuma interpretação útil para o usuário e, consequentemente, poucas conclusões podem ser inferidas (RAFIEI, 2005). Ham e Perer (2009) demonstram que é possível obter informações a partir do grafo e descobrir padrões sem a necessidade de visualizá-lo por completo. Para atingir esse objetivo, utilizam o conceito de grau de interesse, ou Degree-of-interest (FURNAS, 1986), que permite que o usuário defina uma função de filtro para representação de vértices e arestas, de acordo com seu interesse. 
As funcionalidades implementadas na ferramenta de prova de conceito construída são: Search, Show Context, Expand on Demand. A busca (Search) permite ao usuário, tanto de maneira textual como visual, estabelecer aquilo que procura. Show Context acontece quando, dado o subgrafo resultante da busca previamente mencionada, o usuário seleciona um ponto de interesse (ou ponto focal). É aqui que a filtragem utilizando grau de interesse acontece, e somente vértices adjacentes que satisfaçam os critérios estabelecidos pelo usuário são exibidos. Por fim, ao clicar em um determinado vértice, o grafo é expandido, mas ainda restrito às condições impostas pela função DOI (Expand on Demand).

Exemplificando, o usuário estabelece, no grafo, um ponto focal inicial, após visualizar um subgrafo resultante de uma busca textual. A partir daí, ocorre a expansão do grafo, apresentando vértices vizinhos conectados, cuja filtragem irá permitir a visualização de vértices que realmente importam ao usuário. Essa expansão pode ser realizada para encontrar vértices importantes, sem a necessidade de analisar elementos redundantes nesse processo. Como exemplo, a aplicação escolhida foi uma base de citações legais, em que se obtém um grafo com 23 vértices, resultado da filtragem de 2.345 vértices e 2.847 arestas.

Apesar de sua abordagem promissora, Ham e Perer (2009) apresenta testes apenas com uma única base de dados e não exploram sua solução em outros contextos, como de redes sociais. Como dito pelos próprios autores, "Em visualizações de redes sociais, visões egocêntricas da rede são comuns e esta abordagem se encaixa bem com esse paradigma.", o que indica potencial para exploração de bases que sejam redes sociais.

A filtragem por grau de interesse impossibilita a visualização de agrupamentos que, dependendo da aplicação, podem ser relevantes, mas o usuário as desconhece. Outro aspecto é que, como a busca é nivelada pelo interesse, o usuário só pode estabelecer um único ponto de interesse, não podendo estabelecer múltiplos focos simultaneamente.

A solução de Wong et al. (2009) é um exemplo do uso do paradigma multinível para viabilizar atividades exploratórias sobre grafos genéricos. Eles constroem, com o paradigma multinível, diversas instâncias de um grafo $G$, similar ao que foi apresentado no Capítulo 2, e permitem ao usuário a seleção de qualquer uma dessas instâncias utilizando de foco e contexto, ou seja, zoom-in e zoom-out, destacando uma instância de grafo mais esparsa conforme se afasta e uma mais densa conforme se aproxima da visualização. A Figura 6 ilustra o processo de contração de vértices. O paradigma multinível contrai metade dos vértices do grafo no nível em que se encontra, utilizando como parâmetro a união de vértices com o menor número de conexões entre si. A solução, apesar de promissora, não foi aplicada em grafos bipartidos. Os parâmetros do paradigma não podem ser alterados com a interação do usuário.

Em Zinsmaier et al. (2012), a visualização de grandes grafos é feita com uma técnica baseada em densidade, que faz a agregação tanto de arestas quanto de vértices. Essa técnica destaca as principais conexões entre "super-vértices" de acordo com a intensidade da densidade das arestas. O sistema "LaGo" foi introduzido como prova de conceito e traz estudos de caso do 
Figura 6 - Processo de contração de grafos em Wong et al. (2009). À esquerda, tem-se o grafo original, e à direita o grafo contraído. Utilizando de zoom-in e zoom-out, pode-se alternar entre o grafo da esquerda e o grafo da direita.
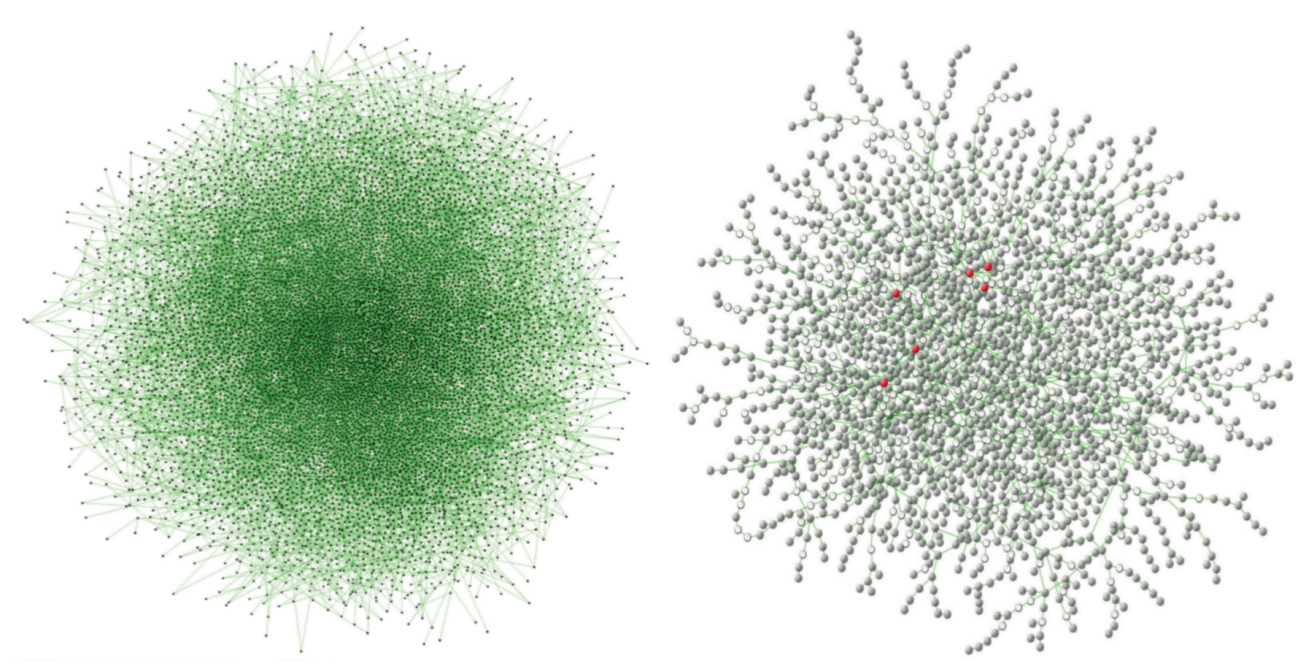

Fonte: Adaptada de Wong et al. (2009).

tráfego aéreo americano e da migração americana no período de 1995 a 2000. Utilizando a ideia de zoom semântico, a interação do usuário e consequente zoom-in reorganizam a visualização, destacando vértices previamente ocultos nesse novo nível de detalhe, como é visto na Figura 7.

Figura 7 - Processo de zoom semântico. Da esquerda para a direita, ao se aplicar zoom-in em uma região, novos vértices são visualizados, previamente ocultos devido ao seu tamanho e relevância.
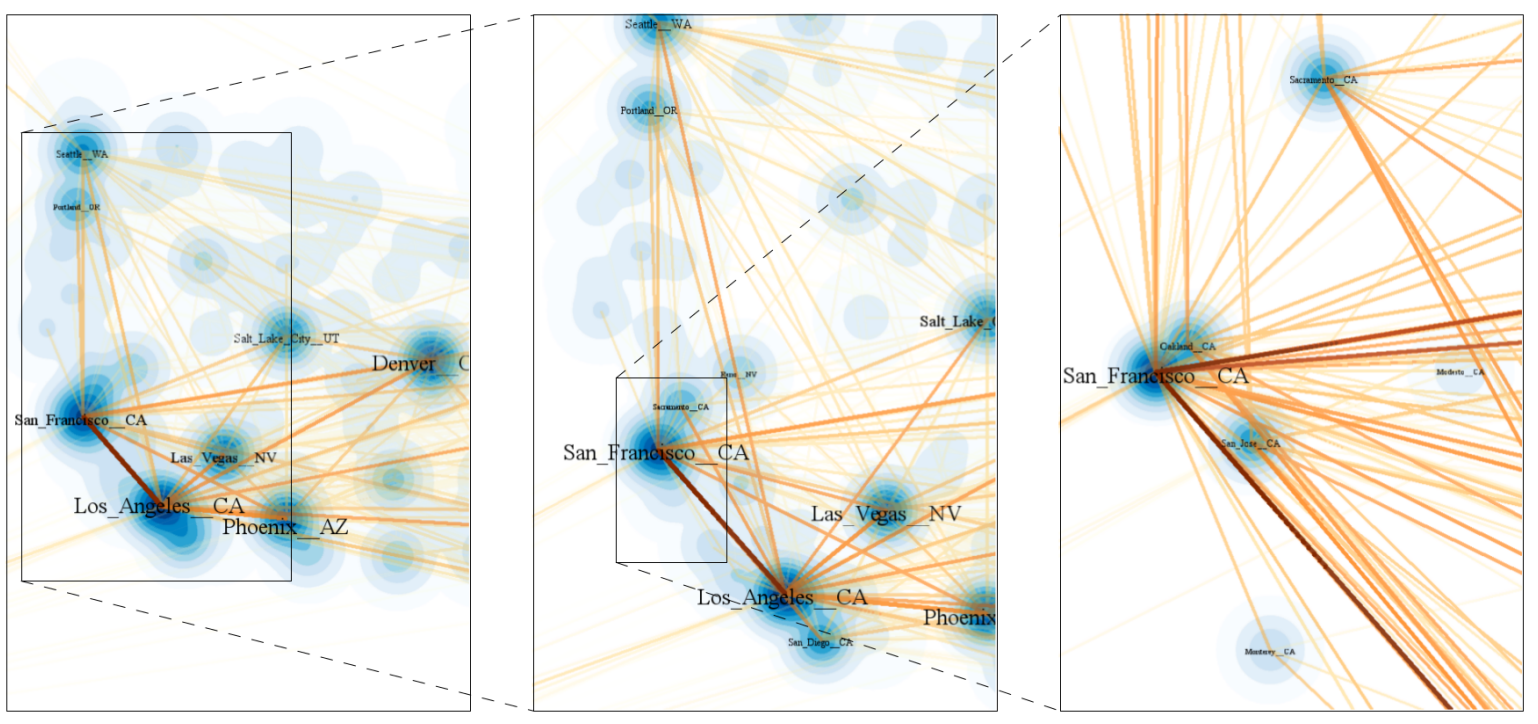

Fonte: Zinsmaier et al. (2012).

Outra abordagem que utiliza uma ideia similar é Nachmanson et al. (2015), que tem como objetivo permitir o zoom semântico do usuário em um grafo, atuando de maneira similar à exploração de mapas online. O objetivo é preservar o mapa mental do usuário quando novos elementos são visualizados com o zoom semântico. Diferentemente de Zinsmaier et al. (2012), 
em que a agregação de vértices utiliza um mapa de densidade, vértices transformam-se em "super-vértices" com base em um nível de importância, podendo ser considerado desde o grau até seu nível de centralidade.

Buscando outras soluções na literatura que utilizam agregação de vértices como alternativa para reduzir a poluição visual, Dias et al. (2017) constroem uma hierarquia sobre um grafo utilizando NMF (Non-negative Matrix Factorization) (LEE; SEUNG, 1999), além de utilizar uma estratégia de matching para junção de arestas. Os autores argumentam que grande parte dos métodos de simplificação de grandes grafos para propósitos de visualização utilizam alguma técnica hierárquica, entretanto, em geral as agregações não consideram as informações associadas aos elementos, somente considerando a topologia do grafo.

Os autores propõem uma agregação que considera tanto a topologia quanto as informações relevantes de um vértice. É feita uma decomposição com NMF, utilizando a matriz de adjacência como base de decomposição. O uso da matriz de adjacência para o NMF incorpora a topologia do grafo como critério de agregação. Assim, tendo a similaridade calculada, realiza-se a agregação de vértices, ou matching. Esse processo é iterado quantas vezes o usuário definir.

Para validar o método de agregação de vértices, os autores utilizam três métricas: modularidade (NEWMAN, 2004), $\Delta$-measure (TIAN; HANKINS; PATEL, 2008) e $K$-way ratio cut cost (CHAN; SCHLAG; ZIEN, 1994). De fato, Newman (2004) e Chan, Schlag e Zien (1994) propõem tais métricas para determinar se suas próprias técnicas de simplificação são eficientes. Portanto, Dias et al. (2017) comparam sua técnica especificamente com esses dois trabalhos, e mostram que sua solução obtém melhores resultados. Isso também ilustra que informações sensíveis aos conjunto de dados são preservadas no processo de construção da hierarquia.

Por fim, Perrot e Auber (2018) apresentam um sistema como prova de conceito denominado Cornac, que constrói uma hierarquia multinível para permitir a interação e visualização de um grafo, similar a soluções apresentadas por Nachmanson et al. (2015) e Zinsmaier et al. (2012). Para construir esses níveis, inicialmente o grafo é processado em um sistema distribuído, com o auxílio das ferramentas Apach Spark ${ }^{1}$ e GraphX ${ }^{2}$, utilizando um algoritmo de agrupamento variante do canopy clustering (MCCALLUM; NIGAM; UNGAR, 2000), que leva em consideração a distância geométrica entre vértices. Com os níveis criados, as arestas também sofrem um processo de agregação, sendo aquelas independentes agrupadas com o uso do Kernel Density Estimation Edge Bundling, ou KDEEB, um algoritmo de edge bundling (HURTER; ERSOY; TELEA, 2012). 


\subsection{Simplificação de grafos bipartidos}

Um dos algoritmos consolidados que realizam a simplificação de um grafo bipartido é o biclustering, também conhecido como co-clustering. Diferente dos algoritmos de agrupamento consolidados, o clustering de vértices em uma camada do grafo bipartido obrigatoriamente força o agrupamento de vértices na outra, o que revela elementos de similaridade (DHILLON, 2001). Revisões sistemáticas descrevem essa técnica utilizada em áreas como expressão gênica (OGHABIAN et al., 2014; PONTES; GIRÁLDEZ; AGUILAR-RUIZ, 2015). Entretanto, poucos trabalhos utilizam o biclustering como uma técnica de simplificação para apoio na visualização exploratória de grafos bipartidos. Em Heinrich et al. (2011), por exemplo, coordenadas paralelas e mapas de calor são utilizados para visualizar o processo de biclustering. A seguir, são destacados trabalhos que, utilizando essa ou outra abordagem de simplificação, viabilizam a execução de tarefas exploratórias sobre grafos bipartidos.

O PivotPaths é um sistema apresentado por Dörk et al. (2012) que tem como objetivo permitir ao usuário "caminhar" em um espaço de informação facetado, ou seja, fazer buscas específicas por determinados atributos em um espaço multivariado, comumente empregadas em filtragens avançadas para motores de busca. As bases de dados utilizadas são modeladas como grafos tripartidos, como visto na Figura 8. Similar ao que foi visto em Ham e Perer (2009), o usuário pode estabelecer um ou um par de vértices como "âncoras", mostrando partes do grafo que tem alguma relação com esses vértices. A partir daí, pode-se explorar facetas desses vértices, ou seja, aqueles que têm algum tipo de relação com esses atributos na busca de informação. Assim, o trabalho de Dörk et al. (2012) não necessariamente cria uma hierarquia simplificada de um grafo, mas sim permite que a interação do usuário produza visualizações que contenham informações de seu interesse.

Xu et al. (2016) argumentam que, apesar das técnicas de biclustering serem fundamentais para identificar relações entre elementos em um grafo bipartido, elas não permitem uma interação do usuário para produzir agrupamentos adequados ao domínio. A proposta, então, é utilizar uma visualização para representar o algoritmo de biclustering criado por Dhillon (2001). Essa visualização usa matrizes de adjacência, table lens e treemaps como suporte ao usuário na compreensão dos agrupamentos. Com base nisso, pode-se indicar quais clusters são mais adequados, servindo de entrada a um algoritmo semi-supervisionado de aprendizado. Esse algoritmo, que utiliza Laplacian Regularized Metric Learning (HOI; LIU; CHANG, 2010), re-executa o biclustering, utilizando a indicação do usuário de agrupamentos como entrada.

A Figura 9 mostra a visualização resultante dessa estratégia. $O$ grafo bipartido é disposto horizontalmente. Ao invés de utilizar ou nó-aresta ou matricial como representação, utiliza-se um híbrido entre eles. Cada agrupamento pode ser representado como um treemap ou como uma matriz de adjacência. $\mathrm{O}$ treemap ajuda na união ou separação de vértices no agrupamento, processos utilizados na etapa de aprendizado semi-supervisionado. Já a matriz de adjacência ajuda a identificar a relação entre vértices de um mesmo agrupamento. As arestas são repre- 
Figura 8 - Visualização do sistema PivotPaths. A autora Mary Czerwinski é escolhida como âncora (à esquerda, no conjunto central) e, com base no filtro estabelecido pelo usuário, são selecionados seus trabalhos mais citados, destacando coautores na parte superior e áreas de interesse na parte inferior. De acordo com o algoritmo de posicionamento implementado, conclui-se que George Robertson é o coautor mais frequente de Mary, sendo disposto no parte mais superior da visualização e com maior tamanho de fonte, e User Study, a área de interesse mais abordada pelos trabalhos, tendo maior tamanho de fonte e disposta na parte mais inferior.

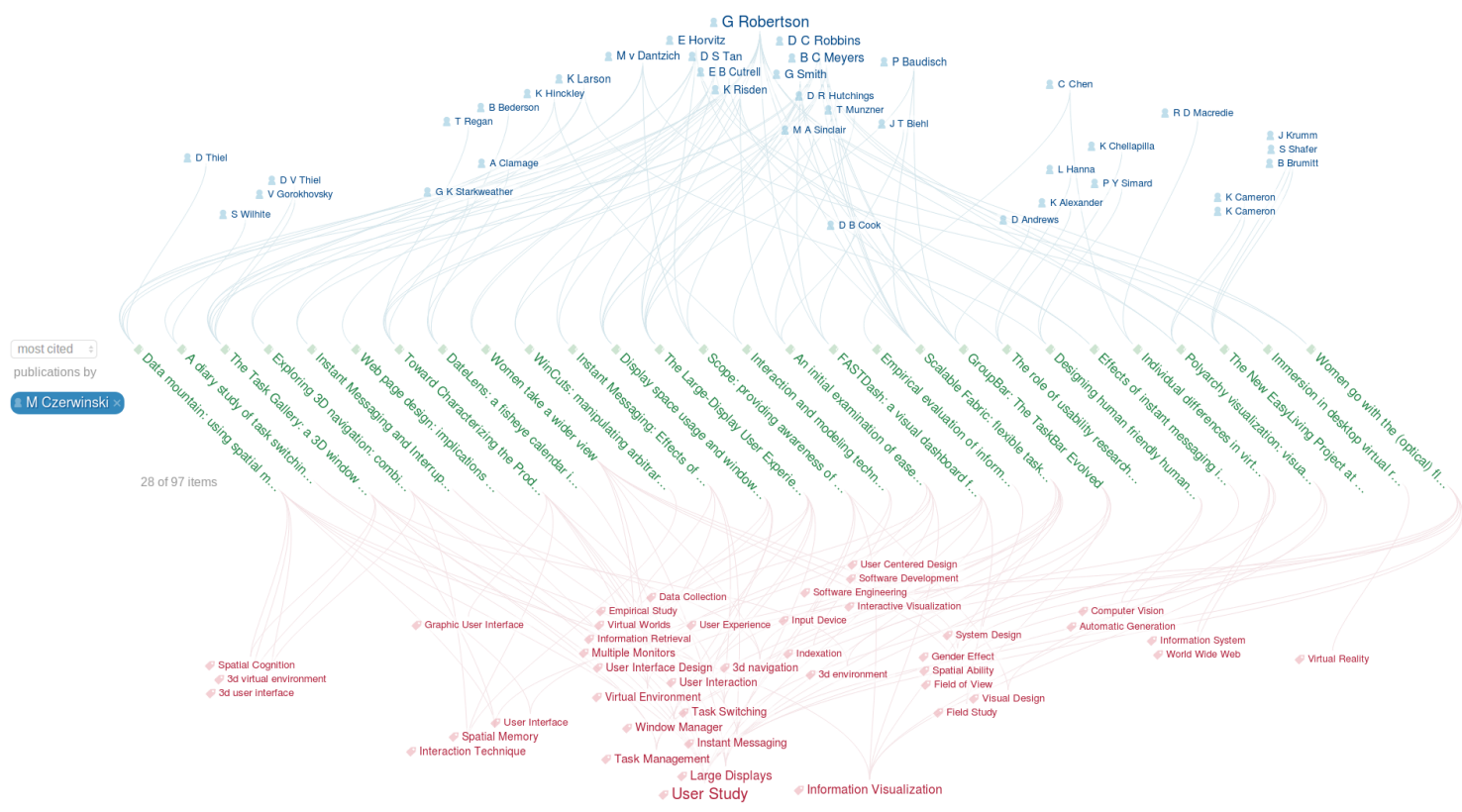

Fonte: Elaborada pelo autor.

sentadas com o uso de bundling (HOLTEN, 2006), e sua espessura indica a intensidade das conexões entre agrupamentos. Uma TableLens é utilizada para identificar os atributos dos vértices agrupados, e ajudar o usuário a identificar quais são os principais atributos dos agrupamentos e a similaridade entre eles. A re-execução do biclustering é feita pelo usuário, permitindo sua interação no processo de simplificação do grafo. O processo de biclustering não necessariamente cria uma hierarquia, o que pode impedir com que padrões escondidos sejam observados em níveis intermediários de simplificação.

Outra solução que utiliza uma técnica de simplificação de vértices para visualização de grafos bipartidos é apresentada por Pezzotti et al. (2018), que reduz um conjunto de dados $n$ dimensional com o uso do Hierarchical Stochastic Neighbor Embedding, ou HSNE (PEZZOTTI et al., 2016), um algoritmo de redução de dimensionalidade. Ele produz, como saída, uma hierarquia de espaços bidimensionais. Cada espaço é composto por pontos de referência, ou landmarks, que indicam regiões aonde existe um agrupamento de instâncias.

A Figura 10 mostra detalhes dessa representação, em que tanto o espaço unidimensional quanto bidimensional são utilizados. No espaço bidimensional, encontram-se os pontos de referência produzidos pelo HSNE. Já nas linhas verticais, encontram-se as projeções dos pontos de referência em um espaço unidimensional. Esses pontos podem ser selecionados para revelar 
Figura 9 - Visualização resultante de Xu et al. (2016). Agrupamentos são representados com matrizes de adjacência ou como treemaps. Por meio da seleção, o usuário pode alternar entre as duas representações, remover ou adicionar elementos e re-enviar agrupamentos editados como parâmetros de entrada para execução do algoritmo de biclustering.

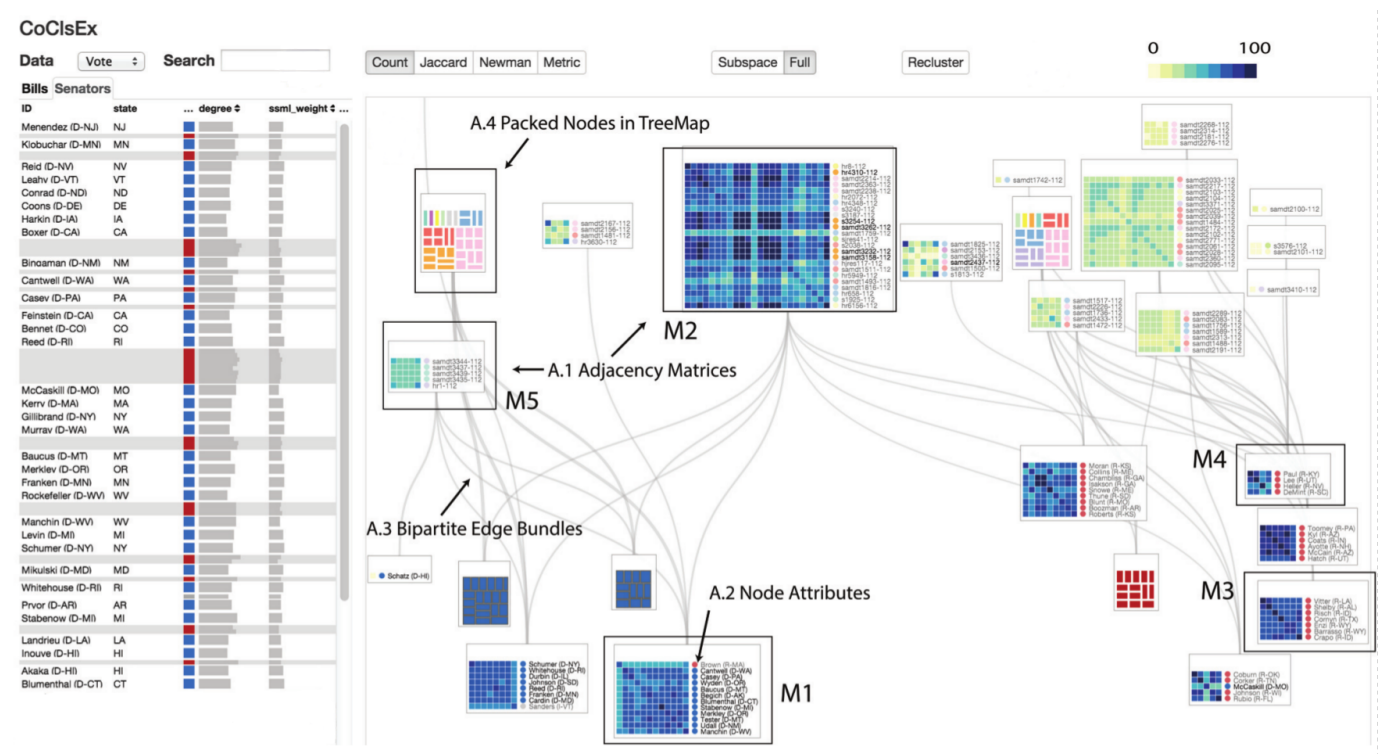

Fonte: Adaptada de Xu et al. (2016).

níveis mais profundos de detalhe, realizando um zoom semântico e produzindo uma nova visualização.

Zhao et al. (2018) introduzem a ferramenta BiDots, tendo como principal objetivo permitir a obtenção de informação explorando biclusters em múltiplos domínios. Por exemplo, pode-se modelar uma base de dados como um grafo bipartido entre organização e pessoa, porém, dependendo dos atributos, outro possível domínio de modelagem desses dados poderia ser entre pessoa e local. Cria-se uma nova metáfora visual, ilustrada na Figura 11, que consiste em dois grafos bipartidos, com uma coluna compartilhada para permitir a exploração de múltiplos domínios. É possível selecionar um agrupamento, que é separado em uma coluna adicional, identificando quais outros agrupamentos estão relacionados com ele. A técnica de agrupamento utilizada é o bicluster (UNO et al., 2004), e o sistema garante flexibilidade ao usuário para alterar os parâmetros de entrada desse algoritmo.

Steinbock, Groller e Waldner (2018) criaram uma nova metáfora de visualização para explorar grandes grafos bipartidos ponderados, com o uso de biclustering como técnica de agregação hierárquica, utilizada como alternativa à interação, como remoção de vértices, foco e contexto, inadequadas para visualização de grandes conjuntos de dados. O BiCFlows é o sistema apresentado como prova de conceito para essa metáfora de visualização, e demonstra uma visão geral dos agrupamentos produzidos para o grafo bipartido, ilustrada na Figura 12a. Ao selecionar um agrupamento, o algoritmo de biclustering é executado novamente, levando em consideração somente os elementos selecionados. Isso gera um nível maior de detalhamento e permite ver 
Figura 10 - Visualização resultante de Pezzotti et al. (2018), após a criação da hierarquia de simplificações obtidas com o HSNE. Os agrupamentos $u$ e $v$ são projetados em duas linhas verticais, similar a um algoritmo de desenho tradicional de grafos bipartidos. Explorando os pontos de referência do espaço unidimensional, o espaço bidimensional é transformado de acordo com o nível de hierarquia desejada.

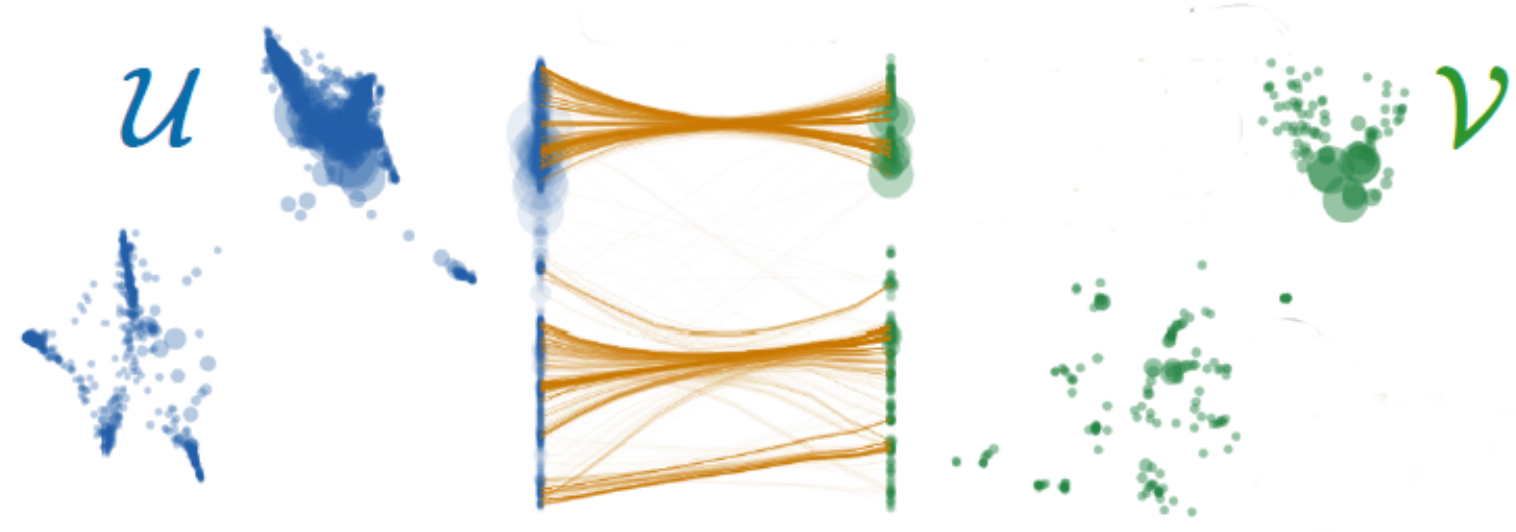

Fonte: Adaptada de Pezzotti et al. (2018).

novos agrupamentos, descendo um nível na hierarquia, como ilustrado na Figura 12b.

A abordagem de Chan et al. (2019) introduz uma otimização ao princípio minimum description length, ou MDL (RISSANEN, 1978), para produzir uma representação visual simplificada de um grande grafo bipartido. Uma nova metáfora visual é introduzida, baseada em uma lista de adjacências, que caracteriza as relações entre agrupamentos e densidade. A Figura 13 ilustra como um grafo bipartido tradicional é representado nessa metáfora. Ademais, o sistema desenvolvido como prova de conceito, $\mathrm{ViBr}$, permite a interação do usuário, filtrando vértices por atributos ou analisando as listas de adjacência mais detalhadamente, na busca de algum padrão oculto. O uso do MDL produz uma versão simplificada de um grafo bipartido, e pode ser manipulado posteriormente pelo usuário quando analisa agrupamentos separadamente.

\subsection{Considerações sobre os trabalhos}

Neste Capítulo foram apresentadas as principais soluções referentes à visualização exploratória de dados representados como grafos. Basicamente, todas as abordagens adotam alguma técnica de simplificação, seja com a construção de uma hierarquia (ABELLO; HAM; KRISHNAN, 2006; ARCHAMBAULT; MUNZNER; AUBER, 2008; STEINBOCK; GROLLER; WALDNER, 2018) ou com a simplificação feita em um único passo (WATTENBERG, 2006; XU et al., 2016). A seguir, detalham-se as conclusões obtidas da análise das abordagens correlatas, no que diz respeito aos conjuntos de dados utilizados, escalabilidade e tarefas exploratórias. 
Figura 11 - Metáfora visual introduzida pela ferramenta BiDots. Dois grafos bipartidos são dispostos (documento/tópico e tópico/palavra-chave) em linhas verticais, com uma coluna sendo compartilhada, para permitir a exploração de múltiplos domínios. Arestas são representadas em linhas verticais dentro de caixas que interconectam agrupamentos, e indicam, com o auxílio dos valores no topo da visualização, o peso da conexão entre biclusters. Vértices ou agrupamentos são codificados como círculos com padrões de linhas. Esses padrões diferenciam os biclusters produzidos, e a intensidade de cor indica a quantidade de elementos - quanto mais intenso, mais vértices estão agrupados.

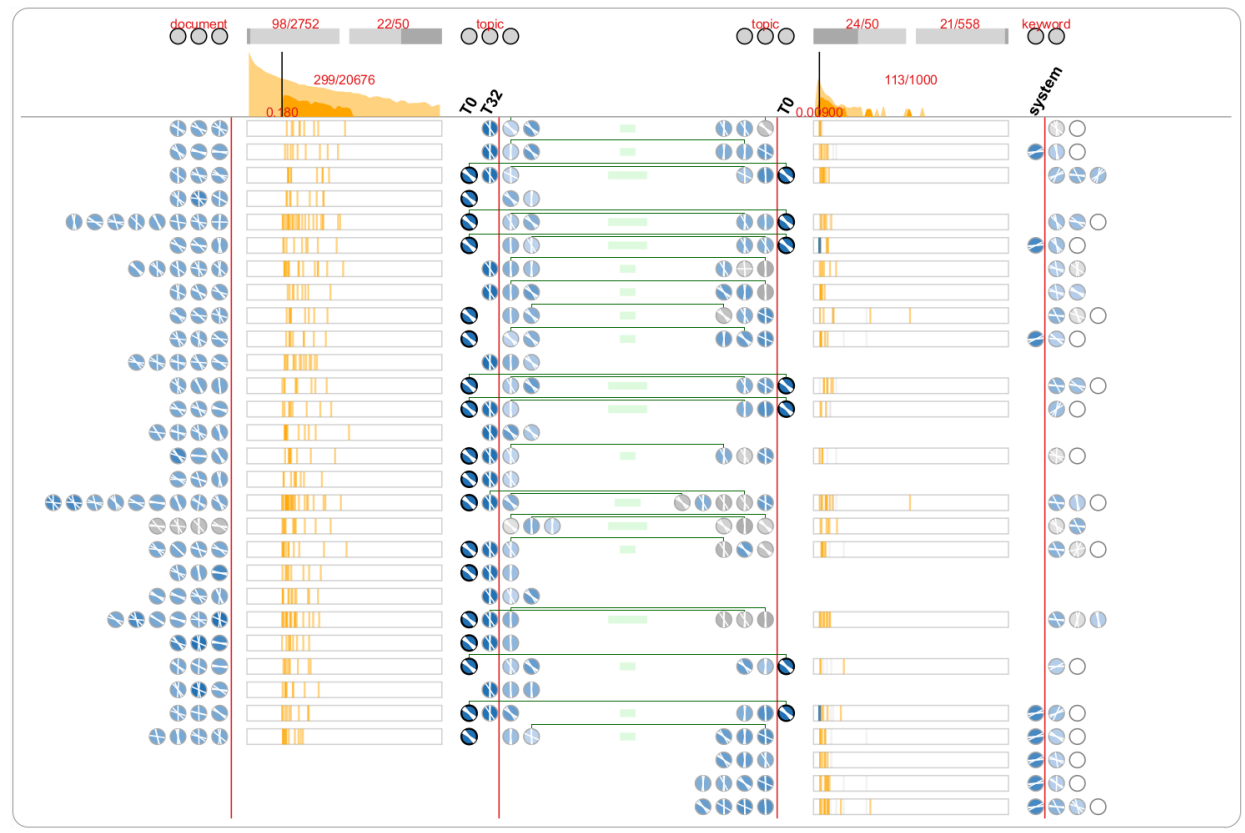

Fonte: Adaptada de Zhao et al. (2018).

Os conjuntos de dados utilizados, bem como seus tamanhos, variam de acordo com as técnicas utilizadas em cada abordagem. Zinsmaier et al. (2012), por exemplo, utilizam um grafo descrevendo as rotas aéreas da Europa, totalizando mais de 37 milhões de vértices. Ham e Perer (2009) conseguem processar um grafo com até 300 mil vértices, entretanto, sua técnica consiste em visualizar apenas partes de interesse do usuário. Percebe-se que, em grande partes dos trabalhos, bases de dados contendo autores e publicações da área de Visualização são utilizadas para estudos de caso (ARCHAMBAULT; MUNZNER; AUBER, 2008; NACHMANSON et al., 2015; DIAS et al., 2017; DöRK et al., 2012).

Abordagens como Wattenberg (2006) e Zhao et al. (2018) consideram grafos multidimensionais, contendo vértices com atributos multivariados. Por exemplo, em Wattenberg (2006) tem-se um conjunto de dados de 146 pessoas em uma companhia, onde os vértices possuem atributos como endereço e qual divisão um funcionário se encontra na companhia. Já Archambault, Munzner e Auber (2008) utilizam o conjunto de dados de Kosara, Jankun-Kelly e Chlan (2007), um grafo de filmes com os vértices contendo atributos como diretor de luz, diretor, atrizes, atores, gênero, entre outros. Chan et al. (2019) realiza estudos de caso em um grafo bipartido contendo modelos de veículos em uma camada e diagnósticos de problemas em outra, onde a camada de 
véiculos possui atributos como tipo de motor, tipo de combustível e tipo de tração nas rodas.

Grande parte das abordagens que simplificam grafos genéricos utiliza Eades (1984) como técnica para desenho de grafos. Entretanto, para a representação de conjuntos de dados que contém atributos, cada abordagem ajusta a visualização de maneira distinta. Enquanto Wattenberg (2006) apresenta uma representação em forma de grade, permitindo ao usuário entender melhor a influência dos atributos no conjunto de dados, Zhao et al. (2018) modela dois grafos bipartidos, cada um contendo atributos distintos. Em algumas situações, como Xu et al. (2016) e Zhao et al. (2018), a visualização acaba se tornando complexa, e pode dificultar a interpretação de informação pelo usuário.

Enquanto algumas soluções têm como objetivo introduzir um novo tipo de desenho de grafos, que priorize a escalabilidade e velocidade de processamento (ZINSMAIER et al., 2012; NACHMANSON et al., 2015; PERROT; AUBER, 2018; PEZZOTTI et al., 2018), outras combinam estratégias de visualização viabilizando atividades exploratórias na obtenção de informação, especialmente aquelas que utilizam grafos bipartidos (HAM; PERER, 2009; XU et al., 2016; CHAN et al., 2019). Em alguns casos, as abordagens compartilham objetivos similares, como em Abello, Ham e Krishnan (2006), Pezzotti et al. (2018), Steinbock, Groller e Waldner (2018), Chan et al. (2019), pois constroem uma hierarquia e permitem ao usuário navegar entre níveis.

Analogamente aos objetivos, algumas das principais tarefas exploratórias desses trabalhos envolvem a interação do usuário por meio de zoom ou filtragem de elementos. Essas técnicas podem ou não rearranjar a visualização, mostrando níveis mais específicos de detalhe. Em Zhao et al. (2018), por exemplo, ao selecionar um agrupamento, toda a visualização é ajustada, mostrando conexões relevantes para aquela seleção. Em Perrot e Auber (2018) e Nachmanson et al. (2015), o zoom é semântico, rearranjando os vértices visualizados conforme se aproxima dos níveis mais finos de detalhes, preservando o mapa mental do usuário.

Com a revisão desses trabalhos correlatos, observa-se que a combinação de técnicas de visualização deve ser simplificada, evitando a adição de complexidade desnecessária que possa dificultar a obtenção de informação. Mesmo introduzindo uma nova metáfora visual para esse trabalho de mestrado, busca-se manter a visualização mais simplificada possível que, em combinação com o paradigma multinível, permite rápida interpretação e obtenção de resultados. Outra conclusão é que a simplificação por meio da construção de uma hierarquia adiciona mais recursos que viabilizam as atividades exploratórias de um grafo, o que também detalha como o paradigma multinível se comporta com a execução de diferentes parâmetros. Isso é essencial para especialistas que trabalham diretamente com algoritmos de paradigma multinível entenderem melhor seu funcionamento. 
Figura 12 - Metáfora visual da ferramenta BiCFlows. Os vértices do grafo bipartido são codificados como retângulos cinza em uma coluna. Os agrupamentos são representados como retângulos coloridos nas colunas adjacentes.

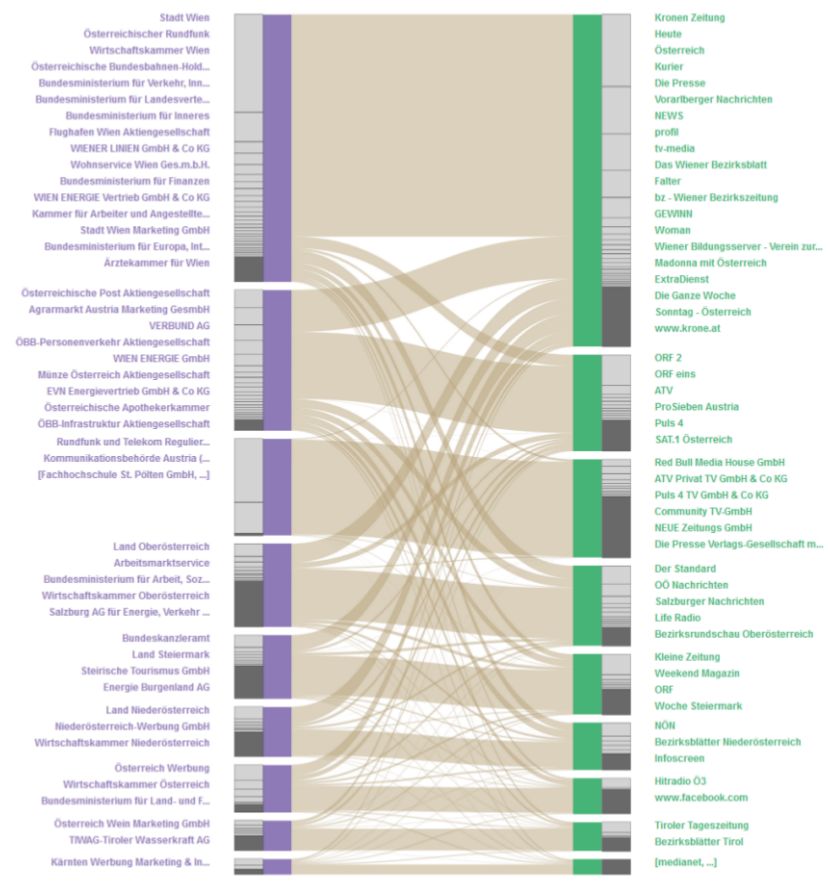

(a) Visão geral do BiCFlows, sem nenhuma interação com o usuário.

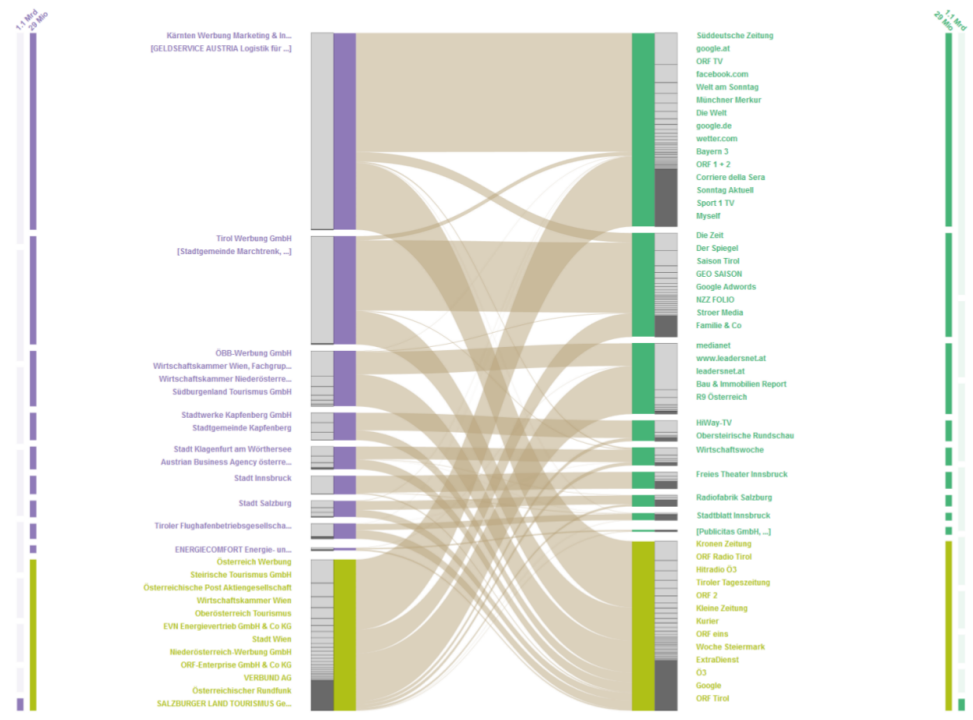

(b) Ao selecionar um agrupamento, ele é disposto no topo das linhas verticais. Aqui, "Kärnten Werbung Marketing" foi selecionado e disposto no topo. A visualização é rearranjada, descendo um nível na hierarquia e re-executando o biclustering para esses novos agrupamentos. Os clusters do nível anterior são agrupados em um único bloco, de cor bege. Duas linhas verticais são criadas nas extremidades da visualização, mostrando qual nível da hierarquia o usuário se encontra.

Fonte: Steinbock, Groller e Waldner (2018). 
Figura 13 - Metáfora visual de listas de adjacência. As cores indicam os agrupamentos encontrados com o princípio MDL. Na representação por lista de adjacência, os agrupamentos são ordenados por densidade, em ordem decrescente, da esquerda para a direita. O preenchimento dos blocos indica a densidade dos agrupamentos - $q_{3}$, por exemplo, conecta-se com todos os vértices de $p_{3}$. Logo, sua densidade é 1 , e todo o retângulo é preenchido.
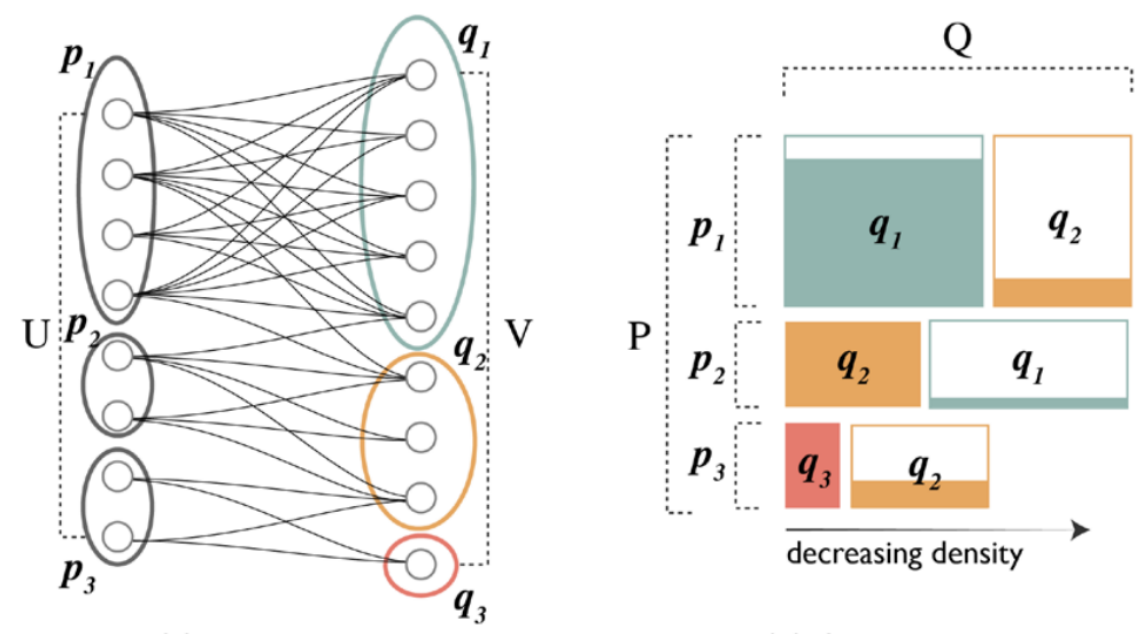

Fonte: Adaptada de Chan et al. (2019). 



\section{VISUALIZAÇÃO EXPLORATÓRIA COM O PARADIGMA MULTINÍVEL}

Neste Capítulo são destacadas as etapas para atingir os objetivos deste trabalho, por meio da ferramenta MObViewer, desenvolvida como prova de conceito. Ela foi desenvolvida como uma ferramenta Web, para que o acesso e uso fossem facilitados para os usuários, sem necessidade de instalação de bibliotecas ou compiladores específicos. O MObViewer funciona de maneira integrada à ferramenta $M O b$ apresentada por Valejo et al. (2018), que implementa um arcabouço do paradigma multinível. Portanto, essa integração requer adaptar os formatos dos grafos utilizados como entrada no MObViewer e os produzidos pela hierarquia de contrações gerados pelo $M O b$.

$\mathrm{Na}$ Seção 4.1, é apresentada uma visão geral da arquitetura do sistema, especificando a separação entre servidor e cliente. Também mostra-se a integração da ferramenta desenvolvida com o arcabouço $M O b$. Na Seção 4.2, uma nova metáfora de visualização para grafos bipartidos multinível é apresentada, que exibe os grafos intermediários produzidos com o paradigma. Por fim, na Seção 4.3, são introduzidas as técnicas de visualização utilizadas para exibição de informação e as principais formas de interação do usuário com o MObViewer.

Em relação aos detalhes de implementação do MObViewer, a principal linguagem utilizada é Javascript, por sua facilidade de integração com arquiteturas cliente-servidor. Para esse tipo de arquitetura, optou-se por adotar Node. js ${ }^{1}$, popularmente utilizado e com extensa documentação, que provê um nível de abstração para criação de um servidor e comunicação entre cliente-servidor. Adotando uma arquitetura cliente-servidor, portanto, do lado do cliente, para desenho de grafos bipartidos, optou-se por utilizar a Three. j. ${ }^{2}$, uma API (Application programming interface) que abstrai os principais comandos e diretivas utilizadas pela WebGL ${ }^{3}$,

\footnotetext{
$<$ https://nodejs.org/en/>

$<$ https://threejs.org/>.

$<$ https://www.khronos.org/webgl/>
} 
para renderização de cenários 2D e 3D interativos sem uso de plugins e compatível com a maioria dos navegadores.

A ferramenta Grunt ${ }^{4}$ foi utilizada não só para os processos de concatenação e uglify ${ }^{5}$ do código como também para automação de diversas tarefas, como excluir arquivos desnecessários, mover arquivos para diferentes pastas e atualizar mudanças ocorridas no sistema, mesmo quando ele já foi implantado em um servidor. Isso contribuiu no desenvolvimento, evitando muito trabalho repetitivo. Como destacado na Seção 4.1, a ferramenta permite ao usuário enviar um grafo de entrada, processado no arcabouço multinível do lado do servidor, e executar todas as etapas necessárias para obter os diversos níveis intermediários. Finalizado o processamento, os resultados são enviados para o lado do cliente, responsável apenas pelo rendering. Essa separação permite lidar mais eficientemente com grafos bipartidos, visto que testes iniciais indicaram que a memória não comportaria a visualização e o processamento simultaneamente do lado do cliente.

Por fim, o MObViewer encontra-se disponível para teste no endereço <https://github. com/diego2337/MObViewer>.

\subsection{Arquitetura do sistema}

Uma visão geral da arquitetura do MObViewer é mostrada na Figura 14, sendo a ferramenta dividida em dois módulos. O módulo "Paradigma multinível" inclui os componentes responsáveis por executar o arcabouço implementado no $M O b$ e fazer a conversão dos formatos de grafos e outras atividades de processamento. Traduzindo essas tarefas para o contexto Web, tem-se o lado do servidor incumbido de realizar as tarefas de contração e conversão. Já do lado do cliente, o módulo "Visualização exploratória" inclui os procedimentos responsáveis por desenhar a metáfora visual de grafos bipartidos, detalhada na Seção 4.2, e permitir a interação do usuário com a ferramenta, por meio de técnicas de visualização detalhadas na Seção 4.3.

Além dos parâmetros do paradigma multinível, estabelecidos pela interação do usuário com o grafo bipartido, também são incluídos alguns parâmetros necessários para a visualização exploratória de atributos associados a um vértice do grafo, representado por um glifo. No caso da metáfora visual, o usuário pode optar por incluir um gráfico de setores em cada vértice, que mapeia a distribuição de valores de um atributo categórico. Portanto, essa informação pode ser definida como parâmetro na etapa de contração e geração da hierarquia de grafos, definindo um "mapa de cores". Mais detalhes dos parâmetros adicionais resultantes da interação do usuário serão descritos na Seção 4.3.

O usuário envia o grafo que deseja explorar pela interface do cliente, que processa os dados relevantes do lado do servidor. O usuário também especifica a configuração dos parâmetros

\footnotetext{
$4<$ https://gruntjs.com/>

$5<$ https://github.com/mishoo/UglifyJS>
} 
Figura 14 - Visão geral da arquitetura do MObViewer. Um grafo bipartido é contraído no sistema $M O b$, gerando uma hierarquia de grafos contraídos. As conversões de formatos de grafos são aplicadas logo em seguida, resultando em uma representação de uma metáfora visual do grafo. Técnicas de visualização são utilizadas quando o usuário interage com a metáfora visual. As interações do usuário nessas representações permitem a redefinição dos parâmetros do paradigma multinível, para uma nova execução, ou a obtenção de conhecimento.

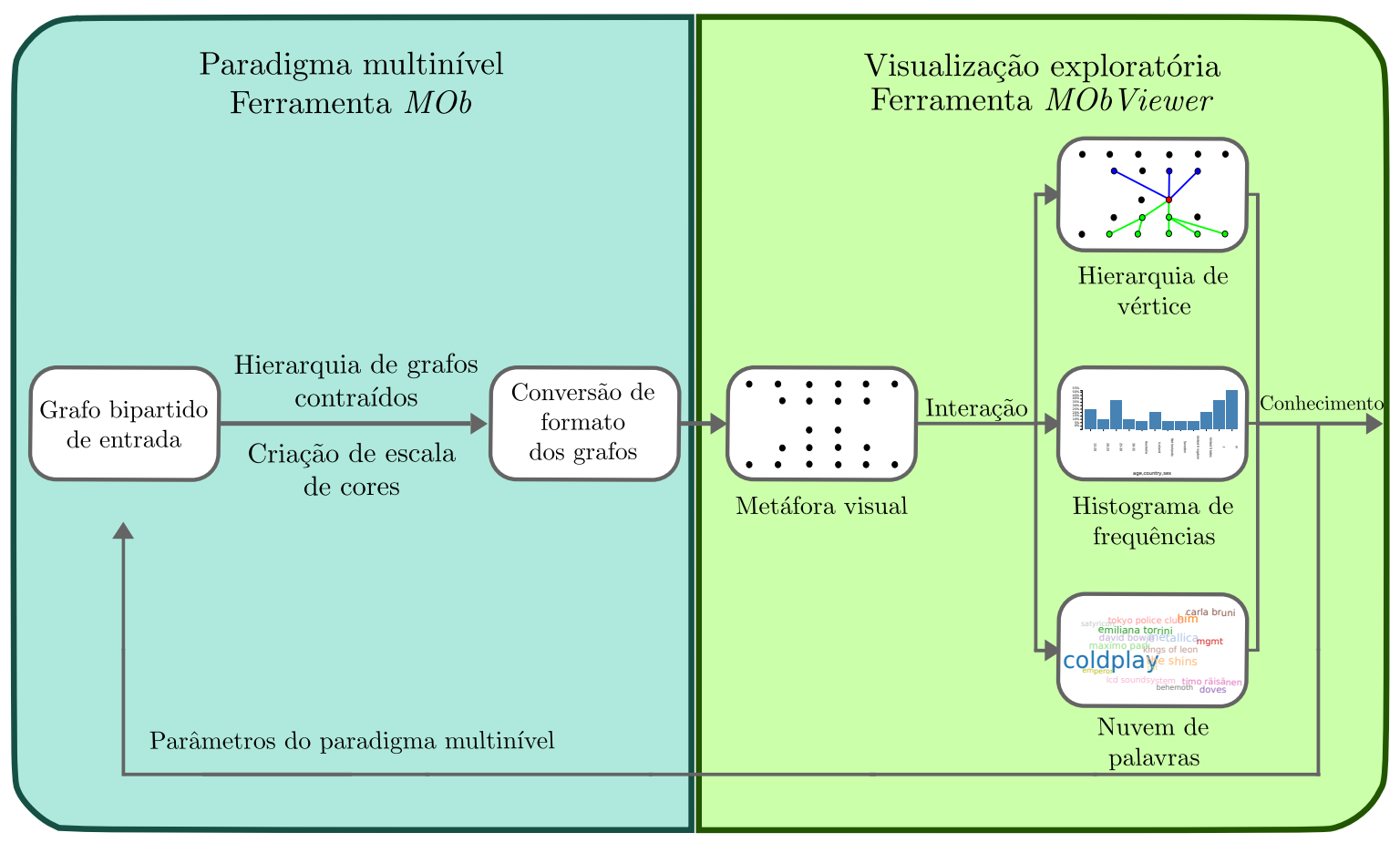

Fonte: Elaborada pelo autor.

do paradigma multinível, por meio de outra interface no lado do cliente, que é utilizada como entrada pelo $M O b$ no lado do servidor.

\subsection{Metáfora visual}

Visto que o paradigma multinível gera uma representação hierárquica dos grafos, visualizar a construção dessa hierarquia torna-se fundamental para compreender fatores relevantes da execução do algoritmo. Por exemplo, com uma representação que demonstre a hierarquia de níveis contraídos, é possível distinguir em que momento vértices com atributos distintos se uniram e formaram um único super-vértice. Pode-se identificar, também, em quais níveis super-vértices foram criados resultantes da união de pares de vértices ou pares de super-vértices.

A Figura 15 mostra a representação do resultado da contração gerada pelo paradigma multinível, inicialmente sem a interação do usuário. Vértices são caracterizados como círculos, e as arestas são inicialmente omitidas da visualização, para diminuir a poluição visual de elementos. Incorpora-se a representação tradicional de grafos bipartidos (TAMASSIA, 2013), em que as duas camadas $V_{1}$ e $V_{2}$ são representadas por duas fileiras de vértices, dispostas de maneira horizontal. As duas fileiras mais internas de vértices retratam as camadas de vértices do grafo 
bipartido mais contraído. Nas fileiras mais externas, retratam-se os níveis menos contraídos até a representação do grafo bipartido original. Essa representação pode ser disposta tanto de maneira vertical como horizontal. Conforme vértices se unem e transformam-se em super-vértices, o tamanho dos círculos também aumenta, representando a distinção entre vértices e super-vértices. O nível mais externo, que representa o grafo original, é desenhado em cinza, diferenciando quais os níveis resultantes da contração e qual o grafo original.

Figura 15 - Representação da metáfora visual da estrutura multinível aplicado a grafos bipartidos. Cada linha de círculos representa vértices de uma camada em um determinado nível. O grafo mais contraído é representado no centro (nível 4), e os níveis intermediários representados nas linhas seguintes (nível 3, 2 e 1). O grafo original é representado em cinza. Os vértices da camada $V_{1}$ são dispostos na parte inferior, enquanto os de $V_{2}$ ficam na porção superior da visualização.
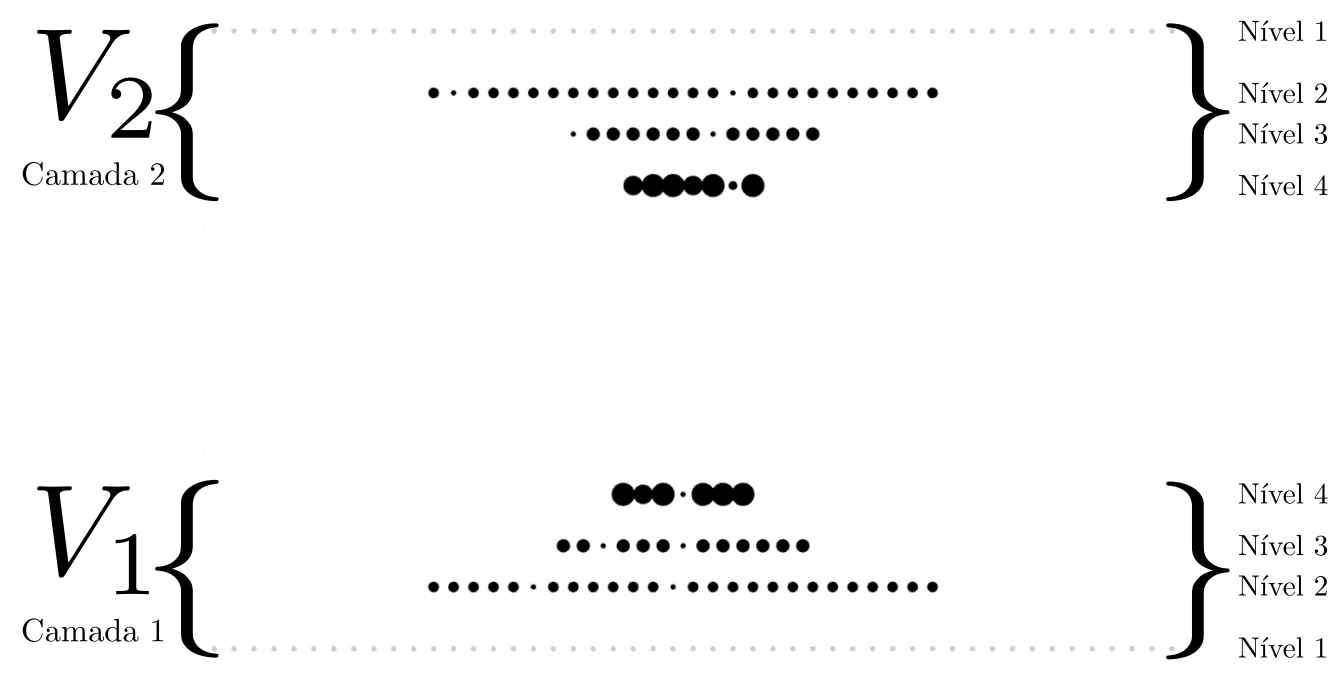

Fonte: Elaborada pelo autor.

A Figura 16 ilustra uma interação do usuário com esta metáfora visual. O vértice selecionado é destacado por um contorno vermelho. Seus predecessores, vértices que o compõem, e sucessores, super-vértices que incluem o vértice selecionado, são representados por um contorno verde. As arestas são representadas nessa seleção, sendo visualmente codificadas em dois tipos. As arestas de hierarquia, representadas por linhas pontilhadas verdes, identificam conexões de vértices predecessores e sucessores. Já as linhas contínuas azuis identificam os vizinhos do vértice selecionado. Caso o usuário selecione um vértice que não está no nível mais contraído, mostra-se, com linhas pontilhadas verdes, o sucessor do vértice selecionado até o nível mais contraído. Daí, mostram-se os vizinhos do vértice no nível mais contraído, que recebem um contorno em azul.

No processo de criação dessa nova metáfora visual, a interação do usuário provoca a exibição das arestas, tanto de vizinhança quanto de hierarquia. Um problema decorrente das arestas de hierarquia é sua sobreposição, visto que um super-vértice pode ser formado por vértices que, quando dispostos na representação tradicional de um grafo bipartido, estão distantes entre si. A Figura 17 representa essa situação. 
Figura 16 - Representação da metáfora visual do paradigma multinível aplicado a grafos bipartidos, com interação do usuário. O vértice selecionado é destacado com um círculo vermelho. Seus sucessores e predecessores são representados por um contorno verde, e conectados por linhas pontilhadas verdes. Neste exemplo, são mostrados os vizinhos de um vértice sucessor do vértice selecionado, destacados por contornos azuis e conectados por linhas contínuas da mesma cor.

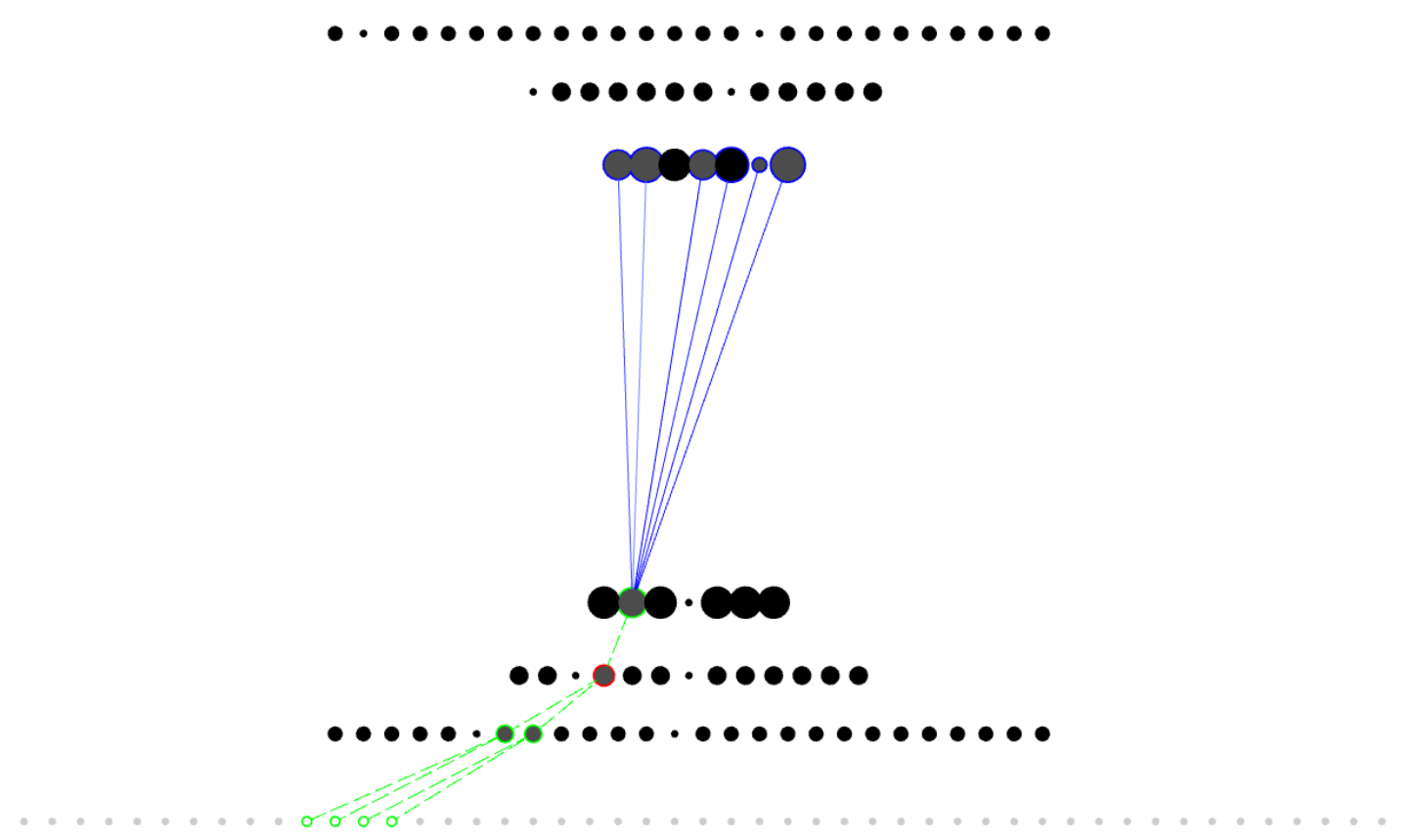

Fonte: Elaborada pelo autor.

Para contornar esse problema, utiliza-se o Algoritmo 5, rearrajando vértices que compõem um super-vértice para que eles sempre fiquem lado a lado. Ele toma como entrada uma lista de grafos contraídos gerados como saída do paradigma multinível, ordenada do mais contraído até o grafo original. Na linha 3, ele itera por todos esses grafos, armazenando, na linha 9, os predecessores de todos os vértices $u \in G_{i}$, retornados pela função preds. É importante notar que a ordem de armazenamento é fundamental para o correto funcionamento desse algoritmo. $\mathrm{Na}$ linha 5, após ter iterado e atualizado a lista de predecessores, o conjunto de vértices do grafo $G_{i}$ é atualizado, recebendo a lista "ordenada" de vértices.

Esse processo continua iterativamente até chegar ao grafo original. Assim, quando o algoritmo de desenho da metáfora visual for executado, ele irá receber a lista de grafos com as posições dos vértices atualizadas, sendo desenhados lado a lado. Como os fatores dominantes do tempo de execução são o número de vértices de cada grafo e a quantidade de grafos gerados, o tempo de execução desse algoritmo é $\theta\left(n^{2}\right)$. Ele garante que, independente do algoritmo de pareamento utilizado, os vértices que compõem um mesmo super-vértice sempre estarão adjacentes.

Conforme super-vértices vão sendo criados, sua representação em círculos também 
Figura 17 - Problema de representação com a metáfora visual apresentada. Vértices que formam supervértices em níveis mais contraídos encontram-se distantes entre si, o que gera um cruzamento de arestas de hierarquia.

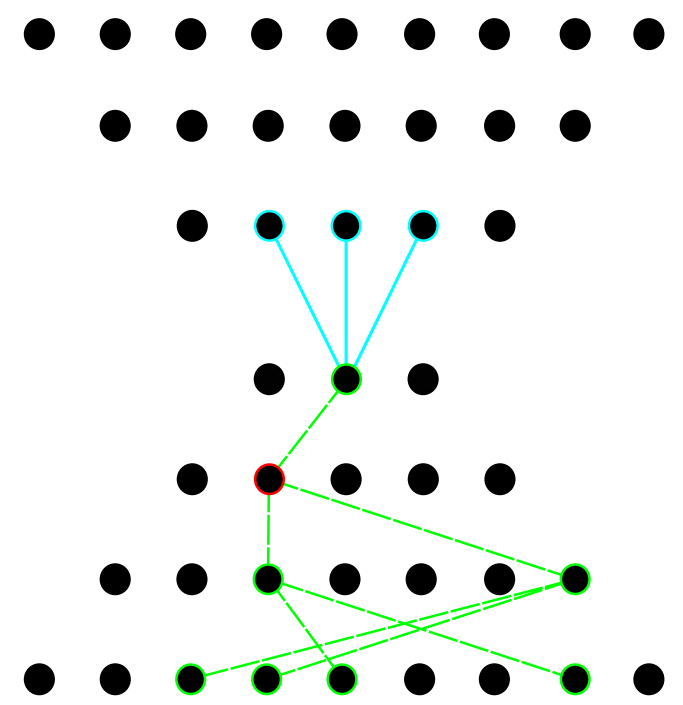

Fonte: Elaborada pelo autor.

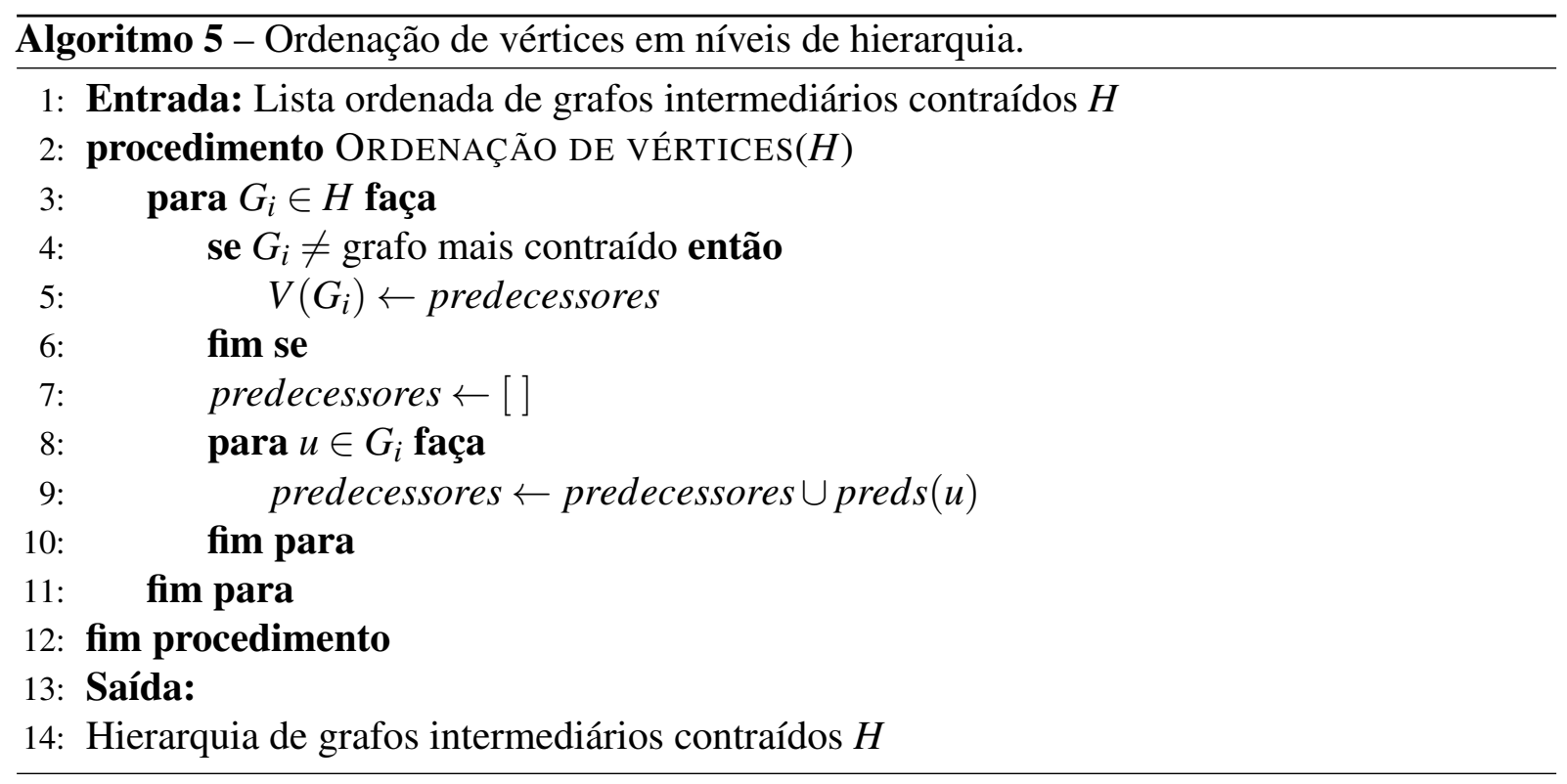

vai aumentando, contrastando com outros vértices e super-vértices com menor quantidade de elementos. Isso indica o tamanho desses agrupamentos na metáfora visual. Inicialmente, todos os vértices recebem um peso unitário. Conforme os super-vértices vão sendo desenhados, seus pesos equivalem ao somatório da quantidade de vértices que o compõe.

\subsection{Análise exploratória de grafos bipartidos}

Como visto na Figura 14, a interação do usuário com a metáfora visual produz visualizações adicionais que representam os atributos dos vértices e suas relações. Inicialmente, os atributos foram dispostos de maneira tabular, o que acabou gerando problemas com a disposição 
dos elementos e a dificuldade de obtenção de informação. Buscando contornar esses problemas, nas Seções seguintes, são destacados o processo de criação das visualizações exploratórias e como elas apoiam a obtenção de informação.

\subsubsection{Informações do grafo}

Após executar o paradigma multinível e produzir uma hierarquia de grafos contraídos, algumas informações sobre esses grafos, como número de vértices e arestas e quantos vértices estão presentes em cada uma das camadas, são dispostas de maneira tabular. A Figura 18 ilustra as principais informações apresentadas ao usuário após a execução do paradigma multinível. Isso é importante para observar, por exemplo, o comportamento de algoritmos de pareamento, identificando quantos vértices foram contraídos de um nível para outro, ou a redução de vértices desde o grafo original até o nível mais contraído.

Figura 18 - Informações sobre grafos produzidos com o paradigma multinível. Os números representam, em ordem crescente, o grafo original até o grafo mais contraído.

\begin{tabular}{|c|c|c|c|c|}
\hline $\begin{array}{c}\text { Nível do } \\
\text { grafo }\end{array}$ & $\begin{array}{c}\text { Número de } \\
\text { vértices }\end{array}$ & $\begin{array}{c}\text { Número de } \\
\text { arestas }\end{array}$ & $1^{a}$ camada & $2^{a}$ camada \\
\hline$\# 1$ & 770 & 887 & 274 & 496 \\
$\# 2$ & 540 & 605 & 192 & 348 \\
\hline$\# 3$ & 379 & 419 & 135 & 244 \\
\hline
\end{tabular}

Fonte: Elaborada pelo autor.

\subsubsection{Histograma de frequências}

Buscando maneiras de representar atributos multidimensionais de vértices, optou-se por uma visualização simples, que identificasse a distribuição de valores de atributos em um determinado super-vértice. Para isso, foi utilizado um histograma de frequências, como pode ser visto na Figura 19. Ele representa uma sumarização visual dos atributos associados aos vértices que compõem um super-vértice. Isso é mais eficiente do que, por exemplo, o usuário percorrer uma tabela de vértices e identificar separadamente os valores. Além disso, o histograma de frequências permite ao usuário identificar características em comum que super-vértices podem apresentar, ou identificar agrupamentos com propriedades distintas, em termos da distribuição dos atributos.

Para criar o histograma de frequências, o usuário precisa identificar os atributos associados aos vértices, e também explicitar quais são os tipos dos dados, sendo categóricos ou 
Figura 19 - Histograma de frequência dos atributos associados a um super-vértice selecionado. Os atributos são identificados na parte inferior, separados por vírgula. No exemplo, "age,country,sex", idade, país e sexo, definem os 3 atributos de cada vértice. As linhas pontilhadas verticais separam os grupos de atributos definidos na parte inferior do histograma. $\mathrm{O}$ eixo $y$ varia entre $0 \%$ até a máxima porcentagem no super-vértice selecionado.

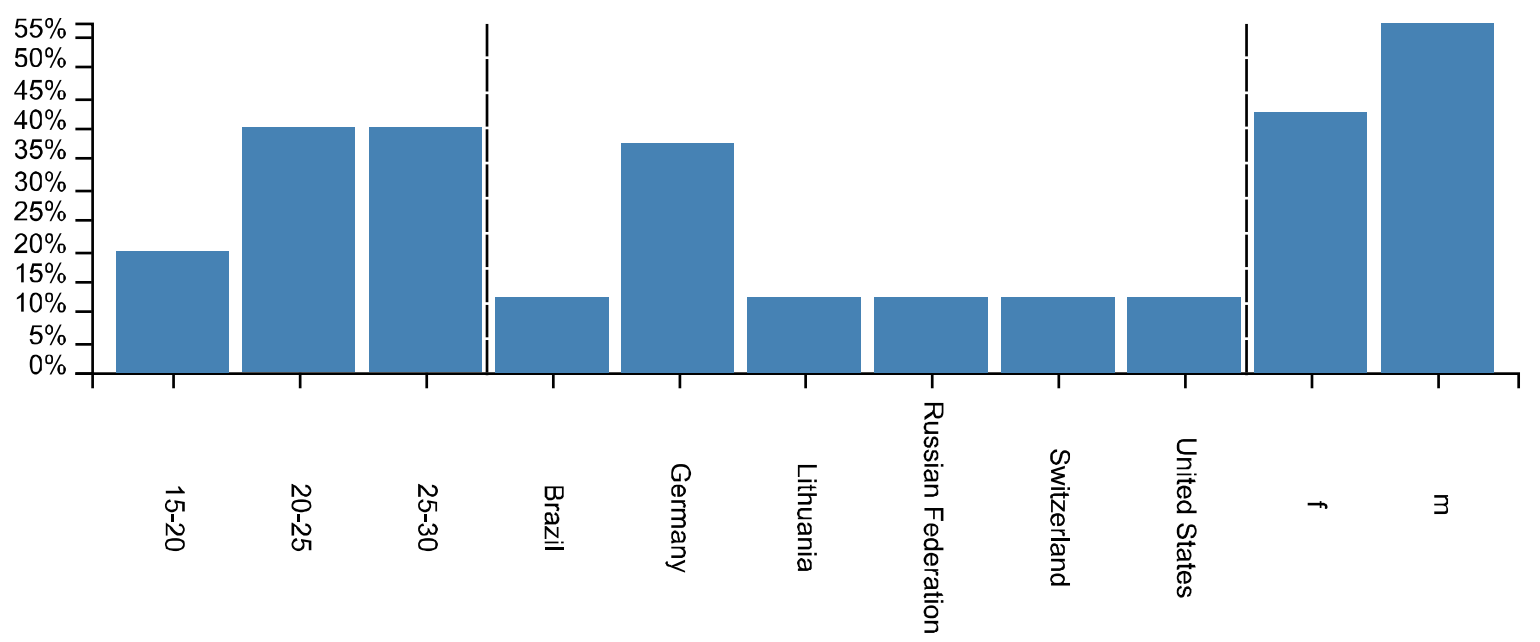

age,country,sex

Fonte: Elaborada pelo autor.

numéricos. Um atributo categórico é um valor não-numérico contido em uma lista de finitas possibilidades. Já valores numéricos podem ser separados em binário (assumindo valores entre 0 ou 1), discretos (que são valores inteiros) e contínuos (valores do conjunto dos números reais $\mathbb{R}$ ) (MUNZNER, 2014). Assim, considere um conjunto de dados cujos atributos de vértices de uma camada são descritos por "idade", "país" e "sexo", conforme visto na Figura 19. Um exemplo de parâmetro de entrada que o usuário envia ao MObViewer pode ser visto no Código-fonte 1.

Código-fonte 1 - Parâmetros do histograma de frequências.

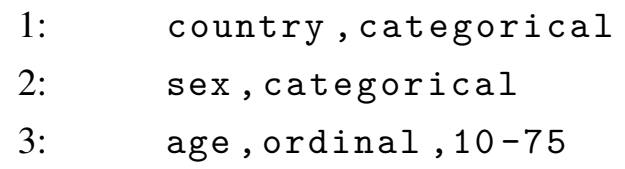

O primeiro parâmetro é o nome do atributo, seguido de seu tipo. Quando um atributo é categórico, a execução interna do MObViewer verifica a quantidade de elementos presentes e realiza os cálculos necessários para produzir o histograma de frequências. Quando um atributo é ordinal, é necessário um parâmetro adicional, que define o intervalo de variação dos valores aceitos. Essa faixa de valores é dividida em intervalos de 5 elementos, por exemplo, "idade" seria dividida em intervalos de $10-15,16-20,21-25$ e assim por diante.

A definição do histograma de frequências permite que atributos de somente uma das 
camadas sejam visualizados. Caso queira, o usuário pode definir atributos de ambas as camadas. Entretanto, selecionando atributos exclusivos de uma única camada, o histograma só será visualizado ao selecionar o super-vértice da camada correspondente.

\subsubsection{Nuvem de palavras}

Considere uma coleção de documentos e termos, definindo um grafo bipartido no qual os pesos das arestas indicam a frequência de um termo em um determinado documento. Caso o usuário quisesse identificar, por exemplo, os termos mais comuns de uma coleção de documentos, agrupados em um super-vértice, uma disposição tabular desses termos não seria adequada.

Para contornar esse problema, introduz-se uma visualização por nuvem de palavras, que transforma essa estrutura tabular em uma visualização que permite identificar os termos mais frequentes em uma coleção. A Figura 20 ilustra a nuvem de palavras correspondente à seleção de um super-vértice, identificando as frequências do atributo dos vértices vizinhos ao selecionado. $\mathrm{O}$ tamanho das palavras indica os pesos das arestas. No contexto da Figura 20, que exemplifica uma coleção de documentos e termos, os tamanhos indicam a frequência dos termos na coleção de documentos no super-vértice. Para definir a nuvem de palavras, o usuário seleciona um atributo associado aos vértices, que é utilizado pelo MObViewer para realizar os cálculos necessários para criar a visualização. O algoritmo usa uma biblioteca do D3. j. ${ }^{6}$.

\subsubsection{Gráfico de setores}

O histograma de frequências apresenta uma visão geral dos atributos associados a um vértice. O usuário pode desejar, por exemplo, observar o comportamento de um atributo específico, quando o algoritmo de pareamento agrupa vértices na construção da hierarquia, entendendo a relação do paradigma multinível com o atributo. Realiza-se, portanto, uma adaptação na metáfora visual apresentada na Seção 4.2, para incrementar a compreensão desse paradigma.

O usuário define, a priori, um atributo que deseja analisar, que será mapeado segundo uma escala de cores. Essa escala é criada associando cores aleatórias para cada valor que o atributo pode assumir, e está exemplificada na Figura 21b. Com isso, os vértices da metáfora visual são coloridos de acordo com esse atributo, ilustrado na Figura 21a. No caso do atributo ser faltante em um dos vértices, ele é colorido com a cor preta e definido como Unknown (desconhecido).

Na construção da hierarquia de grafos contraídos, conforme novos super-vértices são criados, a frequência do atributo selecionado é calculada, e seus valores são representados no super-vértice como um gráfico de setores. Isso significa que os super-vértices são coloridos de acordo com a distribuição dos valores do atributo selecionado no super-vértice.

6 Disponível em <https://github.com/jasondavies/d3-cloud>. 
Figura 20 - Ao selecionar um super-vértice, os vizinhos dele (destacados em vermelho) criam a nuvem de palavras de acordo com a frequência de um atributo definido pelo usuário.

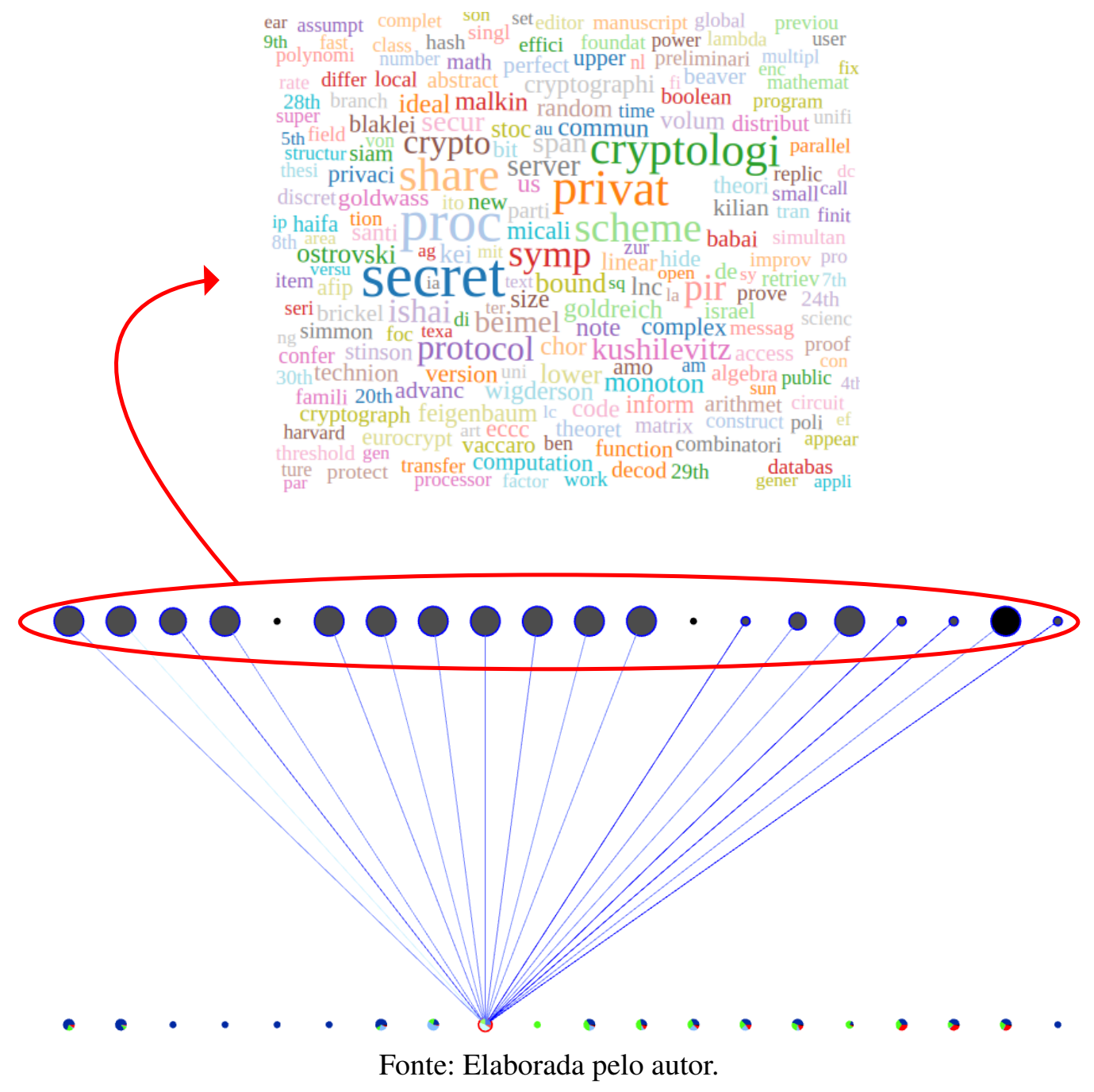

\subsection{Pesos das arestas}

Como descrito na Seção 4.2, quando vértices são selecionados, as arestas que indicam seus vizinhos (ou vizinhos de seu sucessor mais contraído) são mostradas com a cor azul. Entretanto, pode haver conjuntos de dados em que as arestas são ponderadas, e essa informação é relevante ao usuário. Temos como exemplo a coleção de documentos e termos, onde os pesos das arestas indicam a frequência de ocorrência de um determinado termo em um documento. Inicialmente, codificou-se os pesos da aresta como sua espessura, sendo mais espessas as arestas de maior peso. Entretanto, algumas limitações da ferramenta inviabilizaram essa codificação.

Para contornar esse problema, optou-se por utilizar uma escala de cores que define os pesos das arestas, conforme ilustrado na Figura 22. Foi escolhido uma palheta de cores variando de um tom azul claro até um azul escuro. Conforme as arestas se tornam mais pesadas, a intensidade da cor aumenta. A legenda também mostra os intervalos dos pesos das arestas, das mais leves até as mais pesadas. 
Figura 21 - Exemplo de atributo colorindo o glifo que representa o vértice. Aqui, "assunto" foi o atributo escolhido do conjunto de dados, que identifica o tema de um determinado documento. Conforme super-vértices são criados, eles são representados por gráficos de setores, proporcional a quantos vértices têm um determinado valor.

(a) Grafo bipartido com atributo "tema" colorindo vértices de uma camada. Os vértices de cor preta não possuem esse atributo associado.

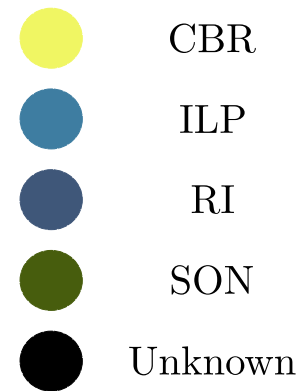

(b) Legenda dos valores que o atributo "tema" pode assumir.

Fonte: Elaborada pelo autor.

Figura 22 - Legenda de pesos das arestas. Da esquerda para a direita, conforme o peso vai aumentando, a intensidade do azul aumenta.

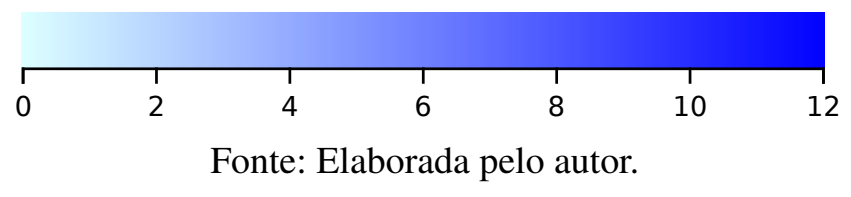

\subsection{Considerações finais}

Neste Capítulo, foram apresentadas as principais visualizações utilizadas para suporte à análise exploratória de grafos bipartidos, incorporadas ao sistema de prova de conceito $\mathrm{MOb}$ Viewer. Esse mesmo sistema também recebeu uma nova metáfora visual, elaborada com o propósito de apoiar na compreensão do funcionamento do paradigma multinível, seus algoritmos de pareamentos, métricas de similaridade e comportamento em geral. Com a metáfora visual, é possível identificar em qual momento super-vértices foram criados, e qual foram seus predecessores. Identifica-se, também, o que a quantidade de níveis intermediários produzidos diz a respeito do algoritmo de pareamento ou métrica de similaridade utilizadas. A metáfora também 
foi acompanhada de um algoritmo de arranjo de nós, que evita o cruzamento desnecessário de arestas.

O histograma de frequências permite ao usuário ver os principais atributos de vértices que compõem um super-vértice. O usuário pode identificar, no exemplo de uma coleção de artistas e usuários, quais são os principais artistas ouvidos por usuários de uma determinada idade ou gênero. $\mathrm{O}$ uso da nuvem de palavras é uma alternativa à recuperação de informação tabular, o que resulta em um processo analítico mais eficiente. O usuário, no exemplo de documentos e termos, pode identificar os termos mais frequentes para um determinado super-vértice apenas verificando os maiores termos da nuvem. Por fim, a alteração da metáfora visual para incluir um atributo, traduzido com cores em vértices, permite ao usuário entender como o paradigma multinível uniu determinados vértices com atributo similar ou não. Os super-vértices representados como gráfico de setores ajudam na análise dos vértices com mesmos valores para um atributo que se uniram em um mesmo super-vértice. 


\section{5}

\section{ESTUDOS DE CASO E RESULTADOS}

Neste Capítulo são apresentados os estudos de caso conduzidos para validação da solução proposta para este trabalho de pesquisa. Em vista do que foi apresentado no Capítulo 1, os primeiros estudos são focados na análise do comportamento do paradigma multinível e apoio à interpretação pelo usuário dos diferentes algoritmos de pareamento e métricas de similaridade. São definidas questões analíticas que ilustram os cenários exploratórios destes estudos, ajudando na compreensão do comportamento das métricas de similaridade nos algoritmos de pareamento em relação à topologia dos grafos bipartidos. Já nos estudos de caso seguintes, dados reais são analisados em apoio a atividades exploratórias, por meio da integração entre a nova visualização (apresentada no Capítulo 4) e o paradigma multinível. Ao final, discussões referentes aos resultados são apresentadas.

O restante deste Capítulo é organizado da seguinte maneira: na Seção 5.1, são detalhados os parâmetros para geração dos grafos sintéticos utilizados. As questões analíticas propostas são descritas, bem como a configuração dos parâmetros do paradigma multinível nos grafos sintéticos. A execução dessas configurações juntamente com a resposta às questões analíticas são apresentadas. Na Seção 5.2, são detalhados os conjuntos de dados obtidos em aplicações do mundo real. Em seguida, essas bases são exploradas com o auxílio do MObViewer, apresentado no Capítulo 4. Por fim, a Seção 5.3 destaca as principais contribuições trazidas pelas nova ferramenta, resultados e limitações.

\subsection{Resultados em grafos sintéticos}

Antes de abordar a exploração dos conjuntos de dados sintéticos, explica-se como eles foram criados com a ferramenta BNOC (Benchmarking weighted bipartite Networks with Overlapping Community structure), introduzida por Valejo et al. (2019b). Ela permite criar grafos bipartidos com pesos e que possuem estruturas de comunidade. 


\subsubsection{Dados sintéticos}

O BNOC possui diversos parâmetros para testes de grafos bipartidos, como número de vértices $v$, número de comunidades $c$, densidade de um grafo $d$, entre outros. Por exemplo, pode-se ajustar os parâmetros visando criar um grafo bipartido esparso com muitas comunidades. Esse controle torna-se fundamental para verificar um dos objetivos definidos no Capítulo 1, que é apoiar o entendimento do paradigma multinível e seu comportamento com diferentes parâmetros, por meio de uma nova metáfora de visualização. Quatro grafos sintéticos, adiante referidos como $G S_{1}, G S_{2}, G S_{3}$ e $G S_{4}$, foram criados com o auxílio dessa ferramenta.

Os valores fixados nos parâmetros foram definidos em colaboração com especialistas no paradigma multinível, que desejam entender o comportamento do algoritmo com a nova metáfora visual introduzida. O parâmetro número de vértices, representado por $v$, varia de 100 vértices em $G S_{1}, 1000$ em $G S_{2}, 2000$ em $G S_{3}$ e 1819 em $G S_{4}$. Esses valores foram escolhidos com dois critérios. O primeiro é explorar a escalabilidade do algoritmo conforme a quantidade de vértices aumenta. O segundo é que o maior valor escolhido, 2000 vértices, se ajusta ao espaço disponível para visualização pelo MObViewer, facilitando a criação de imagens para análise.

O parâmetro quantidade de comunidades $c$ do grafo bipartido variou entre 4 para $G S_{1}$, 7 para $G S_{2}, 12$ para $G S_{3}$ e 8 para $G S_{4}$. Os três primeiros grafos sintéticos contém a mesma quantidade de comunidades para cada camada, porém $G S_{4}$ contém 3 comunidades em $V_{1}$ e 5 em $V_{2}$. Grafos com mais de 15 comunidades produzem agrupamentos muito pequenos. Por exemplo, para $G S_{3}, 15$ comunidades resultam em aproximadamente 133 vértices em cada. Em Valejo et al. (2018), as aplicações de mundo real analisadas não contém mais do que 10 comunidades, para grafos com mais de 15000 vértices. Por exemplo, a rede Escorts ${ }^{1}$ contém 15810 vértices e apenas 8 comunidades.

A densidade, conforme descrita no Capítulo 2, indica a quantidade de arestas em um grafo. Essa propriedade pode ser definida no BNOC por meio de dois parâmetros $d$ e $s$, com valores no intervalo $[0.1,0.9]$. Os valores para $G S_{1}$ foram fixados em $d=s=0.9$, o que produz grafos esparsos. Esses valores foram escolhidos para simular grafos de aplicações de mundo real, que geralmente são esparsos. Já $G S_{2}, G S_{3}$ e $G S_{4}$ tiveram valores de $d=s=0.4, d=s=0.3$ e $d=s=0.3$, respectivamente, resultando em grafos mais densos, visando explorar como as comunidades se comportam no processo de contração.

O ruído $n$ também é um parâmetro de entrada, variando no intervalo $n=[0.01,0.9]$. De acordo com Valejo et al. (2019b), valores entre [0.01,0.4] aumentam a dificuldade em detecção de comunidades sem comprometer as estruturas topológicas do grafo. Valores acima de 0.5 produzem grafos com mais arestas entre vértices de comunidades distintas do que internos a uma comunidade, caracterizando alta aleatoriedade. Fixou-se o valor $n=0.1$ como ruído para os grafos sintéticos $G S_{1}, G S_{2}$ e $G S_{3}$, e $n=0.01$ para o $G S_{4}$.

1 Disponível em <http://konect.uni-koblenz.de/networks/escorts>. 
Três parâmetros controlam os vértices que pertencem a múltiplas comunidades simultaneamente. $x$ e $y$ são parâmetros que permitem ao usuário explicitamente definir quantos vértices têm sobreposição de comunidades, em $V_{1}$ e em $V_{2}$, respectivamente. Já $z$ define, aleatoriamente, quais comunidades possuem pelo menos um vértice sobreposto conectado a outra comunidade. Adotou-se os valores $x=y=z=0$, ou seja, não existem vértices que pertençam a múltiplas comunidades simultaneamente ou comunidades sobrepostas. Para o restante dos parâmetros, os valores são o padrão definido pelo BNOC. A Tabela 1 ilustra as configurações de todos os parâmetros para a criação de cada grafo sintético. A Tabela 2 resume as principais informações dos conjuntos de dados sintéticos utilizados.

Tabela 1 - Parâmetros utilizados na geração dos grafos sintéticos. $G$ representa o nome do grafo sintético, $v$ a quantidade de vértices, $c$ a quantidade de comunidades, $[d, s]$ os parâmetros para definição de densidade, $n$ o ruído, $x$ a quantidade de vértices com comunidades sobrepostas em $V_{1}, y$ a quantidade de vértices com comunidades sobrepostas em $V_{2}, z$ o número de comunidades sobrepostas e $b$ se o grafo possui comunidades balanceadas nas camadas.

\begin{tabular}{|l|c|c|c|c|c|c|c|c|}
\hline$G$ & $v$ & $c$ & {$[d, s]$} & $n$ & $x$ & $y$ & $z$ & $b$ \\
\hline$G S_{1}$ & {$[50,50]$} & 4 & {$[0.9,0.9]$} & 0.1 & 0 & 0 & 0 & Verdadeiro \\
\hline$G S_{2}$ & {$[500,500]$} & 7 & {$[0.4,0.4]$} & 0.1 & 0 & 0 & 0 & Verdadeiro \\
\hline$G S_{3}$ & {$[1000,1000]$} & 12 & {$[0.3,0.3]$} & 0.1 & 0 & 0 & 0 & Verdadeiro \\
\hline$G S_{4}$ & {$[542,1277]$} & 8 & {$[0.3,0.3]$} & 0.01 & 0 & 0 & 0 & Falso \\
\hline
\end{tabular}

Fonte: Dados da pesquisa.

Nota - GS é um acrônimo para Grafo Sintético.

Tabela 2 - Informações sobre conjuntos de dados sintéticos utilizados para estudos de caso.

\begin{tabular}{l|c|c|c|c|c}
\hline Nome & $\begin{array}{c}\text { Número } \\
\text { de vértices }\end{array}$ & $\begin{array}{c}\text { Número } \\
\text { de arestas }\end{array}$ & $\begin{array}{c}\text { Camada } \\
V_{1}\end{array}$ & $\begin{array}{c}\text { Camada } \\
V_{2}\end{array}$ & $\begin{array}{c}\text { Número } \\
\text { de comunidades }\end{array}$ \\
\hline$G S_{1}$ & 100 & 555 & 50 & 50 & $V_{1}=4, V_{2}=4$ \\
$G S_{2}$ & 1000 & 6603 & 500 & 500 & $V_{1}=7, V_{2}=7$ \\
$G S_{3}$ & 2000 & 8482 & 1000 & 1000 & $V_{1}=12, V_{2}=12$ \\
$G S_{4}$ & 1819 & 23052 & 542 & 1277 & $V_{1}=3, V_{2}=5$ \\
\hline
\end{tabular}

Fonte: Dados da pesquisa.

Nota - GS é um acrônimo para Grafo Sintético.

\subsubsection{Questões analíticas e parâmetros de configuração}

O propósito da exploração dos grafos sintéticos é permitir que especialistas que trabalham com o paradigma multinível percebam como mudanças nas configurações impactam o grafo contraído resultante. A partir desse objetivo, consideram-se três questionamentos analíticos a serem respondidos: 
(Q1) É possível perceber como diferentes funções de distância afetam a preservação das estruturas de comunidade?

(Q2) É possível identificar em que momento no processo de pareamento vértices de diferentes comunidades são reunidos em um super-vértice?

(Q3) É possível observar o impacto do fator de redução escolhido na hierarquia de contrações?

Para responder aos questionamentos delineados, utilizaram-se configurações de execução do paradigma multinível descritas na Tabela 3. As configurações C.CN, C.Jac, C.AA e C.PA foram utilizadas para responder os questionamentos Q1 e Q2, e as configurações C.RF40, C.RF30, C.RF20 e C.RF10 para responder Q3.

As configurações C.CN, C.Jac, C.AA e C.PA são similares. O que varia são as quatro medidas de similaridade, respectivamente, "Vizinhos em Comum", "Jaccard", "Adamic Adar" e “Conexão Preferencial”. As outras quatro configurações, C.RF40, C.RF30, C.RF20 e C.RF10 adotam os seguintes parâmetros idênticos: algoritmo de pareamento $G M b$ e medida de similaridade "Vizinhos em comum". O fator de redução e o número de níveis variam, respectivamente, entre $40 \%$ e $3,30 \%$ e $5,20 \%$ e 7 e $10 \%$ e 16.

Tabela 3 - Lista de testes utilizados nos estudos de caso. Aqui, são definidos os parâmetros utilizados no arcabouço de Valejo et al. (2018) para a etapa de contração.

\begin{tabular}{|c|c|c|c|c|}
\hline Configuração & $\begin{array}{l}\text { Algoritmo de } \\
\text { pareamento }\end{array}$ & $\begin{array}{l}\text { Fator de } \\
\text { redução }\end{array}$ & $\begin{array}{l}\text { Número de } \\
\text { níveis }\end{array}$ & $\begin{array}{l}\text { Medida de } \\
\text { similaridade }\end{array}$ \\
\hline C.CN & $G M b$ & $r f_{1}=r f_{2}=50 \%$ & $l_{1}=l_{2}=3$ & $\begin{array}{l}\text { Vizinhos em } \\
\text { comum }\end{array}$ \\
\hline C.Jac & $G M b$ & $r f_{1}=r f_{2}=50 \%$ & $l_{1}=l_{2}=3$ & Jaccard \\
\hline C.AA & $G M b$ & $r f_{1}=r f_{2}=50 \%$ & $l_{1}=l_{2}=3$ & $\begin{array}{l}\text { Adamic } \\
\text { Adar }\end{array}$ \\
\hline C.PA & $G M b$ & $r f_{1}=r f_{2}=50 \%$ & $l_{1}=l_{2}=3$ & $\begin{array}{c}\text { Conexão } \\
\text { Preferencial }\end{array}$ \\
\hline C.RF40 & $G M b$ & $r f_{1}=r f_{2}=40 \%$ & $l_{1}=l_{2}=3$ & $\begin{array}{c}\text { Vizinhos em } \\
\text { Comum }\end{array}$ \\
\hline C.RF30 & $G M b$ & $r f_{1}=r f_{2}=30 \%$ & $l_{1}=l_{2}=5$ & $\begin{array}{l}\text { Vizinhos em } \\
\text { comum }\end{array}$ \\
\hline C.RF20 & $G M b$ & $r f_{1}=r f_{2}=20 \%$ & $l_{1}=l_{2}=7$ & $\begin{array}{l}\text { Vizinhos em } \\
\text { comum }\end{array}$ \\
\hline C.RF10 & $G M b$ & $r f_{1}=r f_{2}=10 \%$ & $l_{1}=l_{2}=16$ & $\begin{array}{l}\text { Vizinhos em } \\
\text { comum }\end{array}$ \\
\hline
\end{tabular}

Fonte: Dados da pesquisa. 


\subsubsection{Estruturas de comunidade (Q1)}

As configurações C.CN, C.Jac, C.AA e C.PA foram executadas em $G S_{1}$, resultando no grafo mais contraído com, em média, 7 super-vértices em cada uma das camadas, com 43 arestas, como visto nas Figuras 23 e 24. As cores mapeiam as comunidades dos vértices, conforme definido na Tabela 2, com quatro cores distintas para $G S_{1}$. As visualizações nas Figuras 23 e 24 permitem observar que C.CN, C.Jac (Figuras 23a e 23b) e C.AA (Figura 24a) construíram vértices intermediários similares, formando super-vértices, em sua maioria, compostos somente de vértices de uma mesma comunidade. Entretanto, em C.PA (Figura 24b), a medida de similaridade "conexão preferencial" acabou agrupando vértices de diferentes comunidades. Isso é característico dessa métrica de similaridade, que conforme discutido no Capítulo 2, vai agrupando vértices com seus vizinhos de maior grau.

Figura 23 - Resultados de execução de C.CN e C.Jac sobre $G S_{1}$. As cores representam as comunidades de cada vértice ou super-vértice. Exceto a métrica de similaridade, todos os grafos têm como parâmetros de contração $r f_{1}=r f_{2}=50 \%, l_{1}=l_{2}=3$ e algoritmo de pareamento $G M b$.

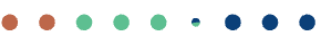

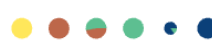

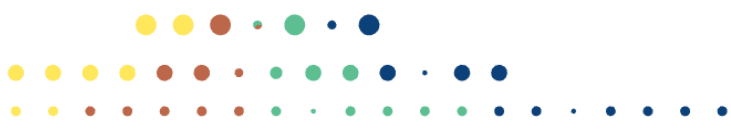

(a) C.CN, com medida de similaridade "Vizinhos em comum".

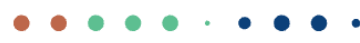

○

(b) C.Jac, com medida de similaridade "Jaccard".

Fonte: Elaborada pelo autor. 
Figura 24 - Resultados de execução de C.AA e C.PA sobre $G S_{1}$. As cores representam as comunidades de cada vértice ou super-vértice. Exceto a métrica de similaridade, todos os grafos têm como parâmetros de contração $r f_{1}=r f_{2}=50 \%, l_{1}=l_{2}=3$ e algoritmo de pareamento $G M b$.

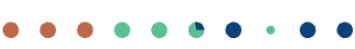

- $\odot$

(a) C.AA, com medida de similaridade "Adamic adar".

(b) C.PA, com medida de similaridade "Conexão preferencial".

Fonte: Elaborada pelo autor.

As configurações também foram executadas em $G S_{2}$, como mostram as Figuras 25 e 26. Para C.CN, C.Jac (Figuras 25a e 25b) e C.AA (Figura 26a), o nível mais contraído desse grafo resultou, em média, em 65 super-vértices em ambas as camadas, com mais de 600 arestas. Já para C.PA (Figura 26b), 65 super-vértices foram gerados, entretanto, permaneceram mais de 1800 arestas. Explorando o grafo, é possível perceber a diferença da quantidade de arestas, não mostradas nas figuras. As visualizações nas Figuras 25 e 26 permitem observar que a medida de similaridade que melhor preservou a estrutura de comunidades foi a "Adamic Adar", como visto na Figura 26a. Nas Figuras 25a e 25b, a visualização identifica super-vértices que agregam vértices de comunidades distintas, destacados com círculos vermelhos. Novamente, "conexão preferencial" foi a medida de similaridade que menos preservou estruturas de comunidade, como a visualização permite identificar na Figura 26 b. 
Figura 25 - Resultados de execução de C.CN e C.Jac sobre $G S_{2}$. As cores representam as comunidades de cada vértice ou super-vértice. Exceto a métrica de similaridade, todos os grafos têm como parâmetros de contração $r f_{1}=r f_{2}=50 \%, l_{1}=l_{2}=3$ e algoritmo de pareamento $G M b$.

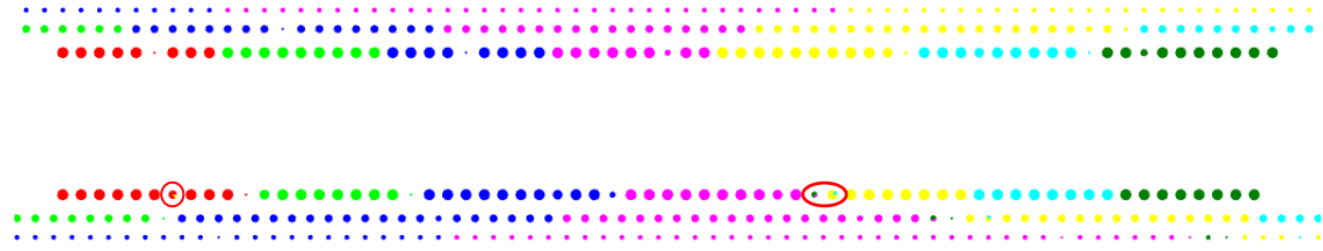

(a) C.CN, com medida de similaridade "Vizinhos em comum". Os contornos vermelhos indicam super-vértices contendo comunidades distintas.

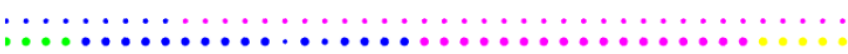

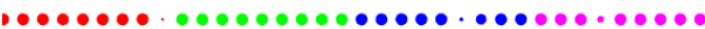

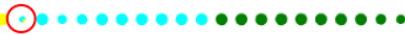

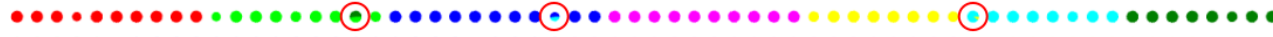

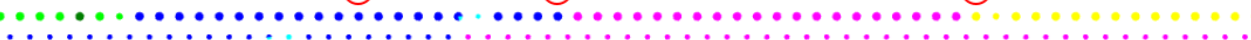

(b) C.Jac, com medida de similaridade "Jaccard". Os contornos vermelhos indicam super-vértices contendo comunidades distintas.

Fonte: Elaborada pelo autor.

Figura 26 - Resultados de execução de C.AA e C.PA sobre $G S_{2}$. As cores representam as comunidades de cada vértice ou super-vértice. Exceto a métrica de similaridade, todos os grafos têm como parâmetros de contração $r f_{1}=r f_{2}=50 \%, l_{1}=l_{2}=3$ e algoritmo de pareamento $G M b$.
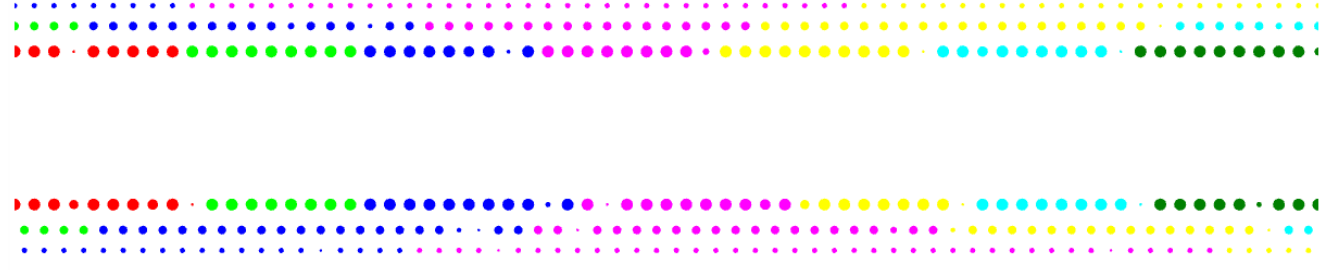

(a) C.AA, com medida de similaridade "Adamic adar".

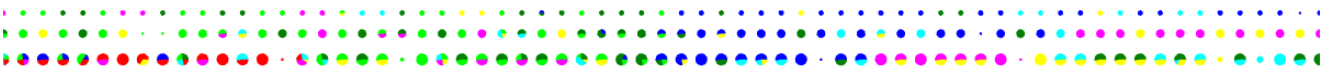

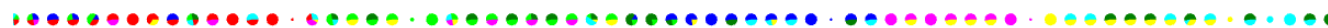

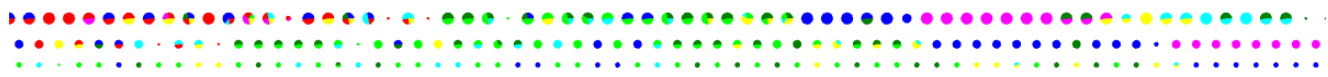

(b) C.PA, com medida de similaridade "Conexão preferencial".

Fonte: Elaborada pelo autor. 
$G S_{3}$ foi contraído com C.CN, C.Jac, C.AA e C.PA. O grafo, em seu nível mais contraído, resultou em média em 135 vértices para ambas as camadas, com mais de 1300 arestas para C.CN, C.Jac e C.AA. A quantidade de arestas na configuração C.PA, assim como em $G S_{2}$, foi maior, com cerca de 2700. A visualização resultante (não apresentada) é similar àquela obtida para $G S_{2}$. Para $G S_{4}$, aplicaram-se as 4 configurações anteriores. Na camada $V_{1}$, em média, obteve-se 69 vértices, e a camada $V_{2}$ produziu aproximadamente 230 vértices. C.CN, C.Jac e C.AA resultaram em cerca de 3600 arestas para o grafo mais contraído, porém C.PA resultou em 7477 arestas.

As Figuras 27 e 28 mostram o grafo mais contraído aplicando as configurações C.CN, C.Jac, C.AA e C.PA em $G S_{4}$. Em relação às medidas de similaridade, identifica-se o que foi abordado anteriormente: C.CN, C.Jac (Figuras 27a e 27b) e C.AA (Figura 28a) resultam em um grafo com super-vértices, em sua maioria, compostos de membros da mesma comunidade. C.PA (Figura 28b), por outro lado, resulta em super-vértices contendo elementos de comunidades distintas. A visualização também permite identificar que $G S_{4}$ tem quantidades distintas de comunidades para cada camada. Na Figura 27a, vê-se em $V_{1}$ (na parte inferior da imagem) vértices de 3 comunidades distintas, e em $V_{2}$, cujos vértices estão dispostos na parte superior, 8 . Mesmo na Figura 28b, na qual foi aplicada a medida de similaridade "conexão preferencial", é possível identificar somente 3 comunidades na camada $V_{1}$, e 8 na $V_{2}$.

Figura 27 - Resultados de execução de C.CN e C.Jac sobre $G S_{4}$. As cores representam as comunidades de cada vértice ou super-vértice. Exceto a métrica de similaridade, todos os grafos têm como parâmetros de contração $r f_{1}=r f_{2}=50 \%, l_{1}=l_{2}=3$ e algoritmo de pareamento $G M b$.

(a) C.CN, com medida de similaridade "Vizinhos em comum".

(b) C.Jac, com medida de similaridade "Jaccard".

Fonte: Elaborada pelo autor.

Avaliando o questionamento apresentado em Q1, a visualização permitiu, de fato, identificar quais métricas de similaridade são mais efetivas em preservar as estruturas de comunidade. 
Figura 28 - Resultados de execução de C.AA e C.PA sobre $G S_{4}$. As cores representam as comunidades de cada vértice ou super-vértice. Exceto a métrica de similaridade, todos os grafos têm como parâmetros de contração $r f_{1}=r f_{2}=50 \%, l_{1}=l_{2}=3$ e algoritmo de pareamento $G M b$.

(a) C.AA, com medida de similaridade "Adamic Adar".

(b) C.PA, com medida de similaridade "Conexão preferencial".

Fonte: Elaborada pelo autor.

\subsubsection{União de vértices com comunidades distintas (Q2)}

A Figura 29a exibe o resultado do $M O b$ com a configuração C.PA no grafo sintético $G S_{1}$. Como abordado no Capítulo 2, a característica da medida de similaridade "conexão preferencial" é agrupar os vértices de maior grau. Com a visualização, é possível perceber, logo no segundo nível da hierarquia de grafos contraídos, que os super-vértices agregam vértices de comunidades distintas. Já na Figura 29b, em que a configuração C.CN foi aplicada a $G S_{1}$, somente no quarto nível da hierarquia pode-se perceber a junção de vértices de comunidades diferentes.

Com isso, é possível identificar o estágio em que vértices de comunidades distintas se unem em um super-vértice. Isso é um apoio ao entendimento do funcionamento do paradigma, seus algoritmos de contração e métricas de similaridade. Outra conclusão que se pode obter, especialmente da Figura 29b, é que a visualização permite identificar em qual ponto a contração "força" a junção de vértices de diferentes comunidades. Com 3 níveis de contração, a configuração C.CN mantém os super-vértices quase que totalmente particionados, contendo somente vértices da mesma comunidade. Somente a partir do quarto nível o algoritmo começa a unir vértices de comunidades distintas.

\subsubsection{Variação do fator de redução (Q3)}

As configurações C.RF40, C.RF30, C.RF20 e C.RF10 foram inicialmente executadas em $G S_{1}$, gerando o grafo mais contraído apresentado na Figura 30. As cores mapeiam as comunidades de cada vértice, conforme definido na Tabela 2, com quatro cores distintas para $G S_{1}$. O fator de redução e número de níveis intermediários foram escolhidos para resultar em um grafo, no nível mais contraído, com aproximadamente 11 vértices. As visualizações permitem 
Figura 29 - Interação do usuário em $G S_{1}$. É possível identificar, com a estrutura hierárquica de visualização do paradigma multinível, em qual dos níveis vértices de comunidades distintas se uniram em um super-vértice.

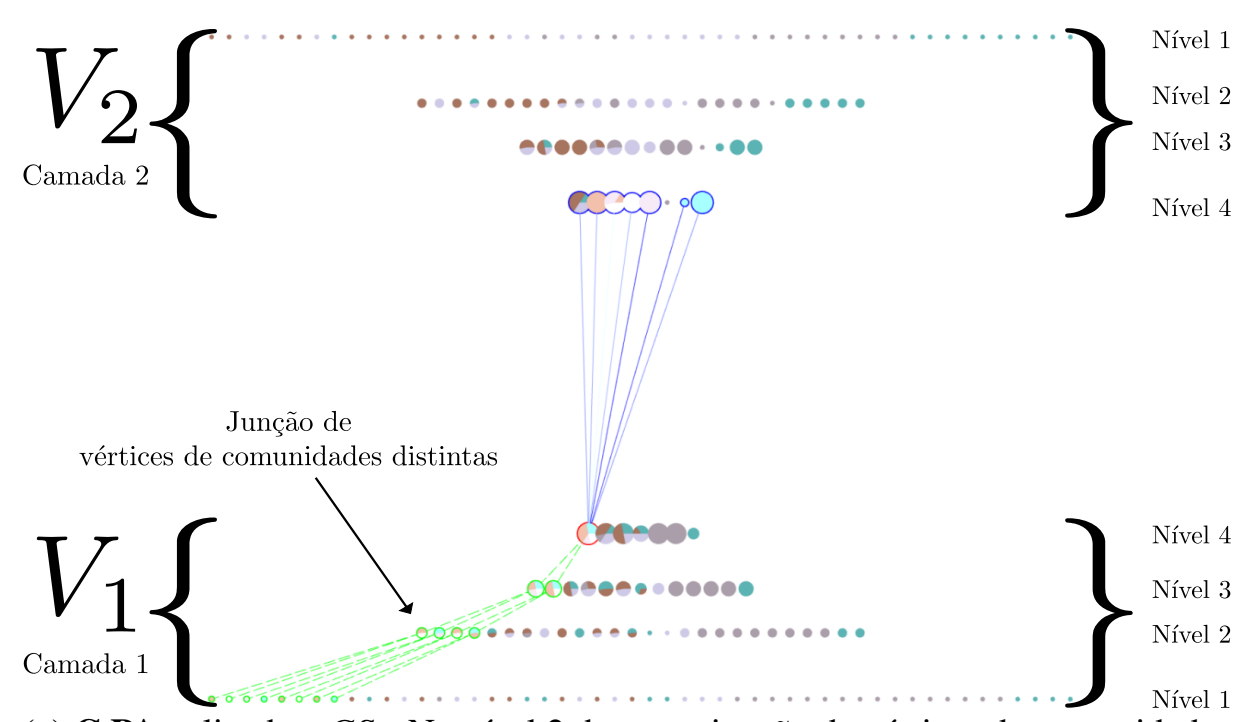

(a) C.PA aplicada a $G S_{1}$. No nível 2, houve a junção de vértices de comunidades distintas. Isso indica uma métrica de similaridade inadequada para esse tipo de grafo.

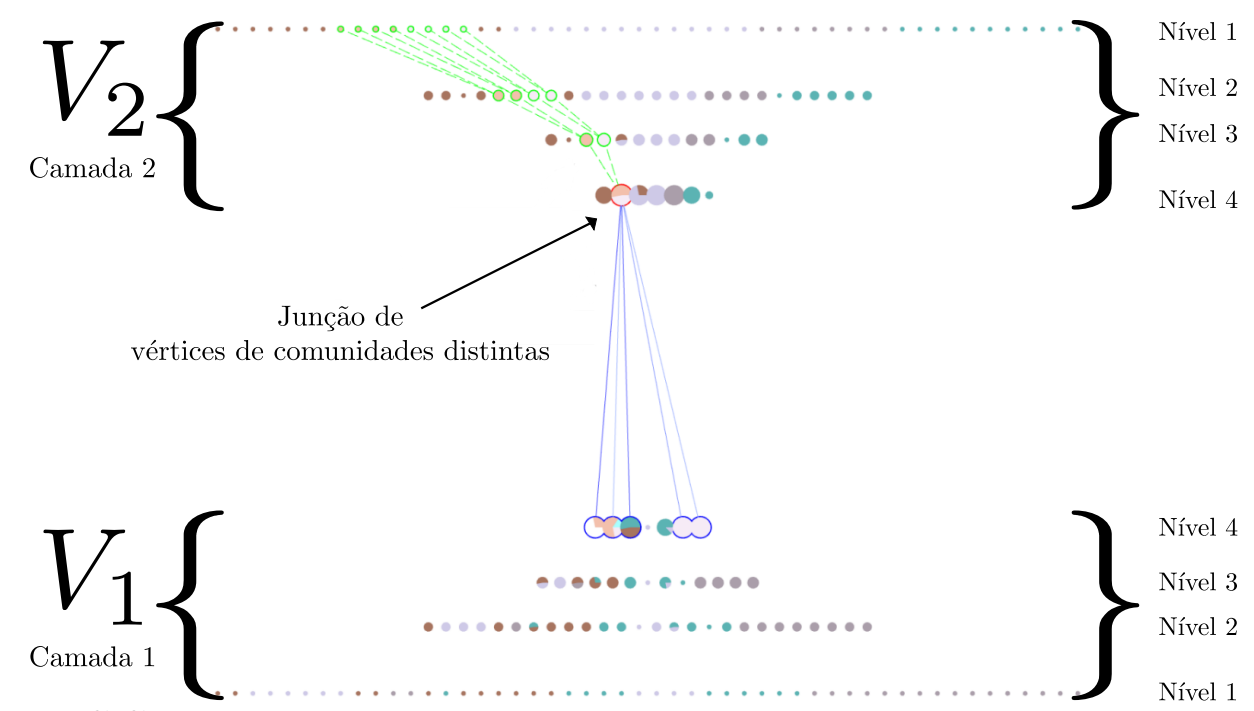

(b) C.CN aplicada a $G S_{1}$. No nível 4, houve a junção de vértices de comunidades distintas. Isso indica uma métrica de similaridade que preservou as estruturas de comunidades de um grafo.

Fonte: Elaborada pelo autor.

identificar um desbalanceamento nos super-vértices, pois quanto menor o fator de redução, mais super-vértices já existentes unem-se a outros vértices. Na Figura 30a, em que o fator de redução é 40\%, observa-se mais super-vértices gerados em comparação com a Figura 30d, em que o fator de redução é de $10 \%$.

As mesmas configurações foram aplicadas a $G S_{2}$, alterando o número de níveis interme- 
Figura 30 - Visualização do nível mais contraído resultante da execução de C.RF40, C.RF30, C.RF20 e C.RF10 sobre $G S_{1}$. As cores representam as comunidades de cada vértice ou super-vértice.

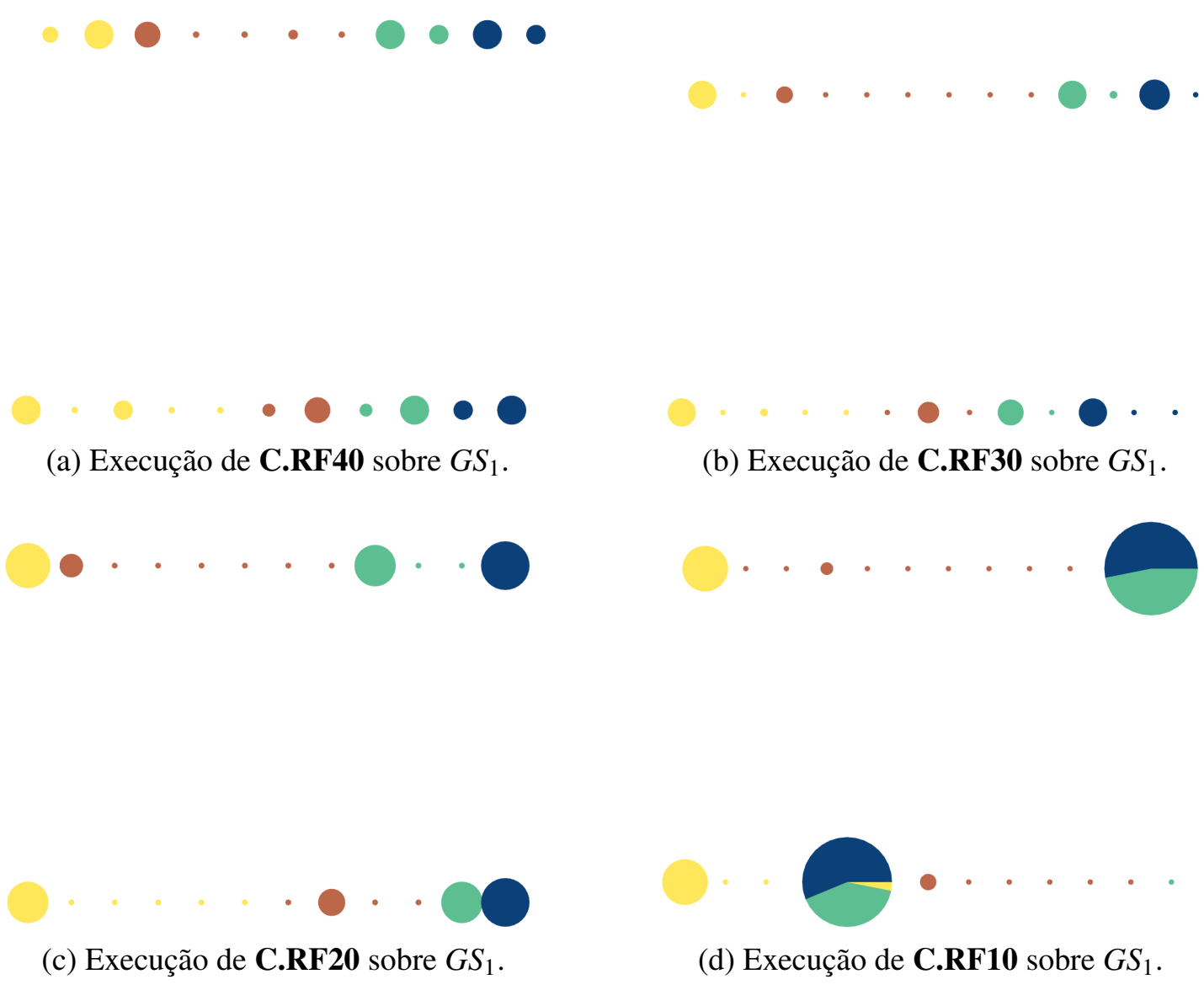

Fonte: Elaborada pelo autor.

diários para resultar em um grafo, no nível mais contraído, com aproximadamente 65 vértices. A Figura 31 ilustra as visualizações resultantes das configurações C.RF40, C.RF30, C.RF20 e C.RF10, utilizando 4, 6, 9 e 20 níveis intermediários, respectivamente. A visualização permite observar o desbalanceamento dos super-vértices identificados em $G S_{1}$. Na Figura 31d, por exemplo, identificam-se dois super-vértices em todo o grafo, contendo vértices de diferentes comunidades, destacados em vermelho. Na Figura 31b, tem-se o mesmo número de vértices no nível mais contraído, entretanto, observa-se a presença de mais super-vértices que contém vértices da mesma comunidade, destacados em vermelho.

Aplicando os parâmetros de configuração para $G S_{3}$ e $G S_{4}$, observam-se resultados similares aos obtidos com $G S_{2}$. Em especial, em $G S_{3}$, para produzir um grafo mais contraído com 47 vértices, alterou-se o número de níveis intermediários nos parâmetros: C.RF40 produziu 6 níveis, C.RF30 produziu 9, C.RF20 produziu 14 e C.RF10, 31. Em relação a Q3, as conclusões obtidas com a interpretação da visualização são duas. A primeira é que, quanto menor o fator de redução, maior o desbalanceamento dos grafos contraídos, que têm poucos super-vértices contendo muitos vértices, como é observado nas Figuras $30 \mathrm{~d}$ e $31 \mathrm{~d}$. A outra é que quanto maior 
Figura 31 - Resultados da execução de C.RF40, C.RF30, C.RF20 e C.RF10 sobre $G S_{2}$. As cores representam as comunidades de cada vértice ou super-vértice.

(a) Execução de C.RF40 sobre $G S_{2}$. A quantidade de níveis foi alterada para 4.

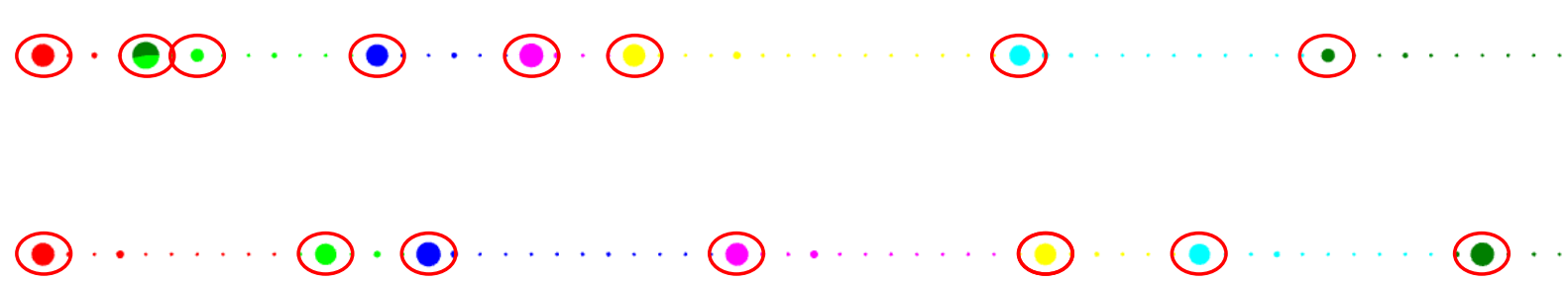

(b) Execução de C.RF30 sobre $G S_{2}$. A quantidade de níveis foi alterada para 6. Os super-vértices estão destacados em vermelho.

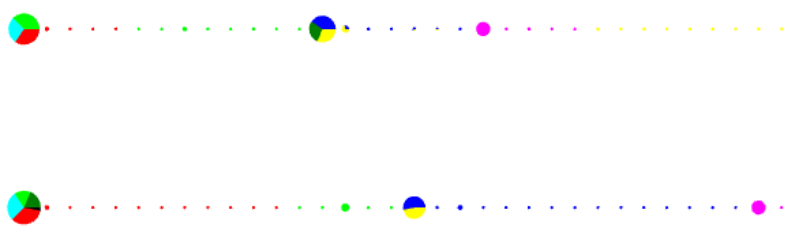

(c) Execução de C.RF20 sobre $G S_{2}$. A quantidade de níveis foi alterada para 9.

(d) Execução de C.RF10 sobre $G S_{2}$. A quantidade de níveis foi alterada para 20. Os super-vértices estão destacados em vermelho.

Fonte: Elaborada pelo autor.

a quantidade de vértices de um grafo e menor o fator de redução, mais níveis intermediários são necessários para reduzir o número de vértices. Para atingir 47 vértices no nível mais contraído de $G S_{3}$, utilizando um fator de redução de $10 \%$, foi necessário produzir 31 níveis intermediários. Para $G S_{1}$, que é um grafo com 100 vértices, foram necessários apenas 16 níveis para um fator de redução de $10 \%$. 


\subsection{Resultados em aplicações do mundo real}

Essa Seção descreve estudos complementares realizados com os conjuntos de dados reais, descritos na Seção 5.2.1. O objetivo desses estudos de caso é investigar como o paradigma multinível permite navegar por diferentes agregações dos dados, aplicando diferentes parâmetros de configuração. Como os vértices dessas aplicações têm dados associados, considera-se o super-vértice como um possível agrupamento de dados, induzido pelo método multinível. Assim, nas seções seguintes, os termos "super-vértice" e "agrupamento" são utilizados com o mesmo significado. Esses agrupamentos também são explorados com as visualizações complementares do MObViewer, descritas no Capítulo 4.

\subsubsection{Dados de aplicações do mundo real}

Foram utilizados três conjuntos de dados reais. O primeiro é uma coleção de filmes e usuários da plataforma Movie Lens ${ }^{2}$, extraído de <https://grouplens.org/datasets/movielens/1m/ $>$, em que em $V_{1}$ tem-se o conjunto de usuários e em $V_{2}$ os filmes cadastrados no sistema. A aresta indica uma avaliação entre 0 a 5 que um determinado usuário fez de um filme. Esse conjunto de dados possui atributos associados aos vértices. A camada de usuários tem os atributos sexo, idade e profissão. Já os filmes têm seu título e seu gênero. Devido a limitações da ferramenta, abordadas no Capítulo 6, foi feita uma amostragem no grafo original, que continha 9923 vértices e 1000209 arestas, para 7933 vértices e 60400 arestas. Essa redução do conjunto consistiu em remover aleatoriamente vértices e arestas, tanto da camada de usuários como da camada de filmes, e extrair o maior componente conexo.

Já o segundo conjunto de dados é uma coleção de documentos investigadas anteriormente (PAULOVICH; MINGHIM, 2006; PAULOVICH et al., 2008) e disponível em $<$ http://vicg.icmc.usp.br/vicg/tool/7/data-sets-from-papers $>$. Os documentos coletados abrangem quatro disciplinas, sendo essas Case-Based Reasoning (CBR), Inductive Logic Programming (ILP), Information Retrieval (IR) e Sonification (SON) . O conjunto $V_{1}$ desse grafo bipartido constitui-se do título dos documentos científicos, contendo como atributo a disciplina correspondente. Já $V_{2}$ foi modelado como um conjunto de termos, e toda a aresta existente conectando $V_{1}$ a $V_{2}$ indica a frequência de um termo em um determinado documento, ou o TF-IDF (WARD; GRINSTEIN; KEIM, 2015). O conjunto de termos passou por um pré-processamento, gerando uma bag-of-words. Essa sequência de passos incluiu a remoção de stopwords, lematização e aplicação do corte de Luhn (LUHN, 1958), mantendo somente os termos mais relevantes, totalizando 2863 termos e 675 documentos.

O conjunto de dados IEEEVis, disponibilizado por (Isenberg et al., 2017), é uma coleção de artigos publicados nas conferências de visualização pela IEEE, entre 1990 e 2018, e contém múltiplos atributos, como data de publicação, autores, lista de referências e lista de palavras-

$2<$ https://grouplens.org/datasets/movielens/> 
chave. Foi gerado um grafo bipartido em que uma camada dos vértices corresponde aos autores, com os atributos nome e universidade. A outra corresponde aos artigos científicos, tendo como atributos o título, data da publicação, e conferência da publicação. O grafo totalizou 7952 vértices e 10221 arestas. Entretanto, para garantir um correto funcionamento do algoritmo MLP, considerou-se a maior componente conexa do IEEEVis, resultando em um grafo com 6297 vértices e 8874 arestas.

Algumas ferramentas de visualização foram desenvolvidas para navegar nesse conjunto de dados, sendo uma delas o VisLists ${ }^{3}$. Essa visualização permite descobrir mais sobre os autores, suas publicações, principais conferências e co-autores (STEINBöCK, 2018). A Figura 32 ilustra um exemplo do funcionamento do VisLists.

Figura 32 - Visualização do sistema VisLists. Tem-se três colunas que representam autores, conferência e ano de publicação. A célula em amarelo indica o elemento selecionado. Os autores indicados em cor laranja são coautores. Nas outras colunas, os elementos alaranjados identificam a principal conferência e período de publicação do autor selecionado. Os números sobrescritos indicam a quantidade de artigos publicados pelo autor, e a barra horizontal preta indica a porcentagem de ocorrências daquele elemento presente no conjunto de dados.

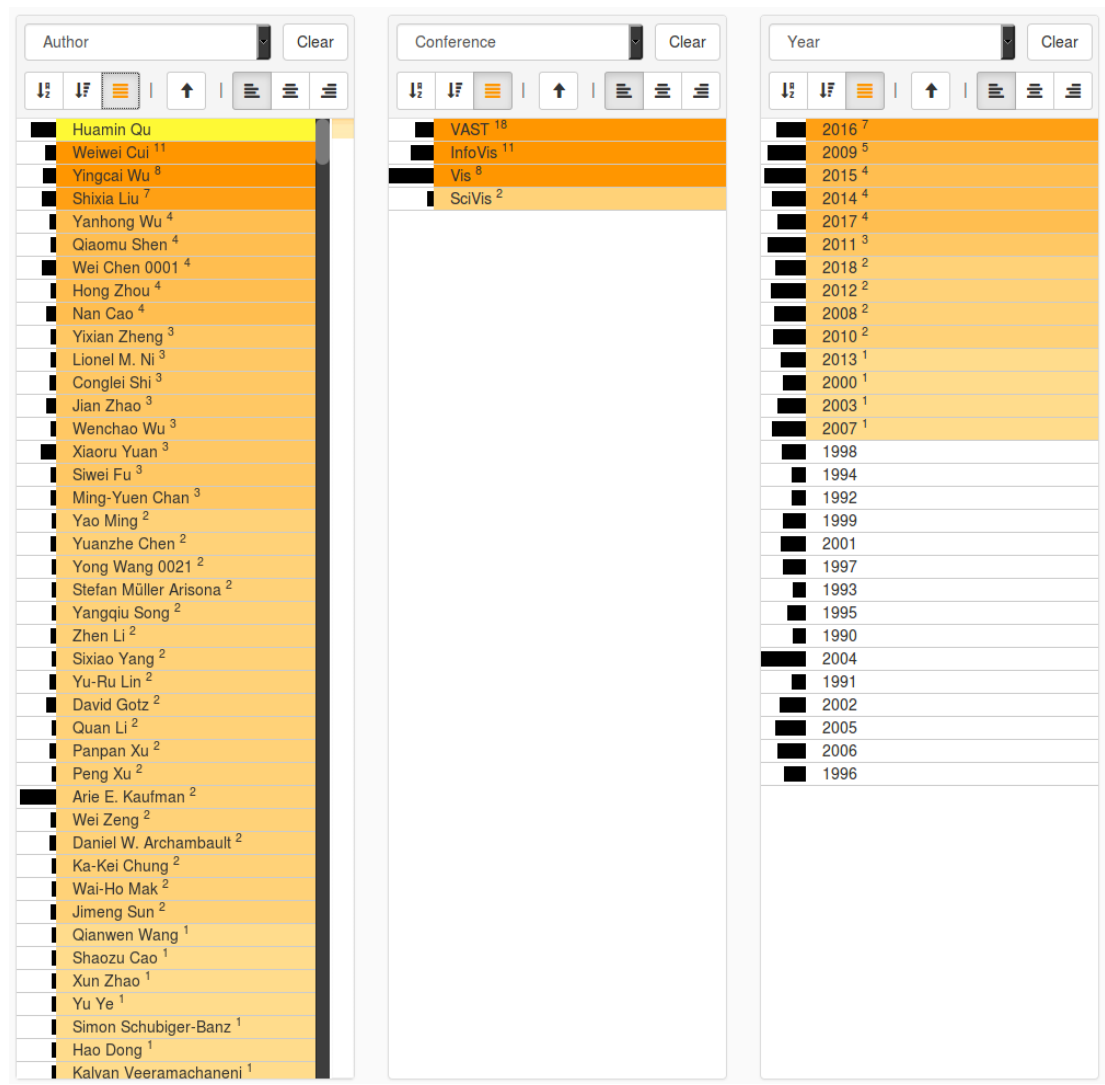

Fonte: Elaborada pelo autor.

A Tabela 4 resume as informações dos conjuntos de dados de aplicações do mundo real.

3 Disponível em <http://www.iilabgt.org/vislists/>. 
Tabela 4 - Informações sobre conjuntos de dados do mundo real utilizados para estudos de caso.

\begin{tabular}{l|c|c|c|c}
\hline Nome & $\begin{array}{c}\text { Número } \\
\text { de vértices }\end{array}$ & $\begin{array}{c}\text { Número } \\
\text { de arestas }\end{array}$ & $\begin{array}{c}\text { Camada } \\
V_{1}\end{array}$ & $\begin{array}{c}\text { Camada } \\
V_{2}\end{array}$ \\
\hline Movie Lens & 7933 & 60400 & 6040 & 1893 \\
Documento-termos & 3538 & 94280 & 675 & 2863 \\
IEEEVis & 6297 & 8874 & 3919 & 2378 \\
\hline
\end{tabular}

Fonte: Dados da pesquisa.

\subsubsection{Parâmetros de configuração}

Para permitir uma exploração visual dos conjuntos de dados, quatro configurações de execução foram definidas, apresentadas na Tabela 5.

A configuração C.MLP.100-100.10, descrita na primeira linha, utiliza o algoritmo $M L P$ para contração dos vértices. Consequentemente, outros parâmetros de entrada são requeridos, conforme discutido no Capítulo 2: o número mínimo de vértices e o número de iterações. Nesse caso, foi definido 100 super-vértices, em ambas as camadas, no nível mais contraído, e a quantidade de iterações foi fixada em 10. Na configuração C.MLP.20-20.1, o MLP também foi empregado, mas nessa situação resultando em 20 super-vértices com 1 iteração. Essas duas parametrizações foram escolhidas para explorar a natureza dos super-vértices gerados pelo algoritmo $M L P$, do ponto de vista da agregação dos dados.

Já as configurações C.GMB.3-3.50-50 e C.GMB.5-5.30-30 utilizam o algoritmo $G M b$, variando apenas o fator de redução e o número de níveis: enquanto C.GMB.3-3.50-50 gera 3 níveis com 50\% de redução em ambas as camadas, C.GMB.5-5.30-30 gera 5 níveis, com 30\% de redução, também para ambas as camadas.

Tabela 5 - Lista de configurações utilizadas nos estudos de caso de aplicações do mundo real.

\begin{tabular}{c|c|c|c|c|c|c}
\hline & $\begin{array}{c}\text { Algoritmo } \\
\text { de pareamento }\end{array}$ & $\begin{array}{c}\text { Fator de } \\
\text { redução }\end{array}$ & $\begin{array}{c}\text { Número de } \\
\text { níveis }\end{array}$ & $\begin{array}{c}\text { Medida de } \\
\text { similaridade }\end{array}$ & $\begin{array}{c}\text { Número de } \\
\text { vértices final }\end{array}$ & $\begin{array}{c}\text { Número de } \\
\text { iterações }\end{array}$ \\
\hline C.MLP.100-100.10 & $M L P$ & - & - & $\begin{array}{c}\text { Vizinhos } \\
\text { em comum }\end{array}$ & $\begin{array}{c}V_{1}=100, \\
V_{2}=100\end{array}$ & 10 \\
\hline C.MLP.20-20.1 & $M L P$ & - & - & $\begin{array}{c}\text { Vizinhos } \\
\text { em comum }\end{array}$ & $\begin{array}{c}V_{1}=20, \\
V_{2}=20\end{array}$ & 1 \\
\hline C.GMB.3-3.50-50 & $G M b$ & $l_{1}=3$, & $r f_{1}=50 \%$, & $\begin{array}{c}\text { Vizinhos } \\
\text { em comum }\end{array}$ & - & - \\
& & $l_{2}=3$ & $r f_{2}=50 \%$ & - & - \\
\hline C.GMB.5-5.30-30 & $G M b$ & $l_{1}=5$, & $r f_{1}=30 \%$, & $\begin{array}{c}\text { Vizinhos } \\
\text { em comum }\end{array}$ & - & \\
& & $l_{2}=5$ & $r f_{2}=30 \%$ & & & \\
\hline
\end{tabular}

Fonte: Dados da pesquisa. 


\subsubsection{IEEEVis}

A Figura 33a mostra parte do nível mais contraído resultante da aplicação da configuração C.MLP.100-100.10, gerando 100 agrupamentos em cada camada, que são os autores (na parte inferior) e artigos (parte superior). Define-se um histograma de frequências para os atributos "conferência" e "ano" na camada de artigos, e codifica-se o atributo "conferência" seguindo a tabela de cores categórica vista na Figura 34. Explorando a base de dados, é possível identificar super-vértices com mais elementos na camada de autores, destacados em vermelho na Figura 33a . Selecionando alguns super-vértices na camada de artigos, explora-se, com o auxílio dos histogramas de frequência e as cores dos super-vértices, a distribuição dos artigos por conferência bem como a distribuição temporal das publicações. Observando a hierarquia na Figura 33b, identificam-se coleções de artigos cuja maioria foi publicada nas conferências "Vis", "InfoVis" e "VAST", coloridas em azul escuro, verde e azul claro, respectivamente.

A Figura 35 mostra a hierarquia resultante do método multinível com a configuração C.MLP.20-20.1, que gerou 20 agrupamentos no nível mais contraído. Definindo o atributo "autor" na nuvem de palavras, identifica-se "Jean-Daniel Fekete" como um dos pesquisadores com mais artigos publicados no "InfoVis", fato confirmado com VisLists, que aponta dezenove artigos publicados pelo autor. Explorando super-vértices que contém, na sua maioria, artigos publicados no "InfoVis", é possível identificar, com uma nuvem de palavras, os principais autores como "Tamara Munzner", "Jean-Daniel Fekete" e "Jeffrey Heer”. Selecionando esses autores no VisLists, encontram-se seus principais coautores, como visto em (A) e (B). As nuvens de palavras permitem identificar os coautores de um pesquisador de maneira similar ao VisLists, pois nota-se que os nomes nas nuvens de palavras (destacados em retângulos vermelhos) são similares aos exibidos no VisLists (também destacados em retângulos vermelhos).

Os parâmetros de configuração C.GMB.3-3.50-50 foram aplicados para reduzir o conjunto de dados IEEEVis, resultando na hierarquia de grafos contraídos vista na Figura 36(A). No nível mais contraído, tem-se um grafo com uma coleção de 899 autores e 452 artigos, totalizando 1800 arestas. A visualização permite identificar o impacto da mudança do algoritmo de pareamento no agrupamento dos dados. Utilizando o algoritmo GMb, visualizam-se coleções de artigos, em sua maioria, publicados na conferência "SciVis" (vermelho escuro), destacados por círculos azuis. Explorando esses super-vértices com nuvens de palavras, identificam-se "Valerio Pascucci", "Hamish Carr" e "Timo Ropinski" como os autores com maior frequência de publicação na "SciVis", vistos na Figura 36(B). Utilizando o VisLists, identificam-se esses mesmos autores como os que mais contribuíram nessa conferência, destacados por retângulos vermelhos na Figura 37.

A Figura 38 mostra o resultado da redução multinível aplicando a configuração C.GMB.55.30-30, gerando, no nível mais contraído, 660 vértices na camada de autores, 401 artigos e aproximadamente 1440 arestas. Em comparação com a hierarquia resultante da configuração C.GMB.3-3.50-50 ilustrada na Figura 39, a visualização permite observar a presença de me- 
Figura 33 - Visualizações parciais do grafo mais contraído e a hierarquia resultantes da aplicação da configuração C.MLP.100-100.10 sobre o IEEEVis.

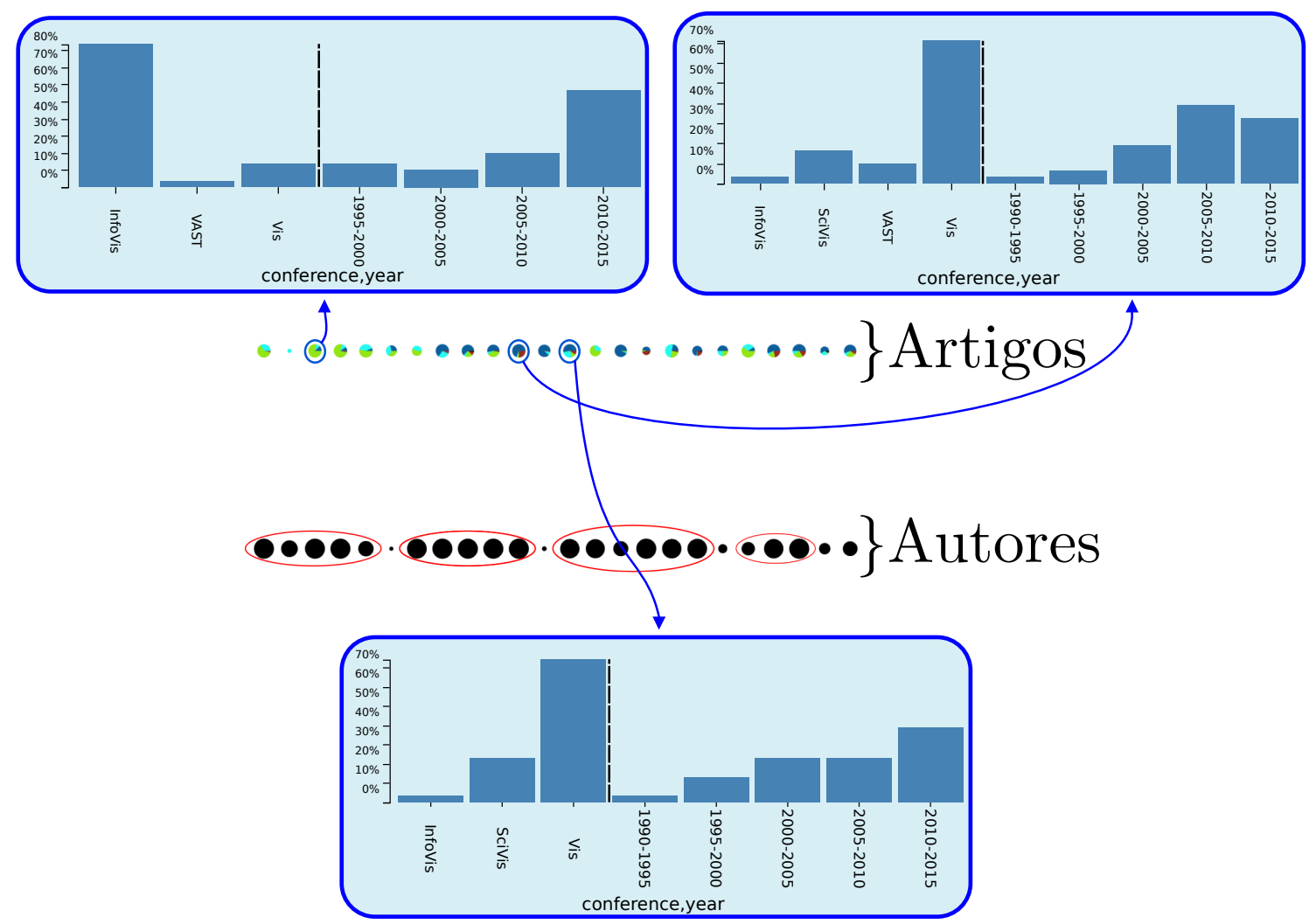

(a) Visualização de uma parte do grafo mais contraído do IEEEVis, resultante da aplicação da configuração C.MLP.100-100.10. Os círculos vermelhos indicam super-vértices com maior quantidade de elementos, e os histogramas de frequência mostram os atributos dos vértices selecionados.

(b) Visão parcial da hierarquia resultante da aplicação da configuração C.MLP.100-100.10 sobre o IEEEVis.

Fonte: Elaborada pelo autor.

nos super-vértices, característicos do desbalanceamento identificado na questão analítica Q3 da Seção 5.1.5. Os super-vértices resultantes contém, em sua maioria, artigos publicados nas 3 conferências "Vis", "InfoVis" e "VAST". Explorando a hierarquia, a visualização permite identificar a união de coleções de artigos de diferentes conferências, destacados na Figura 38(A). É possível, também, verificar quais os autores mais frequentes ao longo dessa hierarquia, como 
Figura 34 - Legenda de cores dos vértices no conjunto de dados IEEEVis. A cor preta identifica vértices com valor ausente do atributo (Unknown).

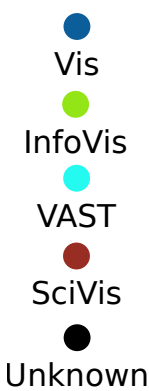

Fonte: Elaborada pelo autor.

Figura 35 - Visão parcial da hierarquia resultante da aplicação da configuração C.MLP.20-20.1 sobre o IEEEVis. (A) e (B) identificam as nuvens de palavras dos vizinhos de super-vértices selecionados, mostrando os autores com maior quantidade de publicações no "InfoVis". Os autores e coautores são comparados com a ferramenta VisLists, sendo os similares destacados em vermelho.

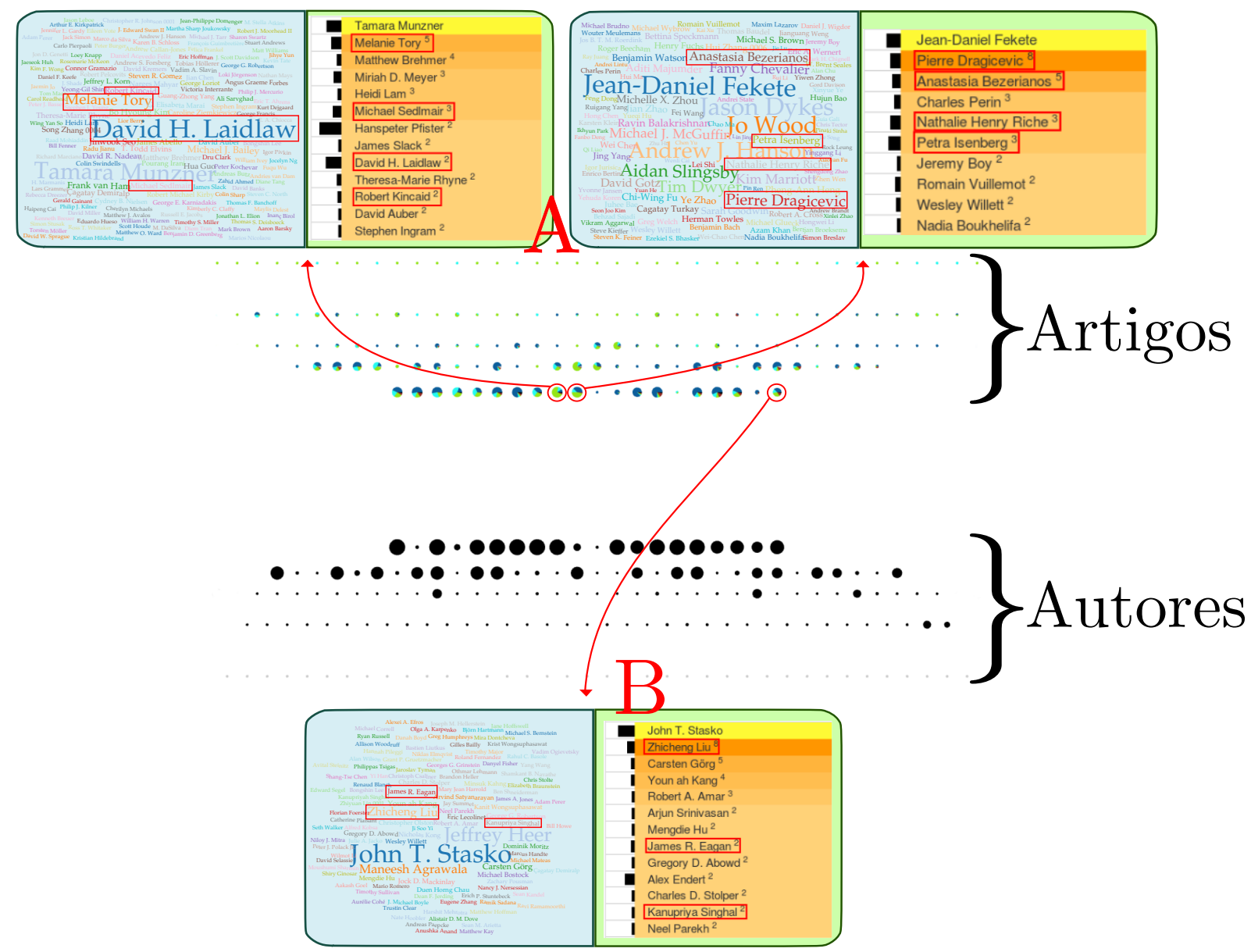

Fonte: Elaborada pelo autor.

ilustrado nas nuvens de palavras da Figura 38(B). 
Figura 36 - Visão parcial da hierarquia resultante da aplicação da configuração C.GMB.3-3.50-50 sobre IEEEVis. Em (A), vê-se a hierarquia resultante. Em (B), nuvens de palavras de super-vértices selecionados ilustram os autores mais relevantes em agrupamentos contendo a maioria de artigos pertencentes à conferência "SciVis".

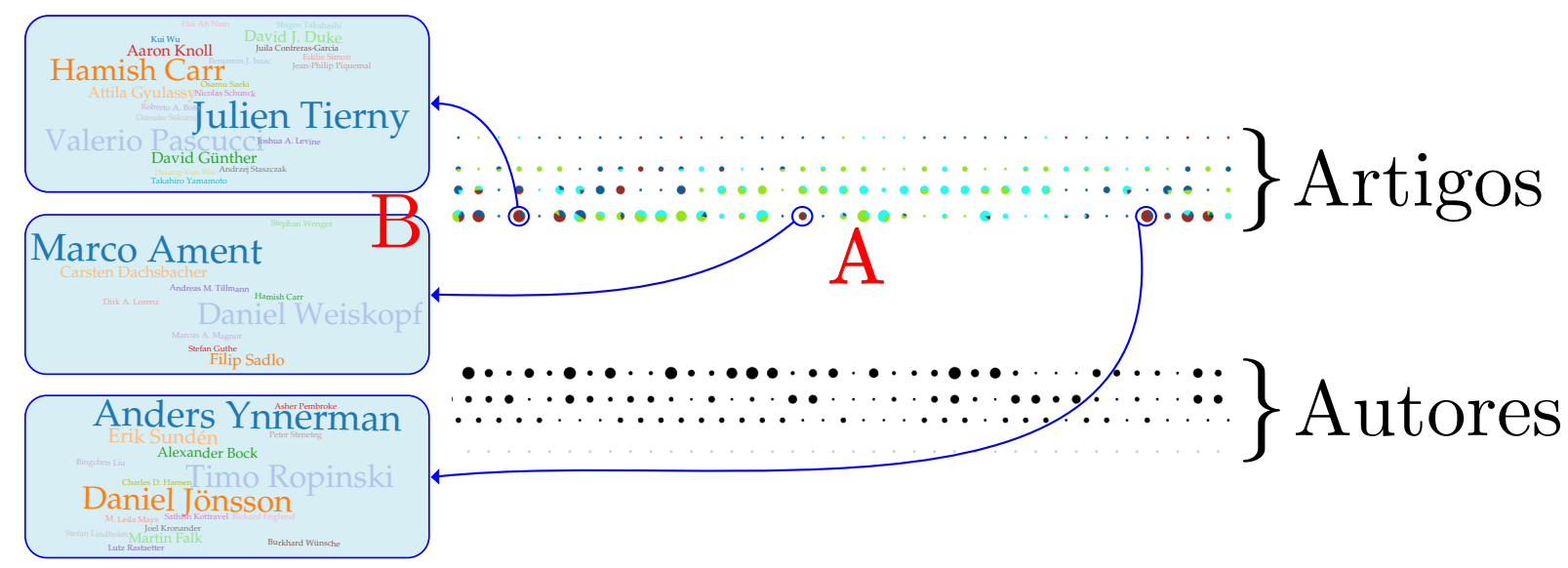

Figura 37 - Interação na ferramenta VisLists para a conferência "SciVis", mostrando os principais autores dessa conferência, destacados em retângulos vermelhos.

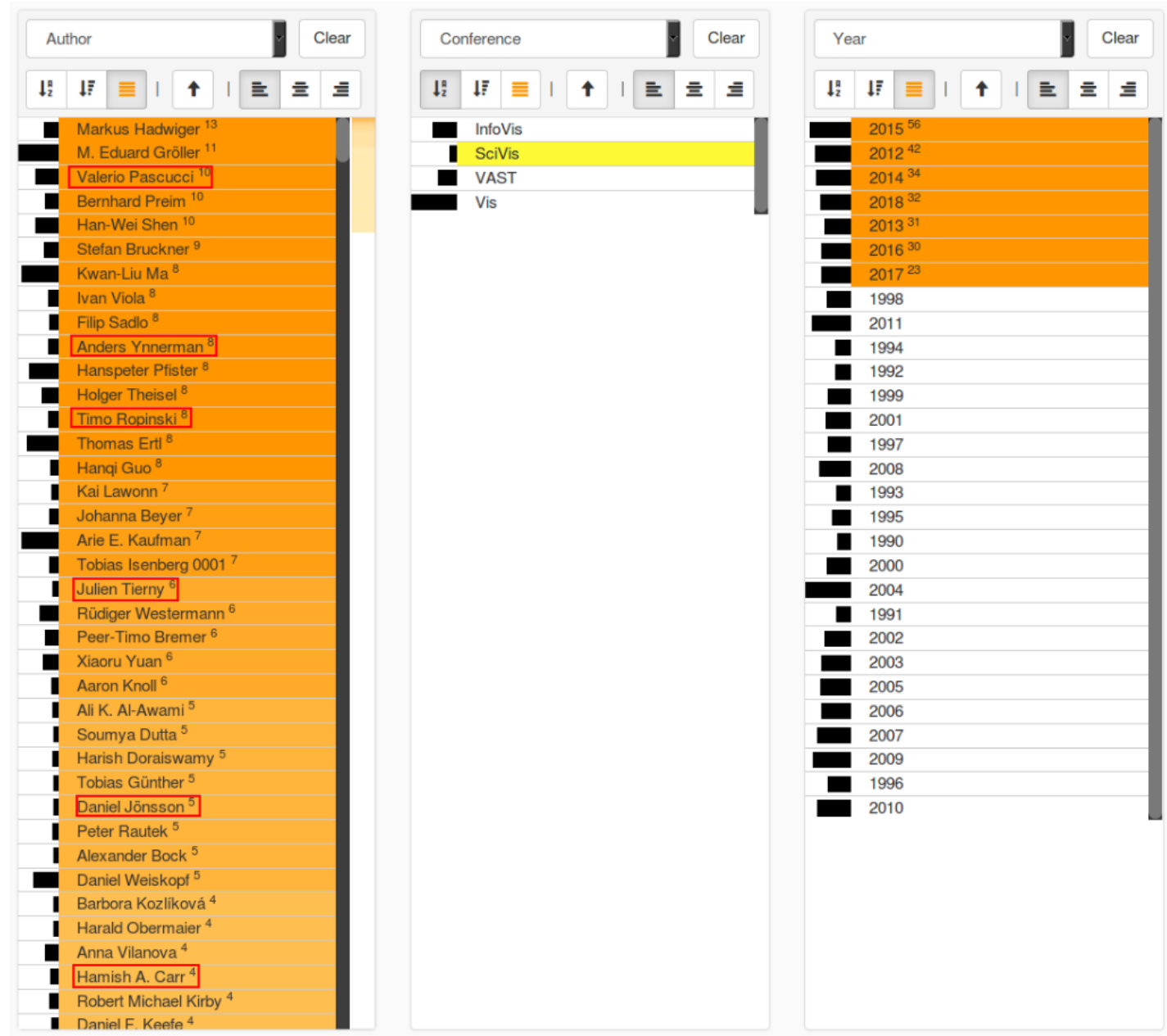


Figura 38 - Visão parcial da hierarquia resultante da aplicação da configuração C.GMB.5-5.30-30 sobre o IEEEVis. Em (A), identificam-se a união de coleções de artigos publicados em diferentes conferências. (B) mostra as nuvens de palavras resultantes dos vizinhos dos super-vértices na hierarquia selecionados, e destacados em azul. Observa-se que a nuvem de palavras do nível mais contraído contém nomes dos autores dos níveis anteriores, como "Anna Vilanova" e "Eduard Gröller".

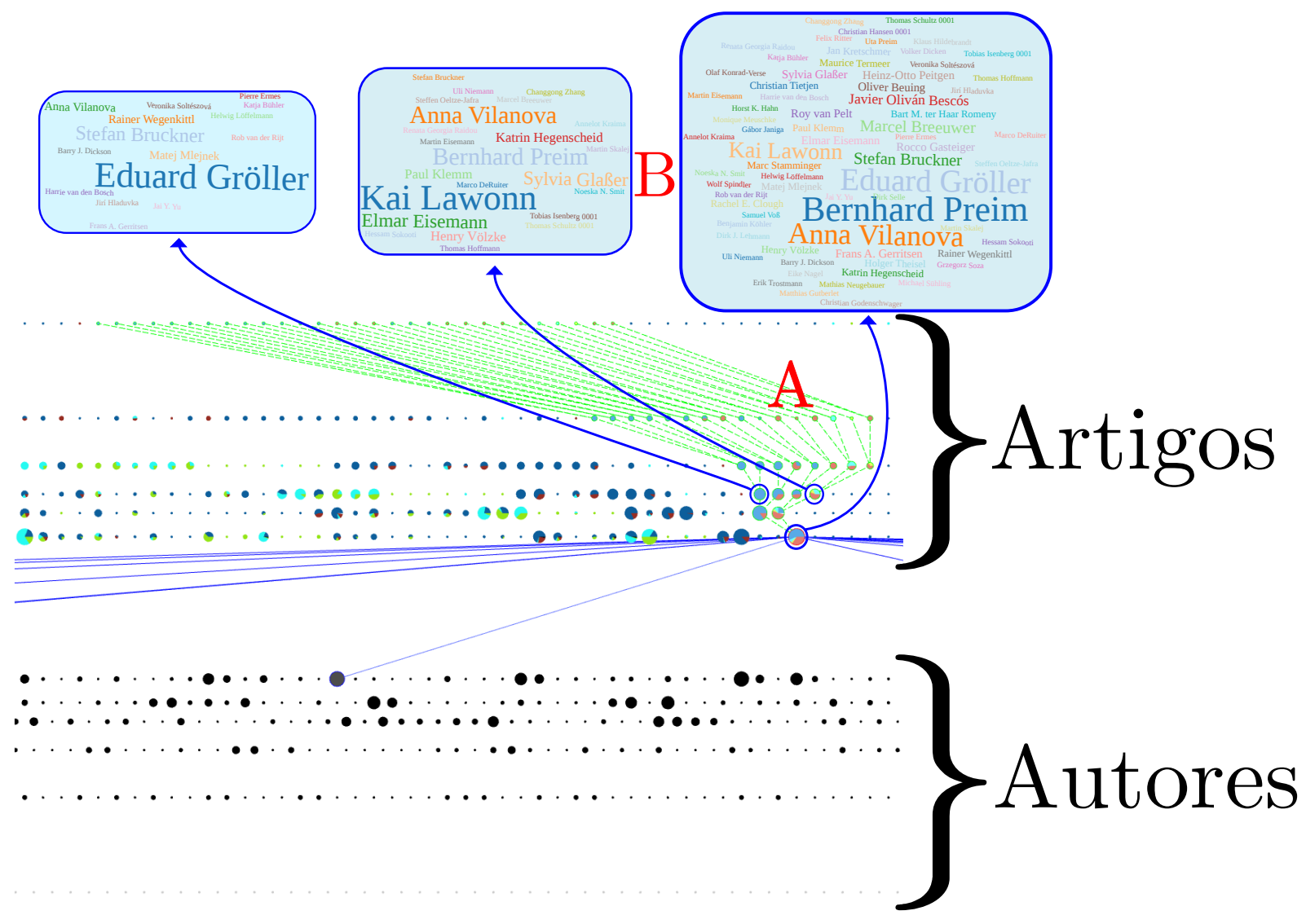

Figura 39 - Visão parcial da hierarquia resultante da aplicação da configuração C.GMB.3-3.50-50 sobre o IEEEVis.

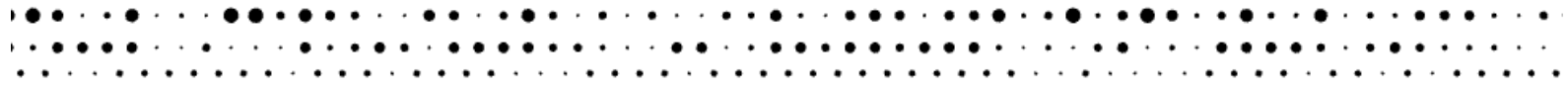

\subsubsection{Documento-termos}

No conjunto de documentos e termos, a camada na parte inferior identifica os títulos dos artigos científicos, tendo como atributo a disciplina associada. A outra camada, na parte superior, identifica o conjunto de termos. A Figura 41 mostra a hierarquia resultante da aplicação 
da configuração C.MLP.100-100.10 sobre o conjunto de documento-termos, gerando no nível mais contraído 100 agrupamentos em cada camada. Observa-se que o paradigma multinível com o pareamento "MLP” gerou apenas 1 nível de contração. Codifica-se o atributo "disciplina" na camada de títulos dos artigos, seguindo a tabela de cores categórica apresentada na Figura 40. Essa tabela de cores permite identificar, na visualização, que os super-vértices de artigos contém, em média, 10 documentos de disciplinas distintas. Definindo o atributo "termo" na nuvem de palavras, explora-se a camada de artigos, identificando as palavras mais frequentes em diferentes super-vértices, como exemplificado na Figura 41.

Figura 40 - Legenda de cores para os vértices no conjunto de dados documento-termos. A cor preta identifica vértices que não possuem valor para o atributo (Unknown).

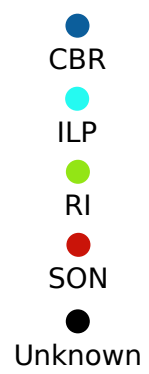

Figura 41 - Visão parcial do da hierarquia de contrações resultantes da aplicação da configuração C.MLP.100-100.10 sobre o conjunto de documento-termos. É possível perceber na camada de artigos (parte inferior) que super-vértices contém documentos de disciplinas distintas. Também identificam-se nuvens de palavras dos vizinhos dos super-vértices selecionados, ilustrando os termos mais frequentes.

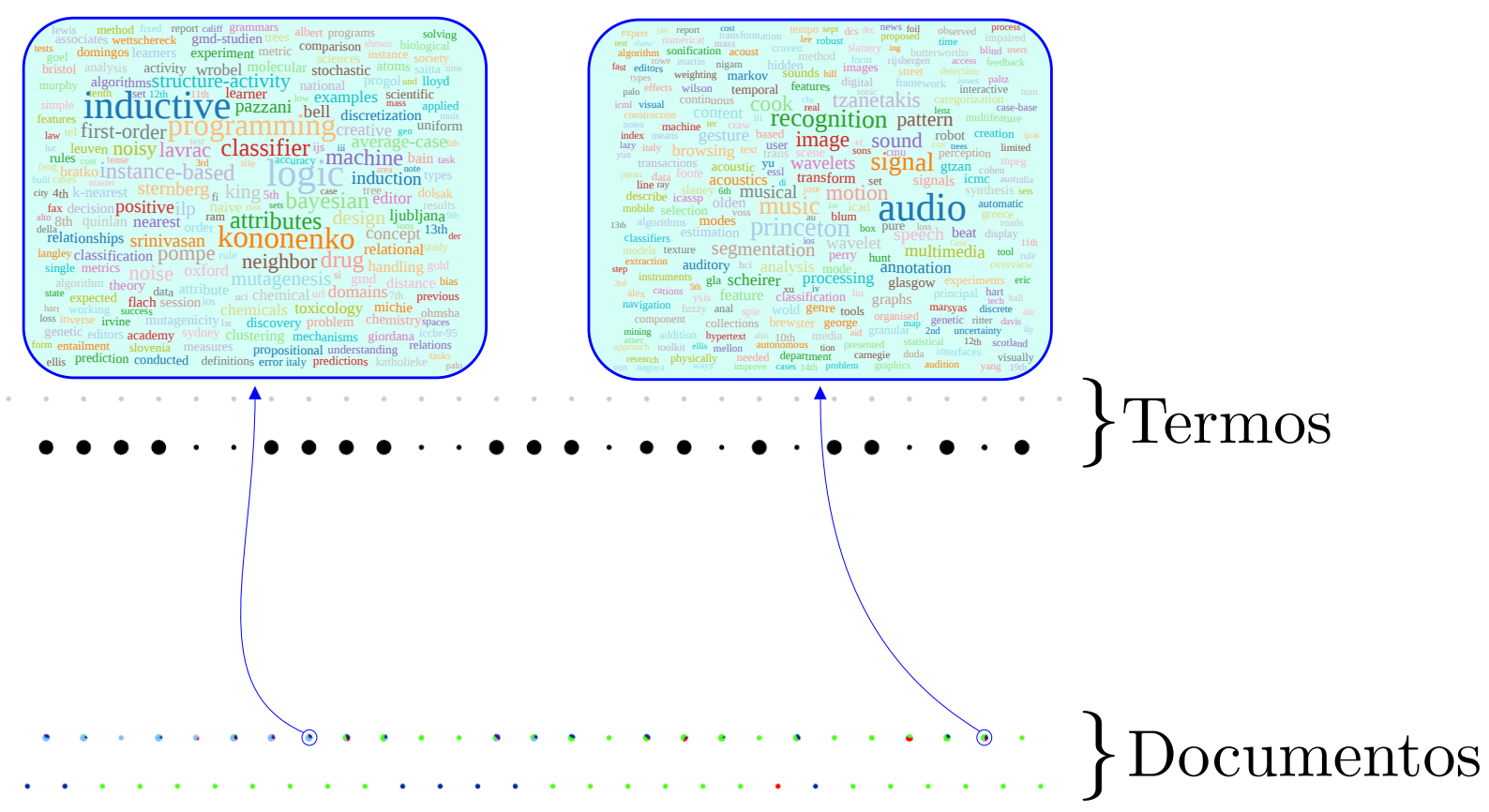

A Figura 42a mostra a visualização parcial da hierarquia resultante da aplicação da configuração C.MLP.20-20.1 sobre o conjunto de documento-termos, gerando no nível mais contraído 20 agrupamentos para cada camada. É possível observar que a visualização é similar 
a da Figura 41, obtida com a configuração C.MLP.100-100.1, salvo a criação de 2 níveis de hierarquia. Isso acontece pois o número de vértices final é 20, em cada camada, e a quantidade de iterações, 1. Explorando a hierarquia, a visualização mostra super-vértices, no nível mais contraído, resultantes da união de muitos ou poucos vértices, como ilustrado nas Figuras 42b e $42 \mathrm{c}$, respectivamente.

Com a configuração C.GMB.3-3.50-50, obtém-se a hierarquia exibida na Figura 43, onde o grafo mais contraído contém 85 elementos na camada de artigos e 355 super-vértices na camada de termos, totalizando cerca de 17700 arestas. A visualização dá ao usuário diversas informações. Observando o gráfico de setores codificado segundo a tabela de cores categórica da Figura 40, a visualização permite identificar super-vértices que agruparam, em sua maioria, artigos da mesma disciplina, como visto em (A). Explorando os super-vértices, identifica-se, no nível mais contraído, uma média de 8 artigos por super-vértice, como mostra (B). Analisando a hierarquia, é possível identificar super-vértices formados da união de artigos de disciplinas diferentes, ilustrado em (C). Selecionando os super-vértices na hierarquia pode-se observar suas nuvens de palavras, que exibem os termos mais frequentes nos diferentes grupos, como visto em (D).

Os super-vértices destacados na Figura 43(B) incluem artigos de diferentes disciplinas. Explorando as coleções com nuvens de palavras, visualizadas em maior detalhe na Figura 44, percebe-se alguns termos relevantes aos dois contextos. Na Figura 44(A), em que o super-vértice selecionado contém artigos das áreas de "CBR" e "RI", tem-se termos como clustering, multidimensional e estimation, pertinentes à área de recuperação da informação ("RI"). astronomical surge aqui como um dos termos de maior relevância, pois alguns dos documentos têm como referências áreas de astronomia, em que a recuperação de informação foi utilizada. A nuvem de termos do super-vértice selecionado na Figura 44(B), com as disciplinas "RI" e "SON", contém termos frequentes como audio, sound, music e signal, comuns à área de Sonificação. Analisando o resumo dos artigos de Recuperação de Informação, infere-se que eles são relacionados a área de recuperação de informação na música, caracterizando forte associação com a área de Sonificação.

Por fim, a Figura 45 mostra a visualização da hierarquia resultante quando aplica-se a configuração C.GMB.5-5.30-30. No nível mais contraído, tem-se 115 coleções de artigos, 478 termos e cerca de 10387 arestas. A visualização identifica grafos contraídos com supervértices desbalanceados e com menos super-vértices do que a configuração C.GMB.3-3.50-50 (Figura 44). Isso é característico da aplicação do algoritmo $G M b$ com um fator de redução baixo (30\%). Explorando os super-vértices, encontram-se alguns com mais de 30 documentos, bem como aqueles contendo somente elementos da mesma disciplina. Explorando super-vértices com publicações de mais de uma disciplina, é possível verificar sua hierarquia e o nível em que duas coleções de disciplinas distintas se uniram, como aponta o super-vértice circulado em (A). Em (B), a nuvem de palavras identifica os termos mais frequentes de uma disciplina, que no 
Figura 42 - Resultados da execução de C.MLP.20-20.1 sobre o conjunto de dados documento-termos.

(a) Resultado da visualização (parcial) da configuração C.MLP.20-20.1 sobre o conjunto de dados documento-termos. Com o atributo "disciplina" codificado como cor dos supervértices, identificam-se agrupamentos que contém documentos de disciplinas distintas.

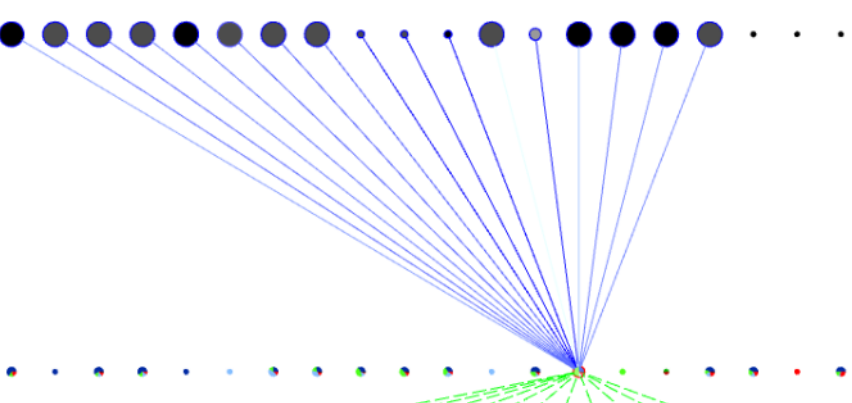

(b) Explorando a hierarquia de vértices contraídos, identifica-se um super-vértice resultante da união de 11 super-vértices do nível anterior, destacados em vermelho.

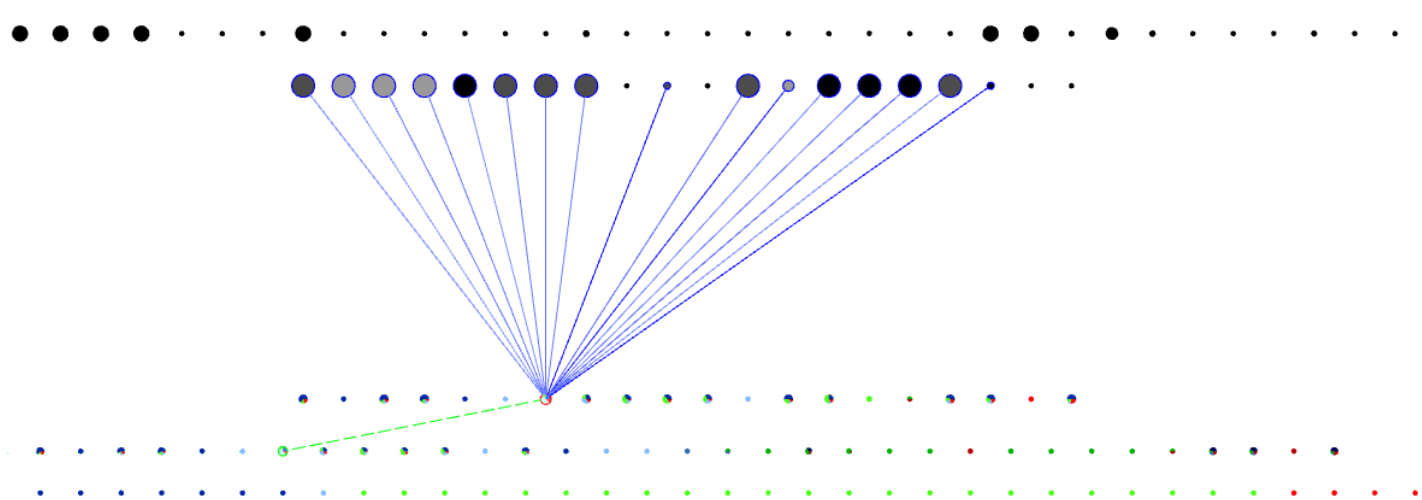

(c) Explorando a hierarquia de vértices contraídos, identifica-se um super-vértice que não resultou do pareamento com nenhum outro elemento no nível anterior.

Fonte: Elaborada pelo autor.

super-vértice selecionado, é "ILP”. 
Figura 43 - Visão parcial da hierarquia de contrações resultantes da aplicação da configuração C.GMB.33.50-50 sobre o conjunto de documento-termos. (A) mostra, no nível mais contraído, supervértices contendo artigos da mesma disciplina, de acordo com a escala de cores. (B) mostra os vértices contidos em um determinado elemento, sendo "subject" o atributo "disciplina" e "title" o título do artigo. Em (C), identifica-se na hierarquia vértices com disciplinas distintas unindose em um super-vértice. (D) mostra as nuvens de palavras dos vizinhos de super-vértices selecionados nessa hierarquia.

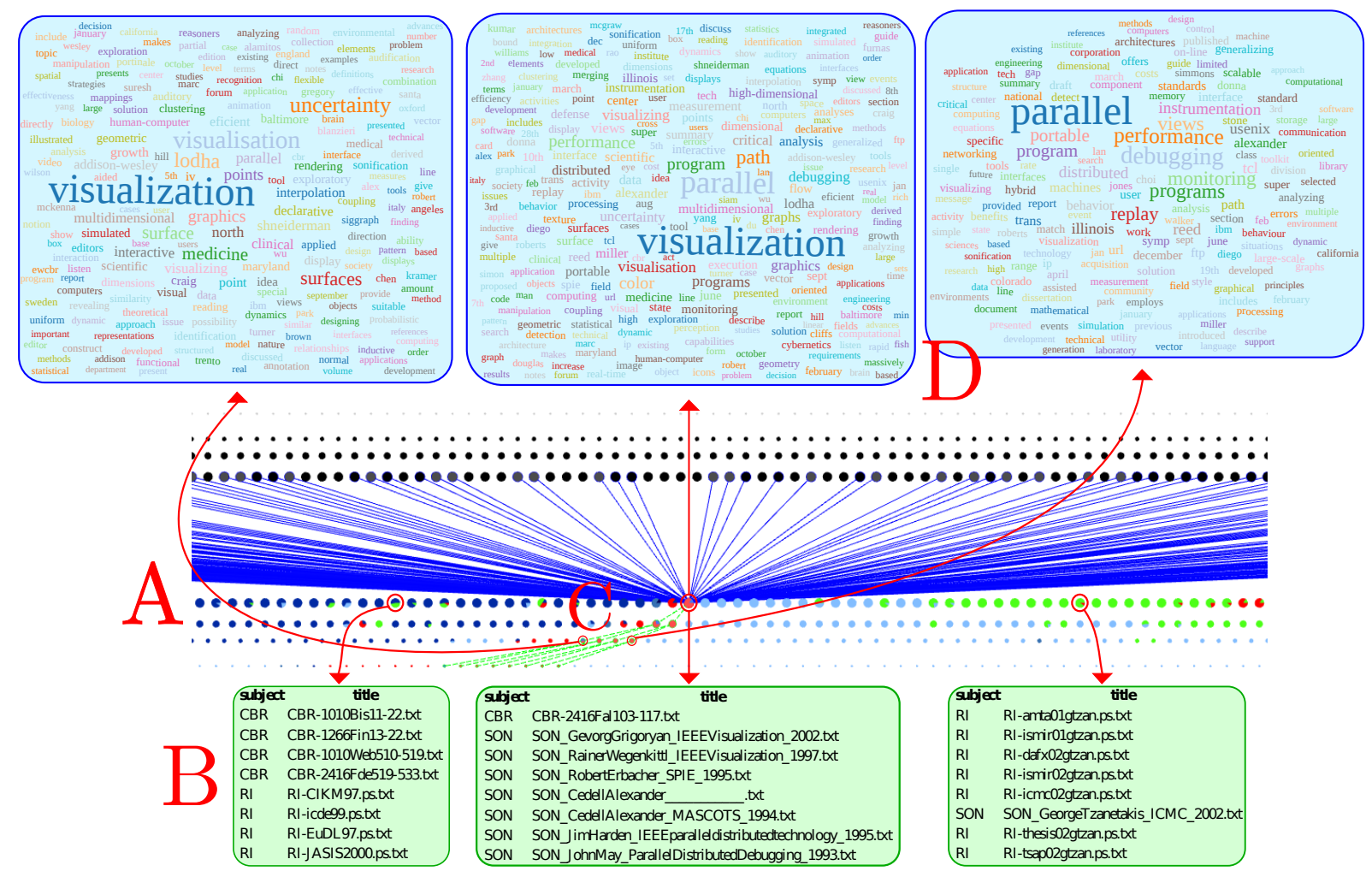

\subsubsection{Movie Lens}

Este conjunto de dados foi explorado com foco em identificar se os super-vértices definem grupos que capturaram algum perfil de usuário ou preferências por filmes específicos. Inicialmente, a visualização da Figura 47 mostra o nível mais contraído de um grafo resultante da aplicação do paradigma multinível com a configuração C.MLP.100-100.10, utilizando o algoritmo de pareamento MLP e produzindo, no nível mais contraído, 100 agrupamentos em cada camada e cerca de 4300 arestas. Na camada inferior estão os usuários com seus atributos, e na camada superior, filmes e seus respectivos gêneros. Codificam-se os atributos "profissão" e "idade" da camada de usuários no histograma de frequências, e define-se "sexo", também da mesma camada, como atributo codificado por cor, respeitando a tabela de cores categórica da Figura 46. A visualização permite identificar, com o auxílio das cores, que a maioria dos usuários é do sexo masculino. Na Figura 47(A), com o auxílio dos histogramas, infere-se que grande parte dos usuários têm idade entre 25-35 anos, e que os usuários agrupados têm profissões distintas, o que não evidencia um tipo de perfil de acordo com a preferência por filmes e profissões. 
Figura 44 - Visão parcial da hierarquia de contrações resultantes da aplicação da configuração C.GMB.33.50-50 sobre o conjunto de documento-termos. (A) mostra a nuvem de palavras dos vizinhos de um super-vértice contendo artigos das disciplinas "CBR" e "RI". (B) mostra a nuvem de palavras de termos das disciplinas "RI" e "SON".
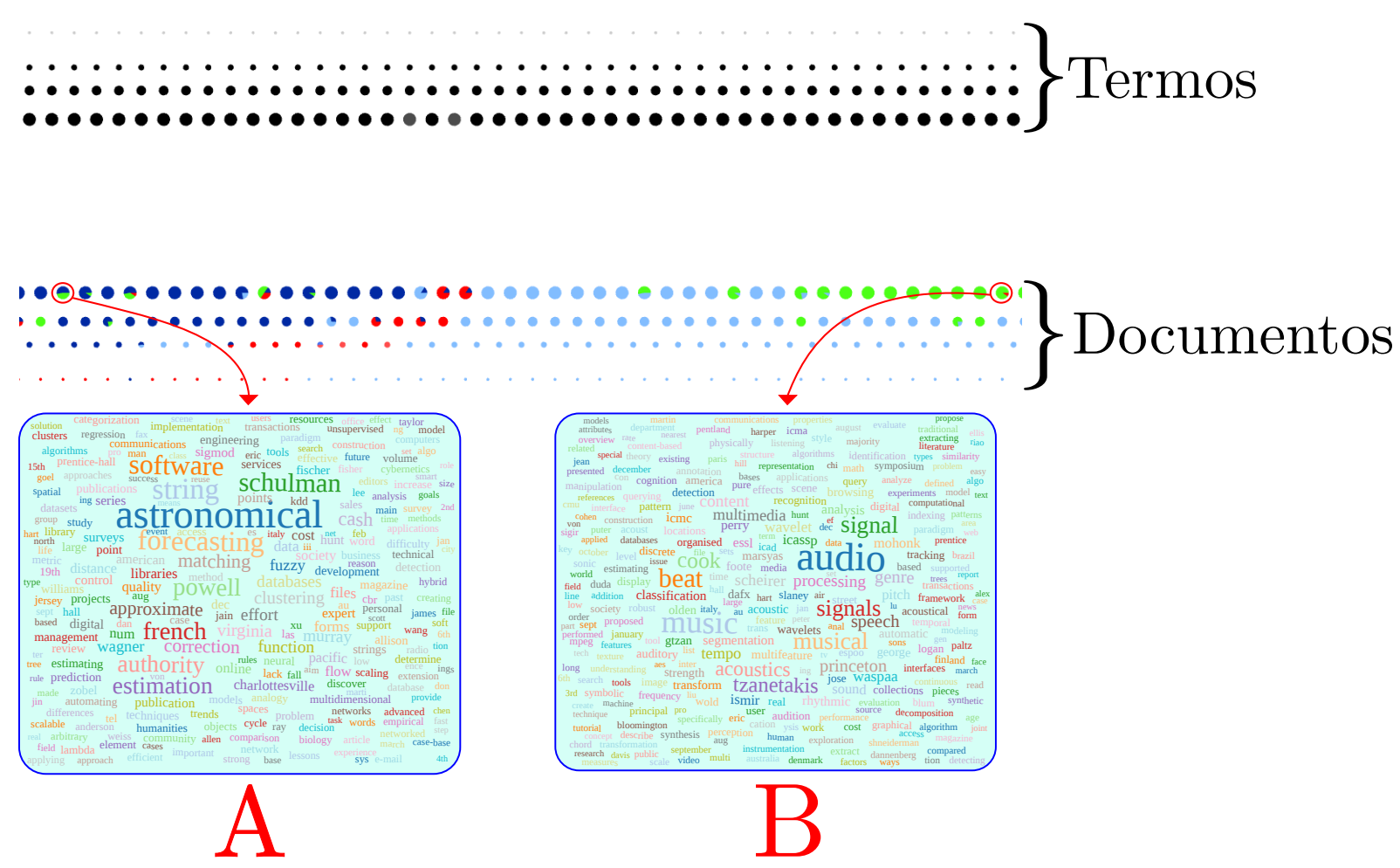

A Figura 48 mostra a hierarquia resultante da configuração C.MLP.20-20.1 aplicada sobre o conjunto de dados Movie Lens, produzindo 20 agrupamentos em cada camada. $\mathrm{O}$ atributo "gênero" é utilizado na nuvem de palavras, buscando identificar coleções de filmes de mesmo gênero. Observa-se, pela visualização da hierarquia, que foram criados poucos supervértices. Exploram-se as coleções de usuários na camada inferior com o auxílio do histograma de frequências e a nuvem de palavras, destacadas em (A). Com a primeira visualização, identificamse coleções onde a maioria dos usuários têm entre 25-35 anos. Nas nuvens de palavras, é possível ver os gêneros dos filmes mais populares, que são "drama", "comédia" e "ação".

A visualização da Figura 49 mostra o nível mais contraído do conjunto de dados Movie Lens, após aplicar a configuração C.GMB.3-3.50-50, utilizando $G M b$ como algoritmo de pareamento. No nível mais contraído, observam-se 760 coleções de usuários, 430 de filmes e cerca de 15000 arestas. Observa-se a presença de vários super-vértices, que em média contém 8 elementos. É possível identificar perfis de usuários mais específicos. Em (A), por exemplo, o histograma de frequências identifica um grupo de usuários cuja maioria têm idades entre 18-44 anos, com preferência por filmes do gênero "Animação", conforme a nuvem de palavras mostra. Já em (B), o histograma mostra usuários de 25 anos ou mais que têm preferência por filmes de "Aventura”, "Ação", "Comédia”, "Drama”, "Western” e "Thriller”, vistos na nuvem de palavras correspondente. 
Figura 45 - Visão parcial da hierarquia de contrações resultantes da aplicação da configuração C.GMB.55.30-30 sobre o conjunto de documento-termos. A visualização permite identificar o desbalanceamento de super-vértices. (A) mostra a hierarquia de vértices que, em um determinado nível, uniu vértices com conteúdos de disciplinas distintas em um único super-vértice, destacado em vermelho. (B) mostra, com uma nuvem de palavras, os principais termos de um super-vértice com artigos da disciplina "ILP".

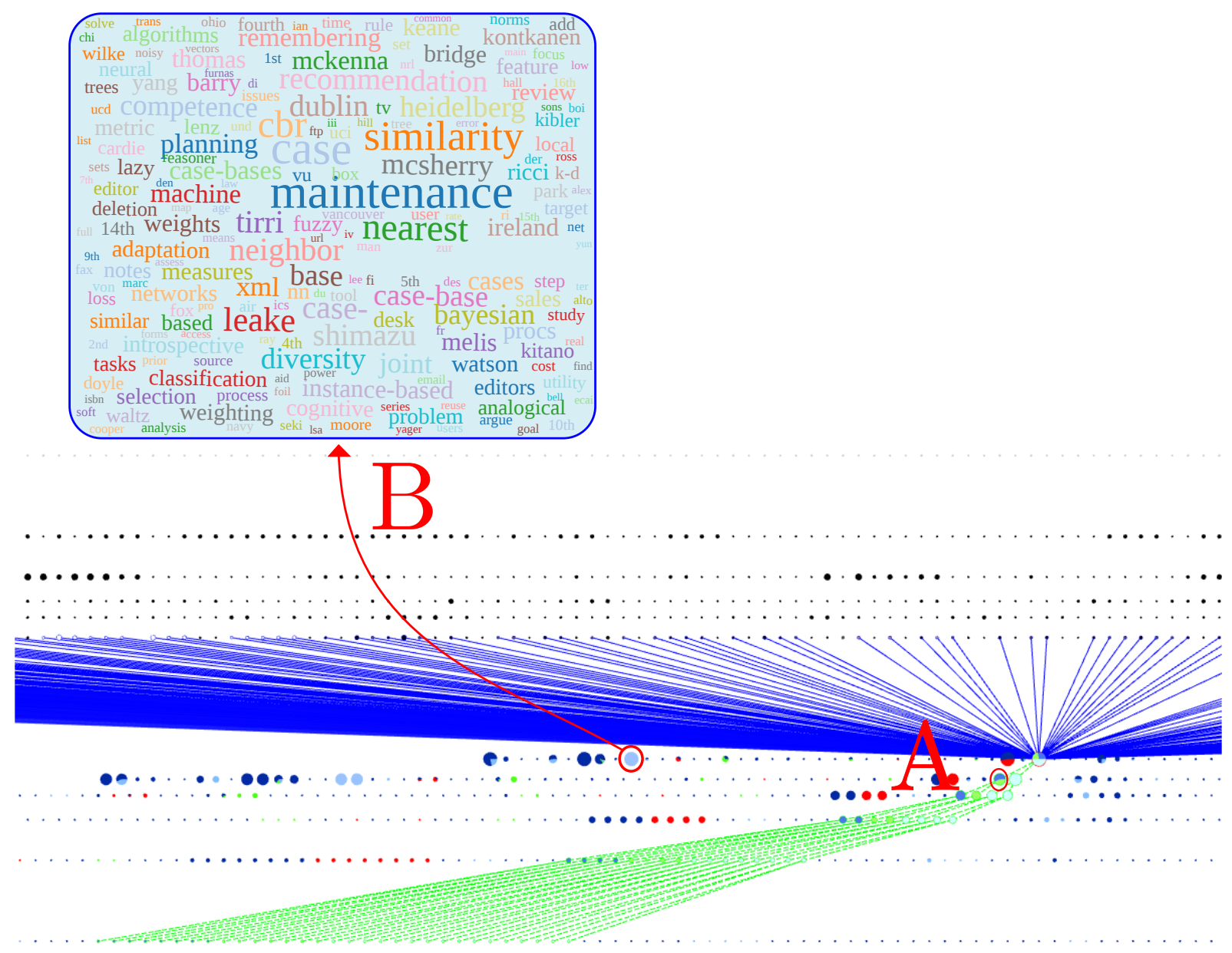

Figura 46 - Legenda de cores dos vértices no conjunto de dados Movie Lens. "F" identifica usuários do sexo feminino, e "M", masculino. A cor preta identifica vértices que não possuem valor para o atributo (Unknown).

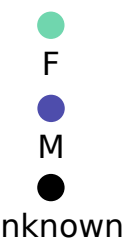

Por fim, a Figura 50 mostra o nível mais contraído resultante da configuração C.GMB.55.30-30 aplicada no conjunto de dados Movie Lens, resultando em 1016 agrupamentos de usuários, 346 coleções e cerca de 9785 arestas. Observa-se o grafo mais contraído desbalanceado, contendo poucos super-vértices quando comparado ao resultado da configuração C.GMB.3-3.5050, vista na Figura 49. Explorando esses super-vértices, identificam-se grupos com menos de 8 
Figura 47 - Visão parcial do grafo mais contraído resultante da aplicação da configuração C.MLP.100100.10. (A) mostra os histogramas de frequências de alguns vértices, que contém, em sua maioria, usuários entre 25-35 anos com profissões distintas.

\}Filmes

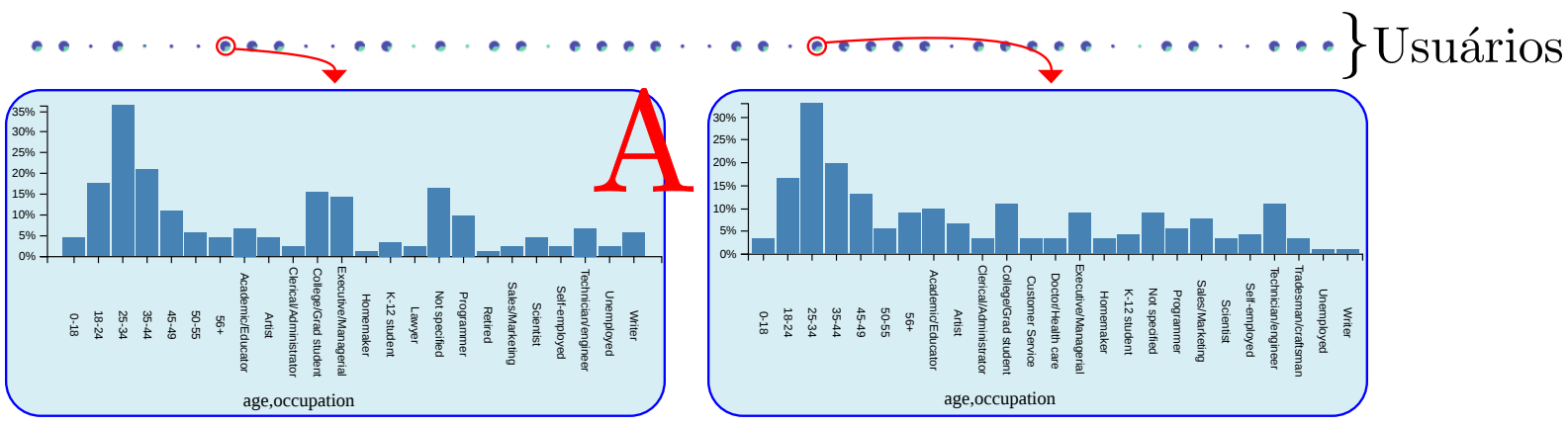

Figura 48 - Visão parcial da hierarquia resultante da aplicação da configuração C.MLP.20-20.1. (A) mostra os histogramas de frequências e nuvens de palavra explorando coleções de usuário, que contém, em sua maioria, entre 25-35 anos com profissões distintas. As nuvens de palavras destacam que gêneros como "drama", "comédia" e "ação" são os mais populares, de acordo com a vizinhança dos super-vértices selecionados.
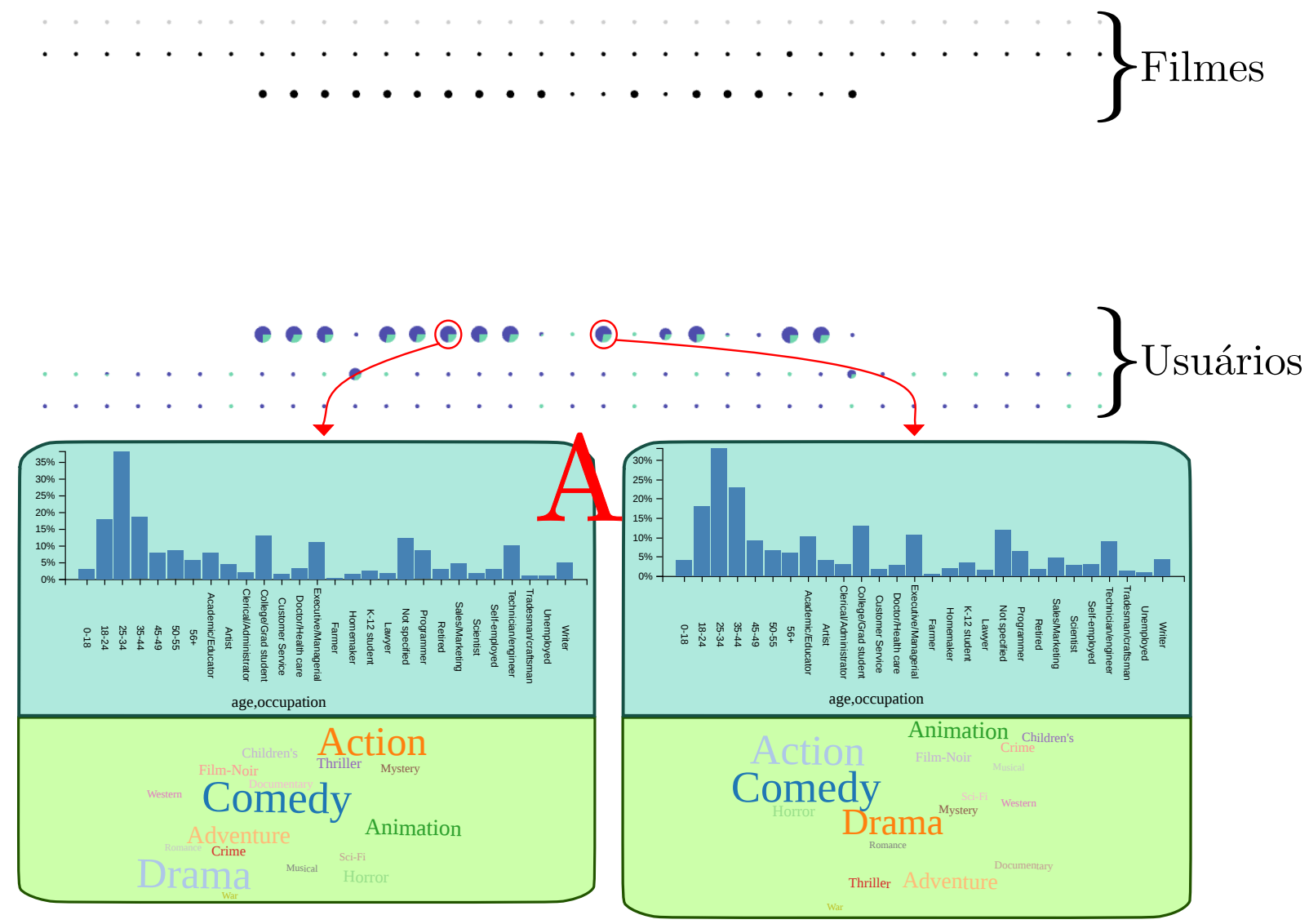
Figura 49 - Visão do grafo mais contraído resultante da aplicação da configuração C.GMB.3-3.50-50. É possível identificar a presença de vários super-vértices e perfis de usuários específicos. (A) mostra os histogramas de frequência e nuvem de palavras explorando uma coleção de usuários, que contém, em sua maioria, entre 18-44 anos com preferências por filmes de "Animação". (B) mostra os histogramas de frequência e nuvem de palavras de uma coleção de usuários com 25 anos ou mais, preferindo filmes de "Aventura", "Ação", "Comédia", "Drama", "Western" e "Thriller".

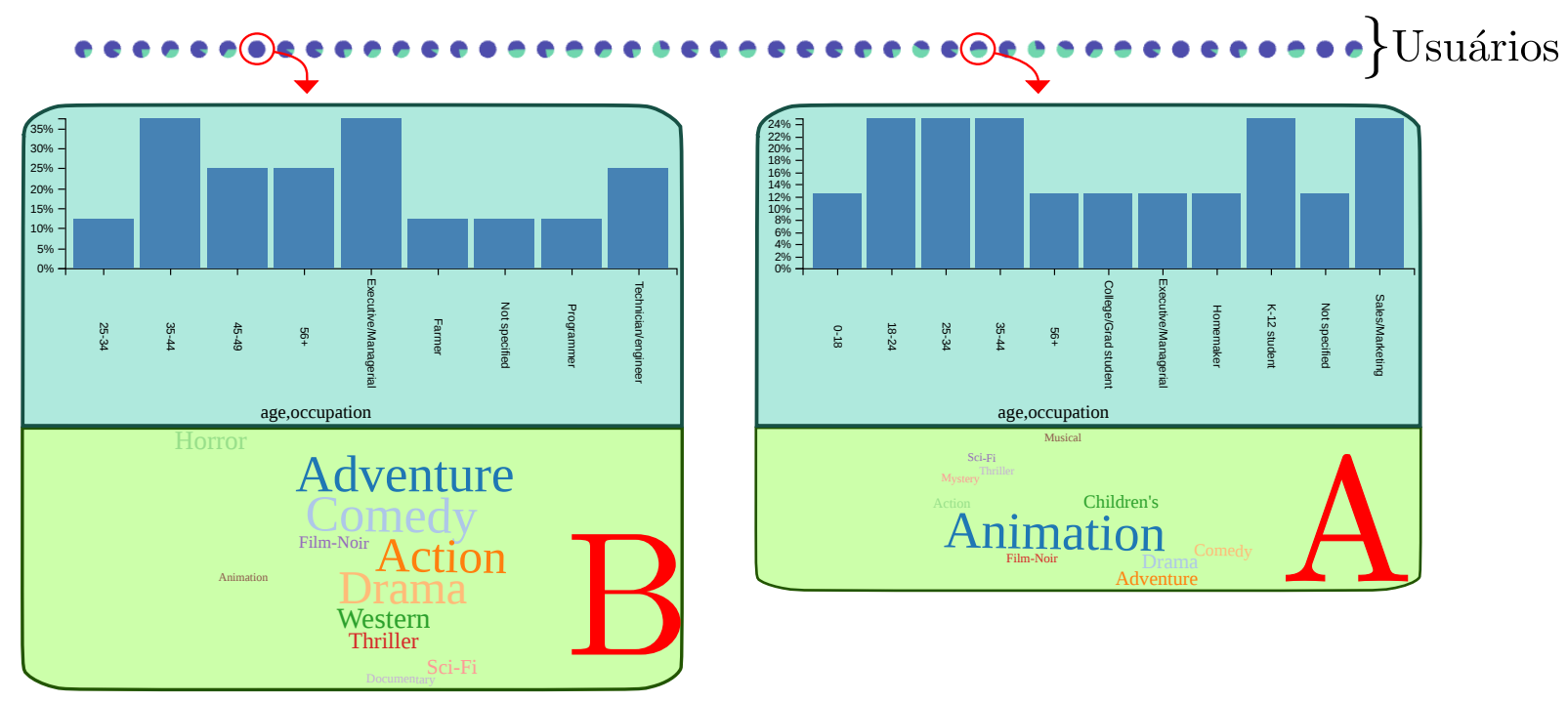

usuários. A exploração do grafo mostra resultados similares aos obtidos com as configurações C.MLP.100-100.10 e C.MLP.20-20.1, nas Figuras 47 e 48, respectivamente: usuários que têm preferência por filmes de "Ação", "Drama" e "Comédia", como visto em (A).

Figura 50 - Visão do grafo mais contraído resultante da aplicação da configuração C.GMB.5-5.30-30. É possível identificar a presença de poucos super-vértices, em comparação a configuração C.GMB.3-3.50-50. (A) identifica nuvens de palavras explorando coleções de usuários, mostrando que eles preferem filmes de "Ação", "Comédia" e "Drama".

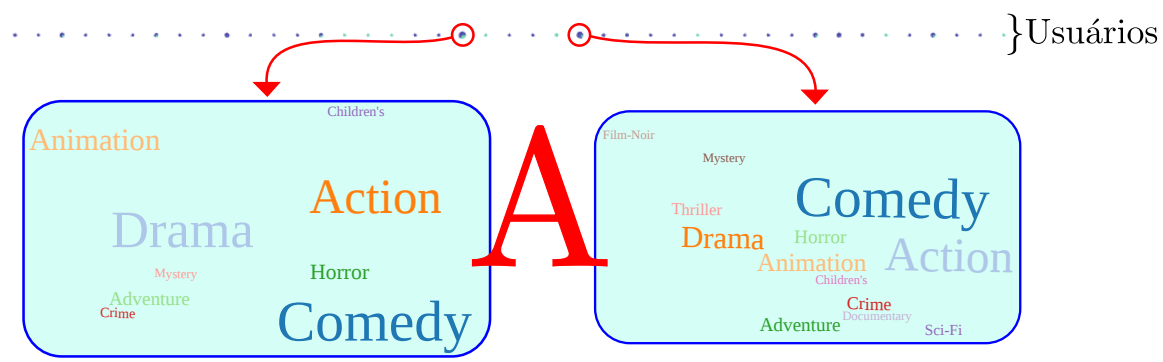




\subsection{Considerações finais}

Neste Capítulo, foram apresentados os estudos de caso conduzidos com o MObViewer, servindo de prova de conceito para a solução proposta aos objetivos apresentados no Capítulo 1. Os estudos consideraram grafos sintéticos e grafos que descrevem conjunto de dados reais. Para os sintéticos, três questões analíticas foram elaboradas para conduzir os estudos de caso. As análises focaram na visualização da preservação de comunidades. Por exemplo, a nova metáfora mostra a criação de super-vértices que unem vértices da mesma comunidade. A utilização dessa metáfora de visualização também permitiu identificar em qual momento vértices de comunidades distintas se uniram e formaram um novo super-vértice. Por fim, foi possível identificar como o fator de redução impacta a criação de grafos mais contraídos, que contém menos super-vértices conforme o fator de redução diminui.

Nos estudos de caso de aplicações do mundo real, a integração das visualizações com o $M O b$ serviu de embasamento na obtenção de informação, por meio da exploração da hierarquia produzida com o auxílio da nova metáfora visual. No grafo do IEEEVis, por exemplo, aplicaramse diferentes configurações do arcabouço do paradigma multinível, produzindo múltiplas hierarquias distintas. Com o MObViewer, navega-se nos super-vértices construídos, interpretando os grupos identificados. $\mathrm{O}$ uso dos histogramas de frequência e nuvens de palavras auxiliaram na sumarização dos dados. Já para o conjunto de dados documento-termos, verificou-se que o algoritmo $M L P$ produziu super-vértices incluindo disciplinas de comunidades distintas. Com isso, a flexibilidade do paradigma multinível é explorada, utilizando o algoritmo $G M b$ e produzindo super-vértices que contém documentos das mesmas disciplinas. Isso foi facilmente identificado graças a nova metáfora visual introduzida, juntamente com a tabela de cores categórica utilizada, separando artigos de diferentes disciplinas por cor. Com super-vértices de tamanho menor que vinte elementos, identificam-se artigos de áreas específicas. Também é possível identificar, com o uso da nuvem de palavras, o porquê de artigos de áreas distintas ficarem juntos.

Por fim, o conjunto de dados Movie Lens é um dos mais heterogêneos de todos os grafos analisados. Isso se deve a sua alta densidade, o que dificultou a análise de um perfil específico de usuários de acordo com gêneros de filmes. Foi possível identificar as principais preferências de gêneros de filmes com as nuvens de palavras. Os histogramas ajudaram a identificar que a maioria dos usuários têm entre 25-35 anos. A criação de super-vértices com seus próprios atributos como medida de similaridade talvez ajudaria na caracterização de perfis de usuários. Essa limitação, assim como futuros direcionamentos da ferramenta aqui apresentada e analisada, são abordados no Capítulo 6. 

CAPÍTULO

\section{6}

6

\section{CONCLUSÕES}

Neste Capítulo são apresentadas as considerações finais relativas a esse projeto de mestrado. A Seção 6.1 apresenta as contribuições do trabalho de pesquisa, com a introdução da ferramenta MObViewer, uma nova metáfora de visualização e a análise de estudos de caso para verificar os objetivos delineados no Capítulo 1. Na Seção 6.2, são destacadas as principais limitações descobertas ao longo da execução de atividades exploratórias com a ferramenta de visualização, e também da abordagem que combina a metáfora com o paradigma multinível. Por fim, a Seção 6.3 identifica, com a análise das limitações, possíveis direcionamentos e trabalhos futuros.

\subsection{Contribuições}

Nesta dissertação, foi apresentada uma nova metáfora de visualização, criada pela necessidade de compreender a construção da hierarquia gerada pelo paradigma multinível, como por exemplo em qual nível vértices com atributos distintos se uniram e formaram um único super-vértice. Com ela, foi possível compreender como medidas de similaridade se comportam na construção da hierarquia do paradigma multinível. Também foi possível identificar quais vértices com atributos distintos se uniram e formaram um único super-vértice. Essas contribuições consequentes da introdução da nova metáfora de visualização foram inseridas em uma ferramenta, o MObViewer, permitindo que especialistas vejam o funcionamento do paradigma multinível e os diferentes resultados produzidos variando os parâmetros de execução, métricas de similaridade e algoritmos de pareamento. A estratégia proposta pode auxiliar o desenvolvimento de novos algoritmos de pareamento, também sendo capaz de encontrar limitações e pontos fortes tanto no $G M b$ quanto no $M L P$.

Com essa ferramenta, foi desenvolvida uma arquitetura cliente-servidor com o propósito de acelerar a criação da hierarquia de grafos contraídos, colocando o processamento e execução do paradigma do lado do servidor, e a criação da metáfora visual do lado do cliente. A mesma 
metáfora também introduziu arestas que conectam vizinhos e vértices que formam super-vértices, o que permite aos usuários visualizar quais vértices compõem um determinado super-vértice. Um algoritmo de "ordenação" de vértices também foi apresentado, para estabelecer vértices que compõem um mesmo super-vértice lado a lado. Uma interface para modificar os parâmetros de execução do paradigma multinível também foi introduzida, o que permite aos usuários mais flexibilidade na execução do algoritmo.

Técnicas de visualização foram adicionadas para suporte a atividades exploratórias sobre grafos bipartidos. O histograma de frequências representa os atributos contidos em um vértice, sendo uma alternativa à representação de grafos multivariados. A nuvem de palavras permite com que o usuário não tenha que analisar separadamente um atributo de maneira tabular, identificando qual a maior ocorrência dele em uma vizinhança de um vértice específico. O gráfico de setores foi introduzido para identificar quais super-vértices contém elementos com mesmos atributos ou distintos. Isso permite aos especialistas, por exemplo, identificar quais super-vértices contém elementos de uma única comunidade.

Os estudos de caso apresentados no Capítulo 5, especialmente os de aplicações do mundo real, demonstraram a descoberta de informações ocultas que o MObViewer é capaz. Pode-se, por exemplo, identificar quais termos são característicos de certas áreas, em um conjunto de dados de termos e documentos.

\subsection{Limitações}

No desenvolvimento desse projeto de mestrado e na ferramenta MObViewer, algumas limitações foram encontradas. A primeira delas é que a ferramenta não é escalável. Para grafos muito densos e contendo diferentes atributos, como o Movie Lens, o processo de construção da hierarquia de níveis com o paradigma multinível demorou cerca de 1 minuto. Outra limitação diz respeito ao desempenho do sistema. A interação com o grafo resultante para gerar histogramas de frequência e nuvens de palavra gerou lentidão no sistema em geral. Isso se deve a alguns cálculos e processamentos referentes a essas visualizações serem realizados diretamente do lado do cliente.

Da análise de um conjunto de dados como o Movie Lens, outra limitação identificada foi o comportamento do paradigma multinível. Mesmo com toda a flexibilidade proporcionada pelo arcabouço de Valejo et al. (2018), podendo alternar entre diferentes distâncias de similaridade, fatores de redução e quantidade de níveis, não foi possível encontrar uma parametrização que garantisse um agrupamento razoável, unindo usuários que têm a mesma profissão e assim caracetrizar um perfil de preferências, como visto na Seção 5.2. Caso o paradigma multinível fosse capaz de utilizar o próprio atributo de um grafo como uma métrica de similaridade, os agrupamentos resultantes poderiam revelar informações mais relevantes para o usuário.

Outra limitação é a visualização de somente um nível ou todos os níveis do grafo bipartido 
gerado pelo paradigma multinível. Seria interessante e prático, por exemplo, que o usuário pudesse alternar entre os grafos em diferentes níveis, sem precisar mostrar todos eles de uma vez. Isso reduziria o consumo de memória principal e permitiria um maior direcionamento das atividades exploratórias. A identificação dos conjuntos $\left(V_{1}, V_{2}\right)$ também poderia ser melhorada, uma vez que não há nenhuma indicação na visualização de qual camada contém quais vértices. Por fim, a codificação de cores representando os pesos das arestas, em geral, foi mal aproveitada. Seria interessante se esses pesos fossem codificados na escala da aresta, sendo os mais pesados espessos, e os mais leves, finos. Por problemas técnicos com a própria biblioteca three.js, não foi possível adotar essa solução neste trabalho de mestrado.

\subsection{Direcionamentos Futuros}

Dada as limitações mencionadas previamente, possíveis direcionamentos futuros para este trabalho incluem:

1. Adaptar o paradigma multinível para utilizar atributos de um vértice como métrica de similaridade. Com essa estratégia, informações ocultas poderiam ser descobertas em supervértices que contivessem elementos de um mesmo atributo, como seria o caso do conjunto de dados Movie Lens.

2. Permitir com que o usuário possa interagir com os múltiplos níveis do paradigma multinível separadamente. Caso o usuário queira saber o porquê um super-vértice possui determinadas características, ele poderia analisar somente um nível anterior de contração daquele conjunto específico. Atualmente, o MObViewer permite somente mostrar ou o nível mais contraído, ou todos os níveis gerados pelo paradigma multinível. Essa especificidade manteria o foco do usuário e, consequentemente, ajudaria na obtenção de informação.

3. Melhorar o desempenho e solucionar os gargalos da ferramenta. Atualmente, a ferramenta possui diversos gargalos de processamento, especialmente na visualização de grafos muito densos ou de diversos níveis da hierarquia produzida. O lado do servidor também sofre de lentidão no cumprimento de algumas tarefas, como executar o paradigma multinível ou obter os vizinhos de um determinado vértice. Algumas soluções a serem aplicadas incluem a otimização de algoritmos de tempo de execução quadráticos. Outra solução é otimizar o uso da biblioteca Three. js na implementação atual. Por fim, um sistema de tolerância e correção de erros pode ser incorporado, facilitando na detecção e correção de bugs e problemas. 



\section{REFERÊNCIAS}

ABELLO, J.; HAM, F. V.; KRISHNAN, N. Ask-graphview: A large scale graph visualization system. IEEE Transactions on Visualization and Computer Graphics, v. 12, n. 5, p. 669-676, Sept 2006. ISSN 1077-2626. Citado nas páginas 58, 59, 67 e 69.

ABELLO, J.; HAM, F. van. Matrix zoom: A visual interface to semi-external graphs. p. 183-190, 2004. ISSN 1522-404X. Citado na página 44.

ADAMIC, L. A.; ADAR, E. Friends and neighbors on the web. Social Networks, v. 25, p. 211-230, 2003. Citado na página 54.

ARCHAMBAULT, D.; MUNZNER, T.; AUBER, D. Topolayout: Multilevel graph layout by topological features. IEEE Transactions on Visualization and Computer Graphics, v. 13, n. 2, p. 305-317, March 2007. ISSN 1077-2626. Citado na página 37.

Grouseflocks: Steerable exploration of graph hierarchy space. IEEE Transactions on Visualization and Computer Graphics, v. 14, n. 4, p. 900-913, July 2008. ISSN 1077-2626. Citado nas páginas 59, 67 e 68.

BATINI, C.; FURLANI, L.; NARDELLI, E. What is a good diagram? a pragmatic approach. Proceedings of the Fourth International Conference on Entity-Relationship Approach, 1985. Citado na página 41.

BONDY, J. A.; MURTY, U. S. R. Graph theory with applications. Oxford, UK: Elsevier Science Ltd., 1976. ISBN 0444194517. Citado na página 41.

BONDY, J. A.; MURTY, U. S. R. et al. Graph theory with applications. [S.1.]: Citeseer, 1976. v. 290. Citado na página 42.

CARD, S.; MACKINLAY, J.; SHNEIDERMAN, B. Information visualization. Humancomputer interaction: design issues, solutions, and applications, CRC Press, v. 181, 2009. Citado na página 35.

CHAN, G. Y.; XU, P.; DAI, Z.; REN, L. Vibr: Visualizing bipartite relations at scale with the minimum description length principle. IEEE Transactions on Visualization and Computer Graphics, v. 25, n. 1, p. 321-330, Jan 2019. ISSN 1077-2626. Citado nas páginas 67, 68, 69 e 71 .

CHAN, P. K.; SCHLAG, M. D.; ZIEN, J. Y. Spectral k-way ratio-cut partitioning and clustering. IEEE Transactions on computer-aided design of integrated circuits and systems, IEEE, v. 13, n. 9, p. 1088-1096, 1994. Citado na página 63.

DHILLON, I. S. Co-clustering documents and words using bipartite spectral graph partitioning. p. 269-274, 2001. Citado na página 64. 
DIAS, M. D.; MANSOUR, M. R.; DIAS, F.; PETRONETTO, F.; SILVA, C. T.; NONATO, L. G. A hierarchical network simplification via non-negative matrix factorization. In: 30th SIBGRAPI Conference on Graphics, Patterns and Images. IEEE, 2017. p. 119-126. Disponível em: <sibgrapi.sid.inpe.br/archive.cgi/sid.inpe.br/sibgrapi/2017/08.22.04.04>. Citado nas páginas 63 e 68 .

DIAS, M. D. S. d. S.; MANSOUR, M. R.; ROMANETTO, L. d. M.; OLIVEIRA, M. C. F. d.; NONATO, L. G. et al. Vizlattes: a tool for relevance analysis from scientific co-authorship networks. In: SOCIEDADE BRASILEIRA DE COMPUTAÇÃO-SBC. Conference on Graphics, Patterns and Images, XXVIII; Workshop on Visual Analytics, Information Visualization and Scientific Visualization, VI. [S.1.], 2015. Citado na página 36.

DONGEN, S. M. V. Graph clustering by flow simulation. Tese (Doutorado) - Universiteit Utrecht, 2000. Citado na página 58.

DöRK, M.; RICHE, N. H.; RAMOS, G.; DUMAIS, S. Pivotpaths: Strolling through faceted information spaces. IEEE Transactions on Visualization and Computer Graphics, v. 18, n. 12, p. 2709-2718, Dec 2012. ISSN 1077-2626. Citado nas páginas 64 e 68.

EADES, P. A heuristics for graph drawing. Congressus numerantium, v. 42, p. 146-160, 1984. Citado nas páginas 36, 37, 44, 58 e 69.

EADES, P.; HUANG, M. L. Navigating clustered graphs using force-directed methods. J. Graph Algorithms and Applications, v. 4, n. 3, p. 157-181, 2000. Citado na página 58.

ELMQVIST, N.; DO, T.-N.; GOODELL, H.; HENRY, N.; FEKETE, J.-D. Zame: Interactive large-scale graph visualization. 2008 IEEE Pacific Visualization Symposium, p. 215-222, 2008. Citado nas páginas 36, 44 e 58.

FRUCHTERMAN, T. M. J.; REINGOLD, E. M. Graph drawing by force-directed placement. Softw., Pract. Exper., v. 21, n. 11, p. 1129-1164, 1991. Disponível em: <http://dx.doi.org/10. 1002/spe.4380211102>. Citado na página 44.

FURNAS, G. W. Generalized fisheye views. In: Proceedings of the SIGCHI Conference on Human Factors in Computing Systems. New York, NY, USA: ACM, 1986. (CHI '86), p. 16-23. ISBN 0-89791-180-6. Disponível em: <http://doi-acm-org.ez67.periodicos.capes.gov.br/ 10.1145/22627.22342>. Citado na página 60.

GAJER, P.; KOBOUROV, S. G. Grip: Graph drawing with intelligent placement. In: MARKS, J. (Ed.). Graph Drawing. Berlin, Heidelberg: Springer Berlin Heidelberg, 2001. p. 222-228. ISBN 978-3-540-44541-8. Citado nas páginas 36, 37 e 44.

GHONIEM, M.; FEKETE, J. D.; CASTAGLIOLA, P. A comparison of the readability of graphs using node-link and matrix-based representations. IEEE Symposium on Information Visualization, IEEE, p. 17-24, 2004. ISSN 1522-404X. Citado nas páginas 37, 44 e 45.

GUALDRON, H.; CORDEIRO, R. L. F.; RODRIGUES, J. F. Structmatrix: Large-scale visualization of graphs by means of structure detection and dense matrices. p. 493-500, Nov 2015. Citado na página 44.

GUPTA, A.; KARYPIS, G.; KUMAR, V. Highly scalable parallel algorithms for sparse matrix factorization. IEEE Transactions on Parallel and Distributed Systems, v. 8, n. 5, p. 502-520, May 1997. ISSN 1045-9219. Citado na página 37. 
HACHUL, S.; JüNGER, M. Drawing large graphs with a potential-field-based multilevel algorithm. Springer-Verlag, Berlin, Heidelberg, p. 285-295, 2004. Disponível em: <http: //dx.doi.org/10.1007/978-3-540-31843-9_29>. Citado na página 44.

HACHUL, S.; JÜNGER, M. Large-graph layout algorithms at work: An experimental study. Journal of Graph Algorithms and Applications, v. 11, n. 2, p. 345-369, 2007. Citado na página 44.

HAM, F. van; PERER, A. "search, show context, expand on demand": Supporting large graph exploration with degree-of-interest. IEEE Transactions on Visualization and Computer Graphics, v. 15, n. 6, p. 953-960, Nov 2009. ISSN 1077-2626. Citado nas páginas 60, $61,64,68$ e 69.

HAREL, D.; KOREN, Y. A fast multi-scale method for drawing large graphs. ACM, New York, NY, USA, p. 282-285, 2000. Disponível em: <http://doi.acm.org/10.1145/345513.345353>. Citado na página 44.

Graph drawing by high-dimensional embedding. v. 2528, p. 207-219, 2002. Citado nas páginas 36 e 37.

HEINRICH, J.; SEIFERT, R.; BURCH, M.; WEISKOPF, D. Bicluster viewer: A visualization tool for analyzing gene expression data. Springer Berlin Heidelberg, Berlin, Heidelberg, p. 641-652, 2011. Citado na página 64.

HENRY, N.; FEKETE, J. D.; MCGUFFIN, M. J. Nodetrix: a hybrid visualization of social networks. IEEE Transactions on Visualization and Computer Graphics, v. 13, n. 6, p. 13021309, Nov 2007. ISSN 1077-2626. Citado nas páginas 44 e 58.

HERMAN, I.; MELANCON, G.; MARSHALL, M. S. Graph visualization and navigation in information visualization: A survey. IEEE Transactions on Visualization and Computer Graphics, v. 6, n. 1, p. 24-43, Jan 2000. ISSN 1077-2626. Citado na página 36.

HOFFMAN, P.; GRINSTEIN, G.; MARX, K.; GROSSE, I.; STANLEY, E. Dna visual and analytic data mining. p. 437-441, Oct 1997. Citado na página 36.

HOI, S. C.; LIU, W.; CHANG, S.-F. Semi-supervised distance metric learning for collaborative image retrieval and clustering. ACM Trans. Multimedia Comput. Commun. Appl., ACM, New York, NY, USA, v. 6, n. 3, p. 18:1-18:26, ago. 2010. ISSN 1551-6857. Disponível em: $<$ http://doi-acm-org.ez67.periodicos.capes.gov.br/10.1145/1823746.1823752>. Citado na página 64.

HOLTEN, D. Hierarchical edge bundles: Visualization of adjacency relations in hierarchical data. IEEE Transactions on visualization and computer graphics, IEEE, v. 12, n. 5, p. 741-748, 2006. Citado nas páginas 57 e 65 .

HURTER, C.; ERSOY, O.; TELEA, A. Graph bundling by kernel density estimation. Computer Graphics Forum, v. 31, n. 3pt1, p. 865-874, 2012. Citado nas páginas 57 e 63.

INSELBERG, A. The plane with parallel coordinates. [S.1.]: Springer, 1985. v. 1. 69-91 p. Citado na página 36. 
Isenberg, P.; Heimerl, F.; Koch, S.; Isenberg, T.; Xu, P.; Stolper, C. D.; Sedlmair, M.; Chen, J.; Möller, T.; Stasko, J. Vispubdata.org: A metadata collection about ieee visualization (vis) publications. IEEE Transactions on Visualization and Computer Graphics, v. 23, n. 9, p. 2199-2206, Sep. 2017. ISSN 1077-2626. Citado na página 97.

JEONG, H.; TOMBOR, B.; ALBERT, R.; OLTVAI, Z. N.; BARABÁSI, A.-L. The large-scale organization of metabolic networks. Nature, Nature Publishing Group, v. 407, n. 6804, p. 651, 2000. Citado na página 36.

JOHNSON, B.; SHNEIDERMAN, B. Tree-maps: a space-filling approach to the visualization of hierarchical information structures. Visualization, 1991. Visualization '91, Proceedings., IEEE Conference on, p. 284-291, Oct 1991. Citado na página 36.

KAMADA, T.; KAWAI, S. An algorithm for drawing general undirected graphs. Inf. Process. Lett., v. 31, n. 1, p. 7-15, 1989. Disponível em: <http://dx.doi.org/10.1016/0020-0190(89) 90102-6>. Citado na página 44.

KEIM, D.; ANDRIENKO, G.; FEKETE, J.-D.; GÖRG, C.; KOHLHAMMER, J.; MELANÇON, G. Visual analytics: Definition, process, and challenges. Information visualization, Springer, p. 154-175, 2008. Citado na página 35.

KEIM, D. A. Information visualization and visual data mining. IEEE Transactions on Visualization and Computer Graphics, v. 8, n. 1, p. 1-8, Jan 2002. ISSN 1077-2626. Citado nas páginas 35 e 44.

KELLER, P. R.; KELLER, M. M.; MARKEL, S.; MALLINCKRODT, A. J.; MCKAY, S. Visual cues: practical data visualization. Computers in Physics, AIP, v. 8, n. 3, p. 297-298, 1994. Citado na página 44.

KOSARA, R.; JANKUN-KELLY, T.; CHLAN, E. IEEE InfoVis 2007 Contest: InfoVis goes to the movies, 2007. 2007. Citado na página 68.

LANDESBERGER, T. V.; KUIJPER, A.; SCHRECK, T.; KOHLHAMMER, J.; WIJK, J. J. van; FEKETE, J.-D.; FELLNER, D. W. Visual analysis of large graphs: state-of-the-art and future research challenges. Computer graphics forum, v. 30, n. 6, p. 1719-1749, 2011. Citado nas páginas 37 e 57.

LEE, D. D.; SEUNG, H. S. Learning the parts of objects by non-negative matrix factorization. Nature, Nature Publishing Group, v. 401, n. 6755, p. 788, 1999. Citado na página 63.

LESKOVEC, J.; FALOUTSOS, C. Sampling from large graphs. 12th ACM SIGKDD international conference on Knowledge discovery and data mining, p. 631-636, 2006. Citado na página 37.

LUHN, H. P. The automatic creation of literature abstracts. IBM Journal of Research and Development, v. 2, n. 2, p. 159-165, Apr 1958. ISSN 0018-8646. Citado na página 97.

MAATEN, L. v. d.; HINTON, G. Visualizing data using t-sne. Journal of Machine Learning Research, v. 9, n. Nov, p. 2579-2605, 2008. Citado na página 36.

MCCALLUM, A.; NIGAM, K.; UNGAR, L. H. Efficient clustering of high-dimensional data sets with application to reference matching. ACM, New York, NY, USA, p. 169-178, 2000. Disponível em: <http://doi-acm-org.ez67.periodicos.capes.gov.br/10.1145/347090.347123>. Citado na página 63. 
MUELLER, C.; MARTIN, B.; LUMSDAINE, A. A comparison of vertex ordering algorithms for large graph visualization. p. 141-148, Feb 2007. Citado na página 44.

MUNZNER, T. Visualization analysis and design. [S.1.]: AK Peters/CRC Press, 2014. Citado na página 80.

NACHMANSON, L.; PRUTKIN, R.; LEE, B.; RICHE, N. H.; HOLROYD, A. E.; CHEN, X. Graphmaps: Browsing large graphs as interactive maps. p. 3-15, 2015. Citado nas páginas 57, $62,63,68$ e 69.

NEWMAN, M. The structure and function of complex networks. SIAM Review, v. 45, n. 2, p. 167-256, 2003. Disponível em: <https://doi.org/10.1137/S003614450342480>. Citado na página 42.

NEWMAN, M. E. The structure of scientific collaboration networks. Proceedings of the national academy of sciences, National Acad Sciences, v. 98, n. 2, p. 404-409, 2001. Citado na página 36.

Fast algorithm for detecting community structure in networks. Physical review E, APS, v. 69, n. 6 , p. 066133, 2004. Citado na página 63.

OGHABIAN, A.; KILPINEN, S.; HAUTANIEMI, S.; CZEIZLER, E. Biclustering methods: biological relevance and application in gene expression analysis. PloS one, Public Library of Science, v. 9, n. 3, p. e90801, 2014. Citado na página 64.

OLIVEIRA, M. C. F. de; LEVKOWITZ, H. From visual data exploration to visual data mining: a survey. IEEE Transactions on Visualization and Computer Graphics, v. 9, n. 3, p. 378-394, July 2003. ISSN 1077-2626. Citado nas páginas 35 e 36.

PADMAVATHI, S.; GEORGE, A. Multilevel hybrid graph partitioning algorithm. p. 85-89, Feb 2014. Citado na página 37.

PAULOVICH, F. V.; MINGHIM, R. Text map explorer: a tool to create and explore document maps. In: IEEE. Information Visualization, 2006. IV 2006. Tenth International Conference on. [S.1.], 2006. p. 245-251. Citado na página 97.

PAULOVICH, F. V.; NONATO, L. G.; MINGHIM, R.; LEVKOWITZ, H. et al. Least square projection: A fast high-precision multidimensional projection technique and its application to document mapping. IEEE Transactions on Visualization and Computer Graphics, v. 14, n. 3, p. 564, 2008. Citado nas páginas 35, 36 e 97.

PERROT, A.; AUBER, D. Cornac: Tackling huge graph visualization with big data infrastructure. IEEE Transactions on Big Data, 2018. ISSN 2332-7790. Citado nas páginas 63 e 69.

PEZZOTTI, N.; FEKETE, J.-D.; HÖLLT, T.; LELIEVELDT, B.; EISEMANN, E.; VILANOVA, A. Multiscale Visualization and Exploration of Large Bipartite Graphs. Computer Graphics Forum, Wiley, v. 37, n. 3, p. 12, jun. 2018. Disponível em: <https://hal.inria.fr/hal-01787046>. Citado nas páginas 16, 65, 67 e 69.

PEZZOTTI, N.; HöLLT, T.; LELIEVELDT, B.; EISEMANN, E.; VILANOVA, A. Hierarchical stochastic neighbor embedding. Eurographics Association, Goslar Germany, Germany, p. 2130, 2016. Disponível em: <https://doi-org.ez67.periodicos.capes.gov.br/10.1111/cgf.12878>. Citado na página 65. 
PONTES, B.; GIRÁLDEZ, R.; AGUILAR-RUIZ, J. S. Biclustering on expression data: A review. Journal of biomedical informatics, Elsevier, v. 57, p. 163-180, 2015. Citado na página 64.

RAFIEI, D. Effectively visualizing large networks through sampling. p. 375-382, Oct 2005. Citado na página 60.

RAGHAVAN, U. N.; ALBERT, R.; KUMARA, S. Near linear time algorithm to detect community structures in large-scale networks. Phys. Rev. E, American Physical Society, v. 76, p. 036106, Sep 2007. Disponível em: <https://link.aps.org/doi/10.1103/PhysRevE.76.036106>. Citado na página 49.

RISSANEN, J. Modeling by shortest data description. Automatica, Elsevier, v. 14, n. 5, p. 465-471, 1978. Citado na página 67.

ROSSI, R. G.; LOPES, A. de A.; REZENDE, S. O. Optimization and label propagation in bipartite heterogeneous networks to improve transductive classification of texts. Information Processing \& Management, v. 52, n. 2, p. 217 - 257, 2016. ISSN 0306-4573. Disponível em: $<$ http://www.sciencedirect.com/science/article/pii/S0306457315000990>. Citado na página 36.

SCHNEIDERMAN, S. Information Visualization: Using Vision to Think. [S.1.]: Morgan Kaufmann, 1999. Citado na página 43.

SHNEIDERMAN, B. The eyes have it: A task by data type taxonomy for information visualizations. In: IEEE. Visual Languages, 1996. Proceedings., IEEE Symposium on. [S.1.], 1996. p. 336-343. Citado na página 44.

SKIENA, S. S. The algorithm design manual: Text. [S.1.]: Springer Science \& Business Media, 1998. v. 1. Citado na página 41.

STASKO, J.; ZHANG, E. Focus+context display and navigation techniques for enhancing radial, space-filling hierarchy visualizations. Information Visualization, 2000. InfoVis 2000. IEEE Symposium on, p. 57-65, 2000. ISSN 1522-404X. Citado na página 36.

STEINBöCK, D. Interactive Visual Exploration Interface for Large Bipartite Networks. Dissertação (Mestrado) - Institute of Computer Graphics and Algorithms, Vienna University of Technology, Favoritenstrasse 9-11/186, A-1040 Vienna, Austria, May 2018. Disponível em: $<$ https://www.cg.tuwien.ac.at/research/publications/2018/steinboeck-2017-vbn/>. Citado na página 98.

STEINBOCK, D.; GROLLER, E.; WALDNER, M. Casual visual exploration of large bipartite graphs using hierarchical aggregation and filtering. p. 1-10, Oct 2018. Citado nas páginas 66, 67,69 e 70 .

TAMASSIA, R. Handbook of graph drawing and visualization. [S.1.]: Chapman and Hall/CRC, 2013. Citado na página 75.

TAN, P.-N.; STEINBACH, M.; KUMAR, V. Introduction to data mining. 1st. [S.1.]: Pearson Addison Wesley, 2005. Citado na página 54.

THOMAS, J. J.; COOK, K. A. A visual analytics agenda. IEEE Comput. Graph. Appl., IEEE Computer Society Press, Los Alamitos, CA, USA, v. 26, n. 1, p. 10-13, jan. 2006. ISSN 0272-1716. Disponível em: <http://dx.doi.org/10.1109/MCG.2006.5>. Citado na página 35. 
TIAN, Y.; HANKINS, R. A.; PATEL, J. M. Efficient aggregation for graph summarization. In: ACM. Proceedings of the 2008 ACM SIGMOD international conference on Management of data. [S.1.], 2008. p. 567-580. Citado na página 63.

UNO, T.; ASAI, T.; UCHIDA, Y.; ARIMURA, H. An efficient algorithm for enumerating closed patterns in transaction databases. p. 16-31, 2004. Citado na página 66.

UTTS, J. M. Seeing through statistics. [S.1.]: Cengage Learning, 2014. Citado na página 36.

VALEJO, A.; FALEIROS, T.; OLIVEIRA, M. C. F.; LOPES, A. A. A coarsening method for bipartite networks via weight-constrained label propagation. Submetido. Knowledge-Based Systems, Elsevier, 2019. Citado nas páginas 23, 49, 50 e 51.

VALEJO, A.; GÓES, F.; ROMANETTO, L.; FERREIRA, M. C.; LOPES, A. A. A benchmarking tool for the generation of bipartite network models with overlapping communities. Submetido. Knowledge and information systems, Springer, 2019. Citado nas páginas 85 e 86.

VALEJO, A.; OLIVEIRA, M. C. F.; FILHO, G. P. R.; LOPES, A. A. Multilevel approach for combinatorial optimization in bipartite networks. Knowledge-Based Systems, Elsevier, v. 151, p. 45-61, 2018. ISSN 0950-7051. Disponível em: <http://www.sciencedirect.com/science/article/ pii/S0950705118301539>. Citado nas páginas 23, 27, 37, 38, 39, 41, 46, 47, 48, 55, 73, 86, 88 e 116.

WALSHAW, C. Multilevel refinement for combinatorial optimisation problems. Annals of Operations Research, Springer, v. 131, n. 1-4, p. 325-372, 2004. Citado nas páginas 37 e 45.

WALSHAW, C.; CROSS, M.; EVERETT, M. Parallel dynamic graph partitioning for adaptive unstructured meshes. Journal of Parallel and Distributed Computing, v. 47, n. 2, p. 102 108, 1997. ISSN 0743-7315. Disponível em: <http://www.sciencedirect.com/science/article/pii/ S0743731597914076>. Citado na página 37.

WARD, M. O.; GRINSTEIN, G.; KEIM, D. Interactive data visualization: foundations, techniques, and applications. [S.1.]: AK Peters/CRC Press, 2015. Citado nas páginas 44 e 97.

WASSERMAN, S.; FAUST, K. Social network analysis: Methods and applications. [S.1.]: Cambridge university press, 1994. v. 8. Citado na página 43.

WATTENBERG, M. Visual exploration of multivariate graphs. Proceedings of the SIGCHI conference on Human Factors in computing systems, p. 811-819, 2006. Citado nas páginas $58,60,67,68$ e 69 .

WATTS, D. J. Small worlds: the dynamics of networks between order and randomness. [S.1.]: Princeton university press, 2004. v. 9. Citado na página 53.

WOLD, S.; ESBENSEN, K.; GELADI, P. Principal component analysis. Chemometrics and Intelligent Laboratory Systems, v. 2, n. 1, p. 37 - 52, 1987. ISSN 0169-7439. Proceedings of the Multivariate Statistical Workshop for Geologists and Geochemists. Disponível em: <http: //www.sciencedirect.com/science/article/pii/0169743987800849>. C Citado na página 36.

WONG, P. C. Visual data mining. IEEE Computer Graphics and Applications, IEEE, v. 19, n. 5, p. 20-21, 1999. Citado na página 36. 
WONG, P. C.; MACKEY, P.; COOK, K. A.; ROHRER, R. M.; FOOTE, H.; WHITING, M. A. A multi-level middle-out cross-zooming approach for large graph analytics. Visual Analytics Science and Technology, 2009. VAST 2009. IEEE Symposium on, p. 147-154, 2009. Citado nas páginas 15,61 e 62 .

XU, P.; CAO, N.; QU, H.; STASKO, J. Interactive visual co-cluster analysis of bipartite graphs. p. 32-39, April 2016. ISSN 2165-8773. Citado nas páginas 16, 64, 66, 67 e 69.

ZHAO, J.; SUN, M.; CHEN, F.; CHIU, P. Bidots: Visual exploration of weighted biclusters. IEEE Transactions on Visualization and Computer Graphics, v. 24, n. 1, p. 195-204, Jan 2018. ISSN 1077-2626. Citado nas páginas 66, 68 e 69.

ZHOU, H.; YUAN, X.; CUI, W.; QU, H.; CHEN, B. Energy-based hierarchical edge clustering of graphs. 2008 IEEE Pacific Visualization Symposium, p. 55-61, March 2008. ISSN 2165-8765. Citado na página 57.

ZINSMAIER, M.; BRANDES, U.; DEUSSEN, O.; STROBELT, H. Interactive level-of-detail rendering of large graphs. IEEE Transactions on Visualization and Computer Graphics, v. 18, n. 12, p. 2486-2495, Dec 2012. ISSN 1077-2626. Citado nas páginas 61, 62, 63, 68 e 69.

ZWAN, M. van der; CODREANU, V.; TELEA, A. Cubu: Universal real-time bundling for large graphs. IEEE Transactions on Visualization and Computer Graphics, v. 22, n. 12, p. 2550-2563, Dec 2016. ISSN 1077-2626. Citado na página 57. 


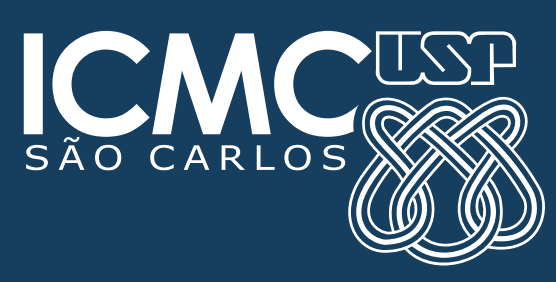

